Portland State University

PDXScholar

1982

\title{
Toward a measure of correspondence in relational perceptions in marital dyads
}

Deborah Anne Coker

Portland State University

Follow this and additional works at: https://pdxscholar.library.pdx.edu/open_access_etds

Part of the Cognition and Perception Commons, Interpersonal and Small Group Communication Commons, and the Speech Pathology and Audiology Commons Let us know how access to this document benefits you.

\section{Recommended Citation}

Coker, Deborah Anne, "Toward a measure of correspondence in relational perceptions in marital dyads" (1982). Dissertations and Theses. Paper 3191.

https://doi.org/10.15760/etd.3182

This Thesis is brought to you for free and open access. It has been accepted for inclusion in Dissertations and Theses by an authorized administrator of PDXScholar. Please contact us if we can make this document more accessible: pdxscholar@pdx.edu. 
AN ABSTRACT OF THE THESIS OF Deborah Anne Coker for the Master of Science in Speech Communication presented October 25, 1982.

Title: Toward a Measure of the Correspondence in Relational Perceptions in Marital Dyads.

APPROVED BY MEMBERS OF THE THESIS COMMITTEE:

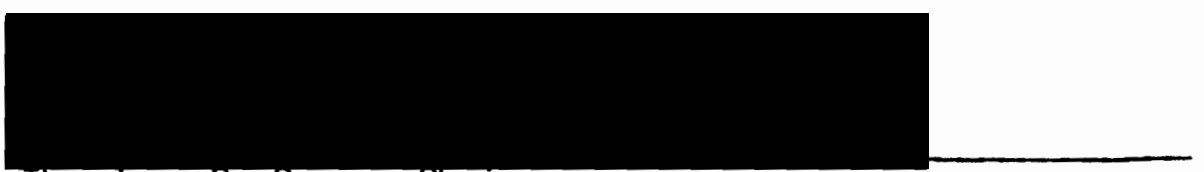

Theodore G. Grove, Chairman
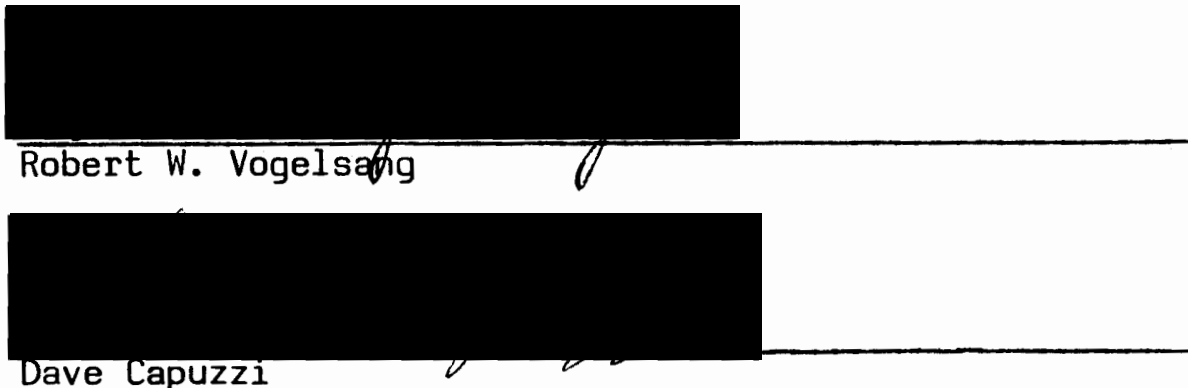

In order to assess a component of communication in interpersonal relationships, an instrument was developed to determine the correspondence in relational perceptions between partners in a marital dyad. The current study focuses on the levels of awareness spouses exhibit regarding phenomenological perceptions of themselves, their partners and the status of their dyadic system.

The Perceptual Diagnostic Inventory (PDI) is a measure capable of deriving data on the perceptions individuals hold on a key range of issues and provides an in-depth view of the workings of a dyad. Characteristics of the instrument include: (1) the ability to produce a scorable unit 
that reflects dyadic interexperience as opposed to assessing monadic, linear properties, (2) issues highly salient to marital relationships, (3) highly reliable items, (4) a high measure of discriminant validity, and (5) potential diagnostic value in delineating the overall quality of communication between dyadic participants.

Objectives of the investigation were achieved through two stages of data collection, data analysis and subsequent instrument refinement. An evaluation of the reliability of the measure included internal consistency analyses of item-total correlations and test-retest item coefficients. An assessment of discriminant validity was provided by comparing the instrument with two other marital techniques which were aimed at related but different constructs.

A pilot study on the instrument was conducted to determine reliable items for the final implementation of the instrument. The original version of the inventory contained 40 items and was given to 15 married couples. After three phases of item analysis, 25 items were found to have sufficient reliability to produce maximal repeatability and were retained for the final instrument.

The final study provided information on discriminant validity as 50 marital couples responded to the PDI, the Marital Satisfaction Inventory and the Marriage Problem Checklist. Results of the correlations on these instruments supported the directional hypotheses proposed. Correlation coefficients revealed an inverse relationship between the measures; the PDI and the Marital Satisfaction Inventory produced a moderately high positive correlation while the PDI and Marriage Problem Checklist produced a moderately high negative correlation.

In general, the evidence generated by this study suggests a 
relatively stable relationship between the degree of perceptual matching and the reported satisfaction and number of problems in a marital dyad. The scale showed high validity and reliability in measuring the accuracies and inaccuracies in perceptual accretions; diagnostic value of the inventory lies in exposing the perceived interexperiences of each partner. Once explicitly stated, congested relational attitudes or behavioral dispositions causing communication inefficiencies can be explored and/or eliminated.

Potentialities of the PDI include refinement in delineating the association between perceptual correspondence and specific communication behaviors which may be successful or unsuccessful. The instrument contributes to the development of a science of interpersonal relationships by providing information on the cognitive operations of individuals as they relate to communication behavior and dyadic experience. 
TOWARD A MEASURE OF CORRESPONDENCE IN RELATIONAL PERCEPTIONS IN MARITAL DYADS

by

DEBORAH ANNE COKER

A thesis submitted in partial fulfillment of the requirements for the degree of

\author{
MASTER OF SCIENCE \\ in \\ SPEECH COMMUNICATION
}

Portland State University

1982 
TO THE OFFICE OF GRADUATE STUDIES AND RESEARCH:

The members of the Committee approve the thesis of

Deborah Anne Coker presented October 25, 1982.

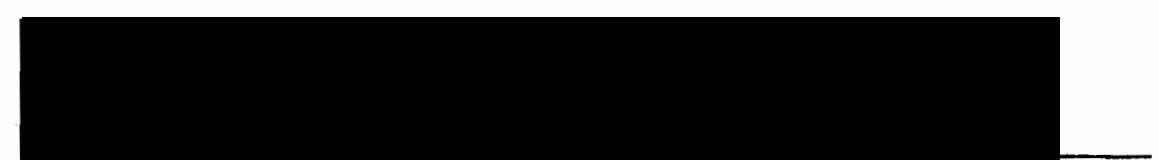

Theodore G. Grove, Chairman
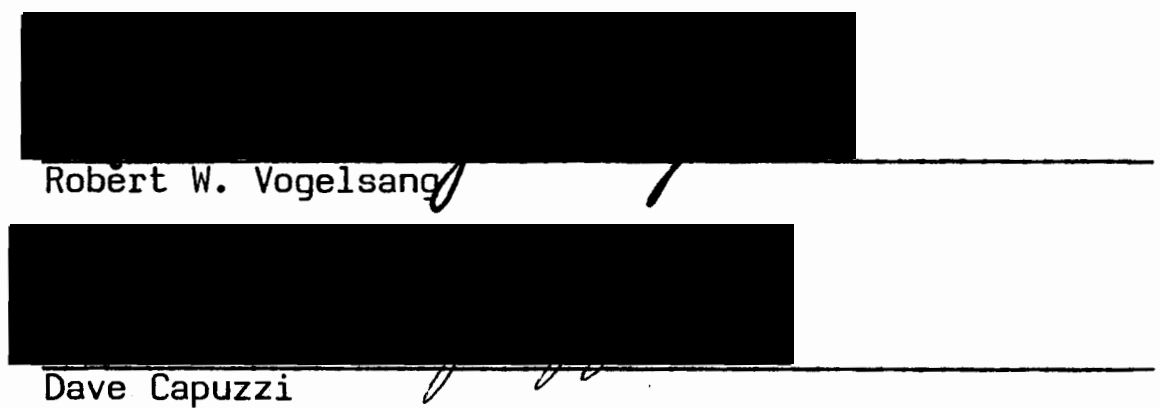

APPROVED:

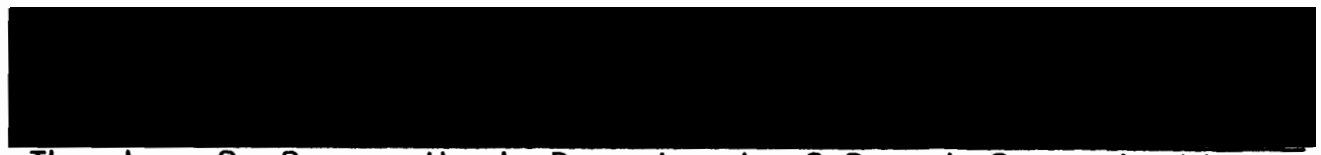

Theodore G. Grove, Head, Department of Speech Communication

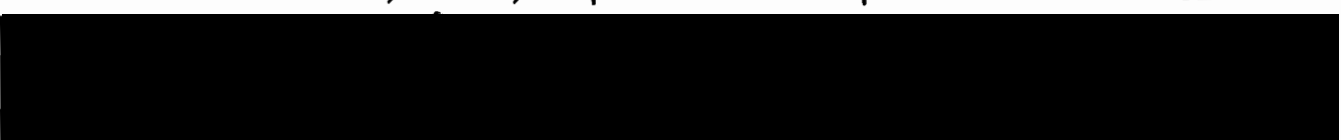

Stanley E. Rauch, Dean of Graduate studies and Research 


\section{ACKNOWLEDGEMENTS}

I would like to acknowledge Dr. Theodore Grove, my committee chairperson and graduate advisor for his continued interest in and enthusiasm about this project. Without his dedication to the development of an instrument for analyzing dyadic perceptual correspondence this research would certainly not have been accomplished. A special thanks to him for his expressions of concern and optimistic attitude throughout; the success of this thesis is highly attributable to him.

Dr. Robert Vogelsang is thanked for his comments and guidance on the written material; he is particularly acknowledged for his willingness to review this thesis on his scheduled vacation time. His support of this project as well as throughout my graduate program is appreciated.

Bright summer days in the windowless basement of Neuberger Hall were made more tolerable by Pat Hamilton and Ed Cavin. Both of these people were supportive and encouraging throughout this study and helped me keep my eye on the goal of this research.

I appreciate those who helped me obtain marital couples to participate in the pilot and final studies. In particular, I would like to thank my family for their time and efforts in contacting couples working in various occupations and in other cities.

Finally, this would not be complete without expressing gratitude to two very important persons in my life. My husband Ray, made possible my devotion to this study by his cooperative attitude and financial support, and my good friend Betsy Crist, also working on a thesis in 
this area, was a constant source of support and encouragement during the hours we spent together working through this difficult task. 
TABLE OF CONTENTS

PAGE

ACKNOWLEDGEMENTS ...................

LIST OF TABLES ................................. vii

LIST OF FIGURES ....................... viii

CHAPTER

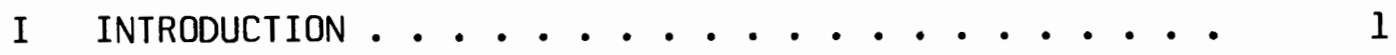

Statement of Purpose ............ 2

Need for the Study............ 4

II THEORETICAL FRAMEWORK ............... 8

Development of a Systems Approach to Human

Communication ............ . . 8

Transactional Communication ........ . 18

Perceptual Interplay ............ 20

Summary ............. 23

III REVIEW OF MARITAL COMMUNICATION MEASUREMENTS . . . . 25

Interpersonal Perception Method ....... . 29

Critique of the Interpersonal Perception Method . 35

Conclusion ............. . . 40

IV METHODS, INSTRUMENT DEVELOPMENT AND PILOT STUDY . . . 41

Methods .............. . . 41

Instrument Development .......... . 42

Pilot Study ............ . . 46

Subjects

Procedures

Data Analysis and Issue Selection

Discussion and Instrument Refinement

V FINAL STUDY ........................... 54

Discussion of Validity . . . . . . . 54

Hypotheses .............. . . 57

Description of Instruments . . . . . . . 57 
CHAPTER

Subjects . . . . . . . . . . . . . 59

Procedures .................. 64

VI RESULTS AND DISCUSSION . . . . . . . . 65

Results ................. 65

Discussion . . . . . . . . . . . . . 70

VII SUMMARY AND IMPLICATIONS . . . . . . . . . . . 73

Summary . . . . . . . . . . . . . . 73

Limitations and Recommendations . . . . . . 75

REFERENCES . . . . . . . . . . . . . . . . 79

APPENDICES . . . . . . . . . . . . . . . . 87

Appendix A - Communication Textbooks Reviewed for Models of Communication and Issue Candidates.

Appendix B - Three Phases of Issue Reduction for

Pilot Instrument . . . . . . . . . . 90

Appendix C - Perceptual Diagnostic Inventory: Pilot

Study . . . . . . . . . . . . .

Appendix D - Pilot Study Instruction Letter . . .

Appendix E - Personal Data Inventory . . . . .

Appendix F - Pilot Study Letter Accompanying

Inventory Feedback . . . . . . . . . . .

Appendix G - Perceptual Diagnostic Inventory: Final

Study . . . . . . . . . . . . .

Appendix H - Marital Satisfaction Inventory . .

Appendix I - Marriage Problem Checklist . . . .

Appendix J - Final Study Instruction Letter . . .

Appendix K - Final Study Letter Accompanying

Inventory Feedback . . . . . . . . . . . 


\section{LIST OF TABLES}

TABLE

PAGE

I Overview of Published Measures of Marital Communication

II Item Analysis of the Perceptual Diagnostic Inventory:

Pilot Study ............... 50

III Descriptive Characteristics of Subjects . . . . . . 61

IV Item Analysis of the Perceptual Diagnostic Inventory:

Final Study ................. . . 66

$V$ Means and Standard Deviations on the Perceptual

Diagnostic Inventory, the Marital Satisfaction

Inventory and the Marriage Problem Checklist . . . .

VI Pearson Product-Moment Correlation Coefficients for the

Perceptual Diagnostic Inventory, Marital Satisfaction

Inventory and Marriage Problem Checklist . . . .

VII Categorization of Couples by Scores on all Inventories 


\section{LIST OF FIGURES}

\section{FIGURE}

PAGE

1. Example Responses at Three Perceptual Levels and Resulting Outcomes for Two Dyadic Partners . . . . . 


\section{CHAPTER I}

\section{INTRODUCTION}

The institution of marriage, once a very stable and predictable component of society, is in a state of increasing disarray. Many factors have contributed to the disorder of this institution including changes in traditional marital roles and role expectations, alterations in structure and size of the family, increased economic uncertainty and financial pressures and greater concentration on personal peace and affluence than has been experienced in recent years. The reorganization of such a major aspect of societal structure cannot exist without serious repercussions. The National Center for Health Statistics (1982) reports that in 1981 there were 2,438,000 marriages and 1,219,000 divorces granted, indicating that the divorce rate is half as high as the rate of marriage. Loss of confidence in marriage, along with widespread marital dissatisfaction have caused both public and professional concern.

One of the key areas recently investigated in marital dysfunction has been communication. Experts from a variety of disciplines have focused on communication, developing methods and techniques to assess and improve dyadic relationships. Scientific investigations have given rise to an outgrowth of material on communication; an abundance of literature is now available on effective verbal and nonverbal interpretation and techniques, conflict management, self-disclosure, listening skills and a host of other communication-oriented topics (Argyle, 1967; Filley, 1975; Fitzpatrick and Winke, 1979; Goffman, 1967; Hamachek, 1971; Jandt, 
1973; Jourard, 1971; Kleinke, 1978; Levy, 1972; Mehrabian, 1973; Miller and Simons, 1974; Phillips and Metzger, 1976; Powell, 1969; Schutz, 1966; Watzlawick and Helmick, 1967; Wilmot, 1979).

Based on the above, and vast related literature, it is clear that communication is widely held to constitute an essential aspect of interpersonal relationships. Unfortunately measurements and techniques for specifically assessing marital relationships are somewhat lacking (Bonjean et al., 1967; Cromwell et al., 1976; Lake et al., 1973; Phillips, 1973; Snyder, 1981; Straus and Brown, 1969); this is expressly the case in the area of marital communication investigation (Fitzpatrick and Indvick, 1982). As will be discussed later, the majority of instruments professed by investigators to assess marital communication focus on the frequency and type of verbal interchange between partners or barriers to communication and omit necessary questions that are, at once, more germane to communication processes and more difficult to examine. These questions include: (1) how an individual's perception of another affects the selection of verbal messages, (2) how verbal messages are misinterpreted and misunderstood because of perceptual biases, and ( 3 ) the general nature of how perceptions of individuals affect dyadic commucation behavior.

\section{Statement of Purpose}

As a result of the felt need for investigation of the aspects of interpersonal relationships stated above, the current study focuses on the levels of awareness spouses exhibit regarding phenomenological perceptions of themselves, their partners and the status of their dyadic system. The specific goal of this research is the development of a tool 
for use in assessing the correspondence of relational perceptions partners in a marital dyad maintain. The instrument will provide an empirical means for differentiating issues in a relationship which are problematic from those which are not.

Characteristics of the instrument aspired to include:

1. Generation of dyadic data where each person's responses are compared with their partner's responses producing a scorable unit

2. Issues that are highly salient to marital relationships

3. Individual scale items and total scores exhibiting high reliability

4. High discriminant validity as suggested by correlations with other measures

5. Potential diagnostic value in deliniating the overall quality of communication between dyadic participants

These features serve as the basis for developing the intended instrument. Objectives of the investigation entail assessment of: (1) reliability substantiated by internal consistency analyses of item-total correlations and test-retest item reliabilities, and (2) discriminant validity established by comparison of the instrument with two other marital assessment measures aimed at related but different constructs. The objectives will be achieved through two stages of data collection, data analysis and subsequent instrument refinement.

It is projected that the results of this study will provide investigators and practitioners with an instrument that is easy to administer, score and interpret, and a source of useful information for the potential assessment of communication in marital relationships. The study itself will provide an additional perspective for research on marital assessment techniques and research on communication behavior. It will also, no 
doubt, generate a number of questions for further investigation.

\section{Need for the Study}

In an attempt to investigate the causes of marital dysfunction, clinical and research efforts have been increasing at an impressive rate (Berman and Lief, 1975; Gurman, 1973; Snyder, 1981). Straus and Brown's (1978) recent review of marital and family measurement techniques listed 813 different instruments, specifically labelling 224 as husband-wife relationship measurements. This plethora of diagnostic and evaluative tools are being utilized by a number of professionals involved in marital assessment. Despite the abundance of technical information and the diversity of measures, several surveys of contemporary marital assessment suggest that a large percentage of the techniques are both highly inferential and deficient in their ability to meet even minimal criteria for sound scientific investigation (Bonjean et al., 1967; Cromwell et al., 1976; Lake et al., 1973; Phillips, 1973).

Improvidence in developing appropriate measures for marital assessment can be fundamentally related to the more general state of social scientific evaluation. In their investigation of diagnotic tools and techniques used in marital and family therapy, Cromwell, 0lson and Fournier (1976), concluded that social science measurement tools were crude and underdeveloped when compared to measurement tools used in the more natural sciences. Straus (1969) confirmed this position when he stated "...it is only slightly stretching the point to say that the conceptual status of measurement is not more primitive in the social sciences than in the physical sciences. The key difference lies in the vastly more primitive state of measurement technology in the social 
sciences"' (p. 337).

The systematic development of marital assessment measures is further confounded by internal factors. The presence of the multidisciplinary methodologies of investigators has interfered with satisfactory development of this relatively new field as most of the measurement tools used for diagnostic purposes have been developed in other fields and were designed for purposes other than assessing marital or family properties (Cromwell et al., 1976). The lack of a comprehensive foundation in research, theory and practice is discussed by Cromwell, Olson and Fournier (1976) to have adversely affected measurement technology.

Several authors also suggest that the concentration on empirical issues is inadequate in many marital and family measurements (Bonjean et al., 1967; Cromwell et al., 1976; Lake et al., 1973; Snyder, 1981). Snyder (1981) comments that many of the contemporary assessment techniques are "armchair" or "seat of the pants" instruments without satisfactory statistical documentation. Frazier (1976) surveyed the most well-known and respected sources of test information and listed 30 separate measures which could be used in marital assessment. of the 30 , only five reported adequate data on reliability and validity.

After reviewing 84 instruments propounding to determine various aspects of social functioning, Lake, Miles and Earle (1973) were of the opinion that the use of diagnostic tools in marital and family assessment suffered from five primary weaknesses. They determined that: (1) empirical standardization is rare and longitudinal studies are minimal, (2) information on existing instruments is scattered throughout the literature in several disciplines and subfields and is hard to utilize, (3) many popularized instruments are used by practitioners and little 
consideration is given to the appropriateness of the instrument for a particular situation or problem, (4) researchers and practitioners develop tools themselves or use simple and easily accessible tools while more reliable and valid instruments are under-utilized, and (5) often researchers and research-oriented clinicians publish very sophisticated and technical materials but lack the resources necessary for systematic compilation and critique of measurement tools as they might be applied to treatment settings.

Growing awareness of these and other problems in evaluation and assessment techniques has led some social scientists to appeal for concentrated efforts in specific areas (Gurman, 1973; Lively, 1969; Snyder, 1981; Straus and Brown, 1978). In summary, the cited investigators request that: (1) the classification of problems be made in both nominal and operational terms, (2) hypotheses and propositions be standardized to eliminate unnecessary procedural and methodological difficulties, (3) research, theory and practice are combined in developing new assessment tools, and (4) the expansion of literature be deferred while a snythesis of developmental and theoretical material takes place so that vertical, not horizontal, understanding of phenomenon can actualize. Efforts directed in these areas can lead to increased research technology and sophistication of assessment techniques in social scientific areas of investigation (Snyder, 1981; Straus and Brown, 1978).

The present study is intended to address some of these problems. Chapter II will present contributions to communication theory scattered throughout social scientific literature as they relate to the development of a systems approach of investigating dyadic interaction. Current communication literature will be cited for information on how transactional 
communication occurs within dyadic systems, and the important role perceptions play in communication behavior. This plan for research is designed to meet the appeal for synthesis of theoretic material and will function as a basis for development of the intended instrument.

Chapter III provides a review of instruments used to measure marital communication. Particular attention will be given to the examination of the Interpersonal Perception Method (Laing et al., 1966) as an existing instrument that assesses the perceptual matching of partners in a dyad. The merits and shortcomings of this method will be discussed prior to application of the methodology in the current investigation.

Chapters IV-VII will address the developmental stages and refinement of the emerging perceptual assessment instrument. In keeping with the previously cited request for compilation of research, this instrument is an attempt to improve upon some features found in previous instrument design and methodology. Inclusion of necessary empirical investigation in both the areas of reliability and validity will provide a basis for additional research in the areas of dyadic communication and marital assessment. 
Development of a Systems Approach to Human Communication

In any discipline, conceptual and methodological development is an ongoing process; refinement of communication theory is no exception as scholars contribute to an increasing accumulation of knowledge and understanding. The origins of communication theory are diffuse and diverse; advancements in anthropology, linguistics, philosophy, psychology, psychiatry and sociology have been particularly influencial in the evolution of this field (Berger, 1977; Littlejohn, 1982; Swensen, 1973).

It is the position of this author that prior to the development of the instrument aspired to, a synthesis of the contributions from these disciplines and a firm conceptual basis must be established. A theoretical framework for viewing individuals as existing within dyadic systems will provide essential information in designing the instrument. The following discussion focuses on important contributions to communication theory specifically related to the development of a systemic or transactional approach to human interaction. Evidence will be presented attesting to a gradual change in communication models embraced by communication theorists which at the most abstract level entails the supplanting of monadic models with interactive/transactional models. Discussion of this evidence will provide a framework for first, exploring the interplay of perceptions and communicative behavior within dyads, and second, for the 
development of an instrument designed to aid examination of that interplay.

For centuries in philosophy, human existence was explored in terms of the most basic, fundamental reality, the self. Individuals were seen as discrete entities possessing a field of experience exclusively oriented around "I" or "me." Laing et al., (1966) note that it was not until Feuerbach developed the notion of "you" as a central element in human experience, did philosophers come to see this agent as primary as the I. The essential inclusion of this category for the presence of others was refined by Martin Buber (1958). He saw the I-Thou relationship, discussed in his works, as the "highest form" of human experience. According to Buber (1958), all individuals live within the world of I-it, interacting with objects, but only persons can enter the world of I-Thou, the world of interpersonal relationships. Buber's work on human interaction was carried on by other philosophers and many philosophical propositions today include both the "I" and "you" elements (Hodes, 1971).

Freud's theories and techniques of psychotherapy were indicative of the self-oriented philosophy that permeated the research and literature of his time. Essentially, he was preoccupied with the self and concentrated on the intrapsychic mind of the individual. The goal of psychotherapy was to produce in the subject insight or awareness of the circumstances out of which his/her symptoms arose (Haley, 1963). It was assumed that a concentration on the repressed emotions or subconscious mind would allow the history, fantasies, guilts and fears of the individual to be understood. The therapist sought to evoke a psychological balance in the distressed patient; it was maintained that only through deeper analysis of the self could individuals change their thought 
processes or behavior (Haley, 1976).

In Freudian psychotherapy, the internal aspects of individuals were emphasized and theorized about in isolation from their external surroundings or relationships and an artificial "boundary" was drawn between individuals and their social contexts (Minuchin, 1974). While Freud did not advocate treating dysfunctioning patients while they were interacting with others in their relational environment, his theories and techniques provided an abundance of information on psychological assessment and therapy which could be evaluated and reconstructed by future researchers. As social psychology evolved, significant contributions were made by investigators in reaction to the self-centered theoretical position expounded by freud and other psychologists and sociologists of this time. George Herbert Mead (1934) introduced the concept "generalized other" in an attempt to explain the influence others have in the socialization process. The principle which he suggested as basic to human social organization was that existence involved communication and participation in the other (Mead, 1934). The appearance of the other in the self, the identification of the other with the self, and the reaching of self-consciousness through the other, were all made possible through human communication. His proposition of this self-other orientation portrayed individuals taking on the role of the other and in so doing, directing their own behavior in accordance with the way this role was perceived.

Cottrell, a social psychologist, influenced by Mead, Cooley, Farris and Lewin, further investigated the importance of a wider context from which to study the human organism (Cottrell, 194lb). His "role theory" suggests that when individuals interact over a period of time, the activity of each becomes a stimulus pattern for a response pattern in the other. 
Furthermore, in any social interaction, the acts of the other, as well as those of the self, are incorporated by each party with previous patterns to form his/her distinct personality (Cottrell, 194lb). One's personality was therefore seen as a collection of self-other patterns which were facilitated by interpersonal communication (Cottrell, 194la, 1942; Dymond, 1948).

Dymond's work in the late 1940's contributed to the development of a systems approach in communication theory. Her early study of empathy was one of the first investigations that dealt with transposing oneself into the thinking, feeling and acting of another. She found that the ability to experience the position of another was positively related to the ability to understand oneself. In other words, the state of empathy seems to involve the ability to stand off and look at oneself from another's point of view. Dymond (1948) used the term "insight" to distinguish the understanding of the self-other patterns or roles in communication interaction. When insight was achieved, this understanding could then be translated to new and ambiguous situations and would serve to facilitate expectation-response patterns for future reference (Dymond, 1948). Dymond's work promoted a concept of self that developed through, and in conjunction with, the communicative interactions with others in communication contexts.

In 1948, a major breakthrough occurred in the field of communication when Norbert Weiner published Cybernetics. During the next decade, many of the sciences and social sciences began emphasizing homeostatic systems with feedback processes that caused the system to be self-corrective (Haley, 1976). Individuals came to be seen as possessing sophisticated feedback mechanisms that allowed them to take external information, 
process it and alter their behavior accordingly. As a result of this and other research, the self was viewed as many selves as it responded to the particular messages it was receiving from outside stimuli. Communication studies began to show a focus on the "process" of communication, which included this feedback mechanism, rather than a simple cause and effect or sender/receiver interchange.

As research on interpersonal interaction began to be refined, assessment techniques and instrumentation were developed. Robert F. Bales (1951) originated a method for analyzing the interaction process in small groups which has subsequently been used in research in interpersonal behavior for over 20 years (Swensen, 1973). Bales' "Interaction Process Analysis" allowed investigators the empirical means to look beyond the individual to the process occurring within a system. He hypothesized that people develop their tendency to interact with others in a particular manner because of their previous interactions with others. These past experiences were seen as the determining factors in interpersonal communication. Bales states, "both the remembered consequences and the expected consequences can become a part of the effective causation of actions" (1951, p. 50). Bales' measurement consisted of aspects assessing the personality of the individual as well as situation or group roles. The significance of this methodology lies in its investigation of the individual and his/her behavior within a group as well as an analysis of how the behavior of others effects the individual.

Bales' method of assessing interaction generated research and methodology that influenced the works of sociologist, George C. Homans (1961) and psychologists, John Thibaut and H. H. Kelley (1959). The exchange theory, developed by these investigators is basically a 
behavioristic approach to the study of interpersonal relationships. The theory proposes that any organism learns to repeat behavior that is rewarded, ceases to behave in ways that are not rewarded, and suppresses behavior that is punished. Homans (1961) notes that the "secret of human exchange is to give the other person behavior that is more valuable to them than is costly to you, and to get from them behavior that is more valuable to you than is costly to them" ( $p .62$ ). Thibaut and Kelley (1959) similarly state that "most socially significant behavior will not be repeated unless it is reinforced, rewarded in some way" ( $p .5)$. The importance of this theory to communication research is that it focuses on how individuals perceive the cost, profit and rewards of a relationship and how their behavior is modified and changed through interaction with others as a result.

The development of the notion of the individual existing within a self-other interactive context was further documented by Gregory Bateson's research on communication. A research project, which existed from 19521962, allowed Bateson and his colleagues to investigate the general nature of human interaction in relation to communication. The group started with the study of schizophrenics and paradoxical messages that dysfunctional patients received within a family system and ended up.producing vital information on the way people communicate in general. Two advances in research resulting from this project were the development of an approach to the study of interpersonal relations which stressed analysis of communication, and a theory of schizophrenia based on the peculiar kind of communication that went on in the family of a schizophrenic (Bateson et al., 1976). The group concluded that the dysfunctional behavior of the "identified patient" was actually the product of the abnormalities in the 
family interaction.

The observations of this group led Haley (1959) to identify the following aspects of importance to communication research: (1) communication can be classified into levels of messages, both verbal and nonverbal, (2) communication is a cybernetic, self-corrective system made up of complicated actions, reactions and modifications, and ( 3 ) when people interact they establish rules or metacommunications for interaction which are implicit communications about communication. This research indicated the necessity of viewing the individual as existing within a system and emphasized the intrinsic role of communication therein.

The systems approach as a framework for diagnosing and assessing the problems of an individual was introduced to family therapy primarily by Jackson (1959, 1961), Haley (1963), Watzalwick et al. (1967) and others at the Mental Research Institute in Palo Alto. It soon became clear that the adoption of this approach made therapy more effective (Haley, 1976). Minuchin (1974) compared the therapist working within the individualistic framework to a person working with a magnifying glass; the details are clear but the context is severely limited. In contrast, the therapist utilizing a systemic approach is more like a photographer with a zoom lens; he/she can view the total functioning of the system, or "zoom in" to analyze the intrapsychic field of one individual. When the social and relational context of the individual was taken into consideration, the therapist could find dysfunctional patterns within the system rather than in one symptomatic patient. The contributions that have led to the broadened conceptual framework of the systems theory and analysis of communication aspects, have had a major impact on the effectiveness of 
marriage and family therapy (Haley, 1976) and on analysis of communication within dyadic and group systems in general.

As a result of these and other works, the systems theory has been developed allowing social scientists a means of viewing individuals as interacting elements within a unified entity. This scientific theory is based on the world view that systems consist of interlinked sets of components organized into structural wholes which interact through time and space and are self-regulating, yet capable of structural change (Monge, 1977). In the following statement Laszlo (1972) described the concept of the organization of a system, "whereas traditional reductionism sought to find the commonality underlying diversity in reference to shared substance, contemporary general systems theory seeks to find common features in terms of shared aspects of organization" (p. 19). He goes on to say, "the notion of organization concerns not what a thing is per se, nor how one thing produces an effect on the other thing, but how sets of events are structured in space and time" (p. 20).

The most basic systemic unit consists of two elements interacting where the outcome is something more than the simple properties of each (Monge, 1977). In communication research, an illustration of this point comes from Rogers and Farace (1975) in their article, "Analysis of Relational Communication in Dyads":

Relational communication analysis requires a perspective that differs from the monadic or individual difference orientation that dominates existing analytic techniques. Relational analysis focuses on communication properties that exist only at the dyadic level; relation variables do not lie within individual interactions, but rather exist between them. The measurements derived from this analysis refer to emergent properties of joint communicative behaviors and have no counterpart in the properties of individuals or single messages. With the present scheme, the transaction-the exchange of paired sequential messages over time-becomes the basic unit of analysis ( $p .222)$. 
Due to refinement of the systems theory in recent years, definitions of systems vary depending on whether one is working within the domain of general systems theory, structural-functional analysis, or cybernetics. Common to all definitions, however, is the notion of a set of variables together with rules of transformation which define the relations among the variables (Monge, 1977).

Systems theorist Peter Monge (1977) presents four distinct properties of systems; wholeness, regulation, adaption and hierarchical imbeddedness. Wholeness refers to the interdependence of parts of the system. This is manifested as change in one element changes the entire system (Ruben, 1975). Regulation implies a technical aspect of the system as it maintains a 'steady state' or homeostatic condition. Energy on the part of the elements within the system is expended to prevent the rearrangement or collapse of that entity. Jackson (1961) relates this concept to family systems as there is a tendency to resist change in order to maintain homeostasis; the behavior of one member of a family system is difficult, if not impossible, to change without changing the entire functioning of that system.

Adaption can be seen in a system as systems existing within an external environment have a propensity to grow, change and differentiate. Monge (1977) cites the old maxim, 'the only permanence is change' to illustrate the fluidness and changing structure a system must sustain (p. 21). Buckley, (1967) an investigator of modern systems, adds to this notion, ". . processes in complex system environment exchanges tend to preserve or maintain a system's growth form, organization or state" (p. 31). In relation to communication, Monge (1977) also notes, "an emphasis on change is important because it permits the study of 
communication as a complex, adaptive system rather than a static, enduring structure. Living systems, communication included, grow and develop, decay and disintegrate, and a full understanding of the communication process requires knowledge of how the system will change over time" (p. 21).

The final property of systems theory introduced by Monge (1977) has to do with hierarchical organization. Systems are seen in terms of increasing levels of complexity which are linked together. Higher-level components exercise control over lower-level components and function as subsystems within the system which pull together and integrate the behavior of all system components. Thus, complexity and role coordination are introduced to the system.

These four properties-wholeness, self-regulation, adaption and hierarchical imbeddedness-represent the distinctive characteristics of the world view provided by systems (Monge, 1977).

The preceeding presentation of contributions to communication theory over the last several decades depicts influences on the development of the systems theory of human communication. In many fields, a transformation of rudimentary beliefs about human behavior has occurred and investigation now accomodates the fundamental aspect of relationships with others in an external environment. The study of communication has become a focal point for many disciplines associated with human behavioral analysis; examining the effect of communication transactions on the individual is crucial in any study of interaction and indicates the importance of this broadened systems perspective. 


\section{Transactional Communication}

The significance of the development of the systems theory cannot be overstated in relation to communication-intensive contexts. Relationships, rather than individuals, have become the object of investigations and various aspects of the dyadic system are being scrutinized by scholars. Berger (1977) observed that during the 1950's and 1960's role models for students of communication theory were found in other disciplines, but in the past few years, communication experts have produced an increased number of journal articles and books concerned with issues related to: (1) the process of theory construction in general, and (2) the presentation of specific substantive theories or models. A major emphasis in theory development now deals with interpersonal communication as a process occurring in relational or transactional contexts (DeVito, 1982; McCall, 1970; Miller and Steinberg, 1975; Rogers and Farace, 1975; Roloff, 1981; Steward, 1977).

Former communication models expressed human interaction linearly; Schramm's (1954) model, Lasswell's (1948) model, and the Shannon/Weaver (1949) model are examples of models describing communication in sender/ receiver or source/destination terms. Because each participant is affected in a dyadic transaction (interaction), dyadic communication is not a linear, one-way event (Wilmot, 1979). One does not communicate to someone as if they were a nonentity; one communicates with another. One does not originate communication; one participates in it (Watzlawick et al., 1967). John Stewart (1977) supports this statement saying, "communication seen as an action, something one does to somebody else, is drastically oversimplified-all of our communication behavior is 
affected by not only our own expectations, needs, attitudes and goals, but also by the other's and is facilitated by the responses and feedback each gains from the other in an interchange" (p. 7). He determines, in conjunction with many other communication experts, that it is more accurate to view communication as transaction, a process of mutual or reciprocal influence and exchange (Stewart, 1977).

Early authors (Bales, 1951; Homans, 1950) advocating the systems theory provided great impetus in the development of an interactive approach in analyzing human communication. A review of over 30 communication textbooks (Appendix $A$ ) indicates that theorists currently adhere to the transactional model of communication where communication is seen as a process occurring between individuals. Process communication is operationally defined as being: dynamic, systemic, adaptive, continuous and transactional (Brooks, 1981). Communication is an act, an event, or an activity in an ongoing process where there is a state of constant change (DeVito, 1982). Transactions involve elements integrally related to one another; each exists in relation to the other. DeVito (1982) describes dyadic transactions as "the relationship among elements in which each influences and is influenced by each other element," and goes on to say, "communication is a transactional process since no element is independent of any other element" (p. 574).

McCall (1970) defines an interpersonal relationship as the substantial probability of transaction between two people. An interpersonal relationship exists when two people interact in a specific manner. We know that a person has a relationship with another person because he/she is likely to communicate with the other. The way persons communicate is determined by such relational constraints as boundary rules and definitions 
and role patterns which influence the nature of transactions (Roloff, 1981). Interpersonal communication occurs in a relational context, is guided by knowledge of one's relational partner, involves the transmission of various types of symbols and is functional-serving some purpose (Roloff, 1981).

The analysis of relational communication in dyads done by Rogers and Farace (1975) exemplifies the systems approach to communication as the authors focus on messages and patterns in ongoing transactions. Transaction was expressed by these scholars as the exchange of paired sequential messages over time. Observable, ongoing aspects were analyzed rather than internal consequences, and systemic properties of communication were addressed. Rogers and Farace (1975) proposed that relational analysis needs to focus on communication aspects that exist only at the dyadic system level; relational variables do not lie within individual interactors, but rather exist between them.

Contemporary investigators of communication currently identify the systemic nature of dyadic behavior and examine partners in transaction in order to assess over "workingness" of the relationship in terms of communication behavior (Fitzpatrick and Winke, 1979; McCall, 1970; Miller and Steinberg, 1975; Monge, 1977, 1982; Roloff, 1981).

\section{Perceptual Interplay}

As interpersonal communication has been examined in light of the systems theory, one of the key aspects of communication that has elicited interest in investigators is the notion of the perceptual interplay that occurs with individuals involved in a dyadic relationship (Foa and Foa, 1976; Goffman, 1959; Hasdorf et al., 1970; Newcomb, 1961; Taguiri, 1958; 
Watzlawick et al., 1967; Wilmot, 1979). This essential component of relational transactions will be discussed and definedin the following as a vital part of any assessment of dyadic behavior.

Perception, an active rather than a passive process, stems from the ability to symbolically represent the external world in terms of our past experiences, desires, needs and wants, and loves and hatreds. Hans Toch and Malcolm MacLean (1967) express the essence of this transactional view of perception clearly in the following:

Each percept (that which is perceived) from the simplest to the most complex, is the product of a creative act .. . we can never encounter a stimulus before some meaning has been assigned to it by some perceiver . . . Therefore, each perception is the beneficiary of all previous perceptions and in turn, each perception leaves its make on the common pool. A percept is thus a link between the past which gives it its meaning and the future which it helps to interpret (p. 56).

We all live in very private worlds-worlds unique to our own ability to symbolically represent external reality. It is impossible to ever really establish identical meanings between people because of the complex structure of this symbolic world, as a result, communication becomes meaningful and inevitable (Barnlund, 1973). The complexity of communication in a dyadic relationship stems from the merging of symbolic realities of two interacting persons with different sets of past experiences, emotional states, information, intelligence, imagination and so forth. Each has his/her own characteristic set of social behaviors but these vary to some extent depending on the age, sex, and personality of the others this individual comes into contact with (Argyle, 1969).

Perceptions affect communication in a very significant way as all persons behave and communicate in light of that which is perceived. While perceptions are one of the fundamental elements in the process of communication, seldom are their cognitive and affective results fully 
disclosed in everyday interactions. The behavior of an individual will vary as a function of the situation and the nature of the other participant. How you categorize and perceive me will influence how you behave toward me, and your behavior, in turn, will influence how I behave toward you. Before person A can select one style of behaving rather than another, $A$ has to perceive and categorize $B$. And of course, while $A$ is categorizing $B$ and preparing to use a particular set of social responses, B is doing exactly the same with regard to A (Hasdorf et al.,1970). Thus, while perceptions of the self affect communicative transactions, perceptions of the other are no less important in determining the direction of a relationship (Wilmot, 1979). The meaning of behavior to interacting persons is consequently mediated through the interplay of perceptions each has of the other.

A crucial aspect of the interplay of perceptions is the way partners in a relationship not only perceive themselves and each other, but also the way they perceive the others perceiving them. Philosopher Martin Buber (1958) depicts this notion in his description of the six "masks" involved in all human interactions. First there is "my you, "then there is "your you," and finally there is "the you which you think I perceive." The same three persons occur for me-my me, your me, and the me I interpret you as perceiving. Laing, Phillipson and Lee (1966) illustrate the same concept in different terms. "My field of experience is filled not only by my direct view of myself (ego), and of the other (alter), but of what we call metaperspectives-my view of the other's (your, his, her, their) view of me" (p. 5). All these aspects occur in dyadic transactions and facilitate communication within interpersonal systems.

Complications in communication naturally arise as we give special 
attention and meaning focus to selected components of an interaction which may differ from another's selection and perception of components. This, as well as their, and our, selective retention of information may cause relational strains when there is a lack of agreement on these issues by interactors. While communication occurs at all times, and on all levels, misinterpretation and misperception of communication behaviors represent a major source of conflict in relationships (Foa and Foa, 1976). Hasdorf, Schneider and Polefka (1970) support this allegation with the following statement in the conclusion of their book Person Perception:

We need to know more about how people get to know one another; such knowledge would entail the matching of one person's perception of another with the other's perception of himself. Precisely defined roles and normative rules, once existing, grease the mechanics of interpersonal behavior in that they provide shared rules for behavior, and by the same token, they may reduce the chances for interpersonal attribution ( $p .103)$.

From this discussion, it is clear that scholars view perceptions as an important component in communication behavior. As individuals interact in interpersonal relationships, it is important to assess the perceptions each has of him/herself and of the other before adequate understanding of the communication behavior can be managed.

\section{Summary}

Over the past several decades, experts from a variety of disciplines have contributed to communication theory development and the result has been rapid expansion in knowledge about the communication process. The presentation of these works emphasizes human behavior as occurring and functioning in structurally complex relational systems where a multitude of interacting forces occur that influence communication behavior.

Stemming from systems theory assumptions, the nature of dyadic 
interaction was discussed and a relational model was suggested as the current widely accepted prototype of communication processes. Transactional communication was presented as exhibiting nonlinear properties such that the process of communication involves mutual or reciprocal influence and exchange. This approach to communication is a recent development in communication theory and stands in opposition to the one-way or hypodermic models of communication.

The discussion of the importance of perceptions in communication transactions offers a basis for the construction of a perceptually-based diagnostic instrument. It was suggested that dyadic interaction assessment include the necessary aspect of the perceptual interplay between partners.

This chapter has provided a conceptual framework from which an instrument can be derived that analyzes the correspondence in relational perceptions of partners in a marital relationship. 
REVIEW OF MARITAL COMMUNICATION MEASUREMENTS

Marital assessment instrumentation focuses on a variety of constructs such as: communication; conflict management; marital adjustment, happiness, satisfaction and success; role definitions and behavior; and sexual and family issues and problems. In an attempt to narrow down this plethora of marital instruments, only those measures relating specifically to marital communication will be reviewed here. The measures that have been developed and published over the last several years are listed, and descriptive information is summarized in Table $\mathrm{I}$.

While recent studies investigating aspects of marital communication are available in marital and communication literature (Albrecht and Cooley, 1980; Beier and Sternberg, 1977; Campbell and Barnlund, 1977; Ericson and Rogers, 1973; Fitzpatrick and Indvik, 1982; Gottman et al., 1977; Hawkins et al., 1977; Navran, 1967; Rogers-Millar and Millar, 1979; Schrumm and Jackson, 1980; Thompson, 1981; Wampler and Sprenkle, 1980), instrumentation specifically designed for communication analysis is rare. It is notable that in Straus and Brown's (1978) survey of husband-wife relationship measures they reviewed 224 assessment techniques, only ten of which dealt with communication.

Conjecture on the reason for the limited number of marital communication instruments, when compared with marital assessment measures in other areas, relates to the discussion in Chapter I on the state of the art in social science measurement. As was cited, Lake, Miles and Earle 


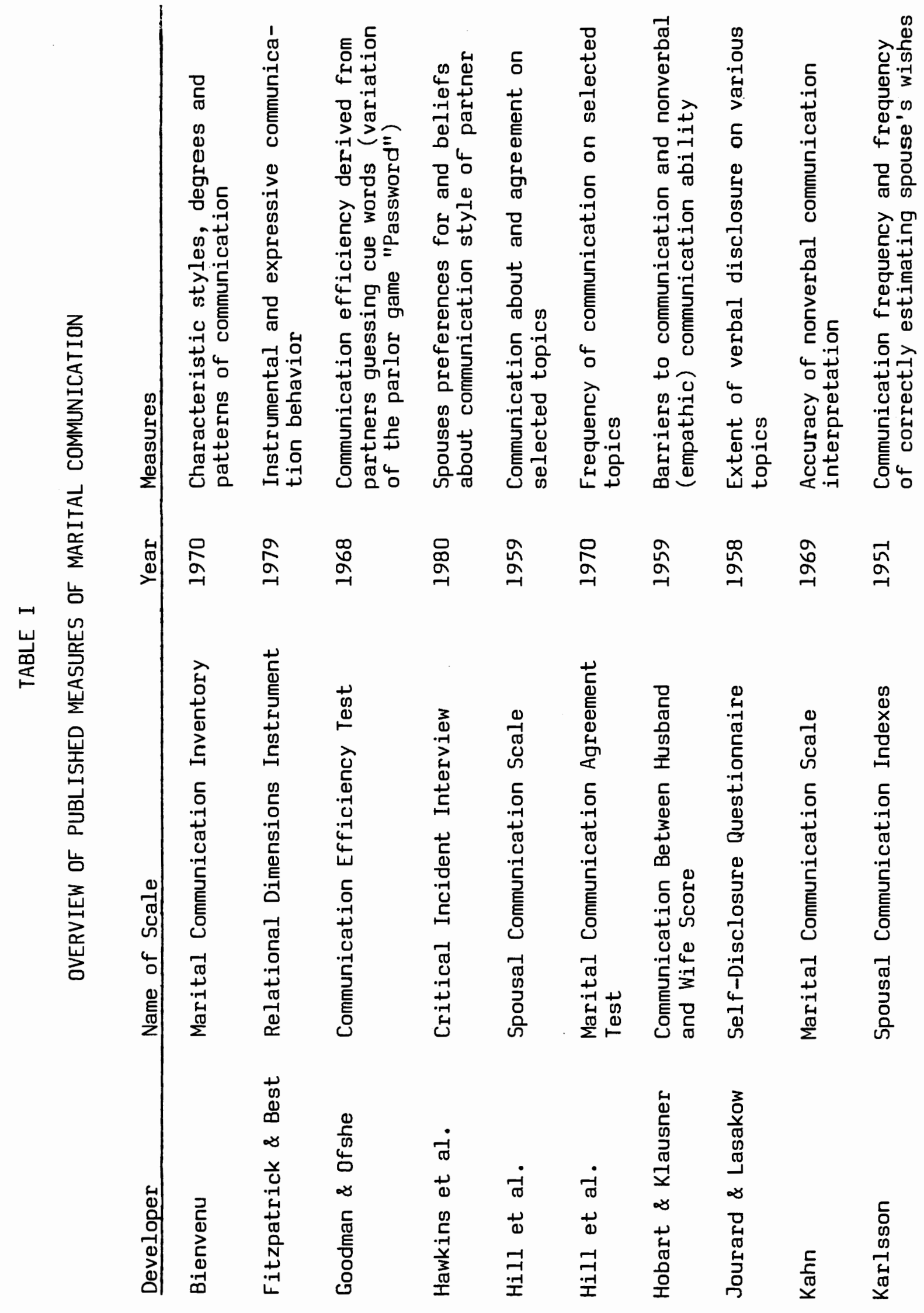




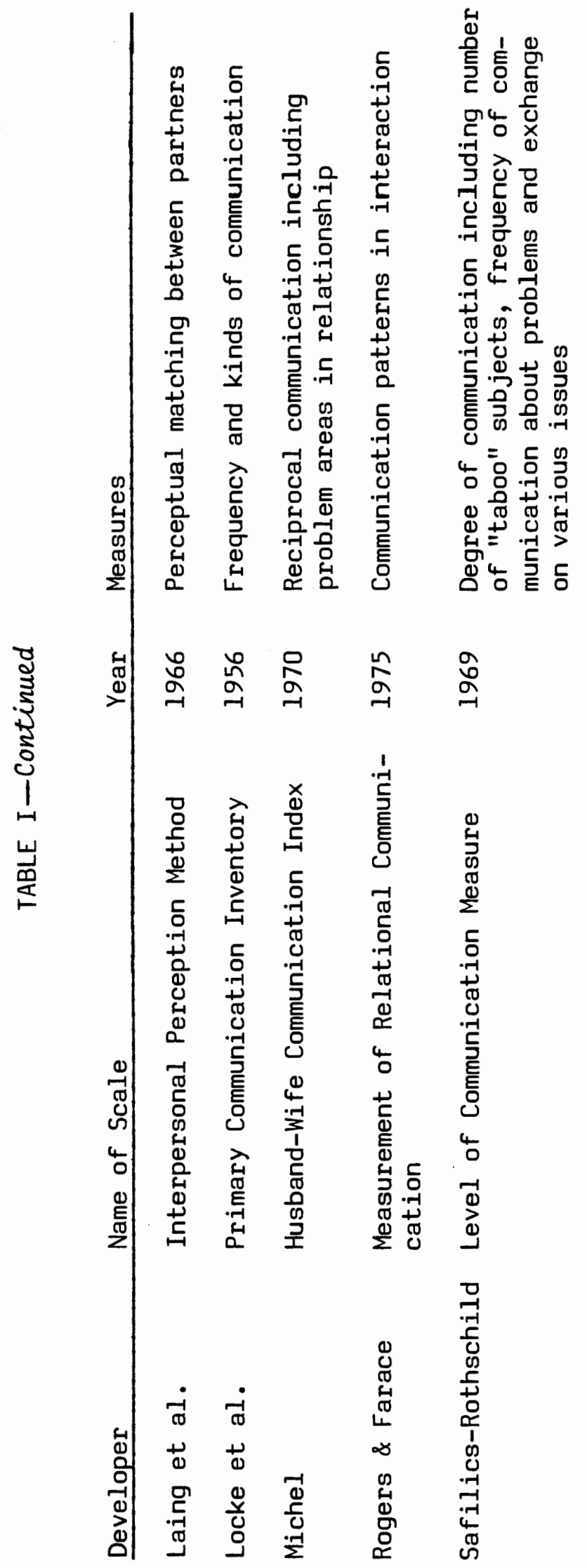


(1973) expressed several weaknesses in the diagnostic use of measurement tools, many of which apply to instrumentation for the assessment of marital communication. Analysis of marital communication measures indicates that: (1) empirical standardization is rare, in this relatively new field, and longitudinal studies are minimal, (2) many popularized instruments used in overall marital adjustment are also used to assess communication when a more suitable instrument for such assessment may be available, (3) investigators develop tools themselves for a specific study and these are not standardized, and (4) for one reason or another, investigators do not perform the follow-up refinement work on existing communication instruments that is necessary to produce highly reliable and valid measures.

A cursory examination of the measures in Table I reveals that the majority of instruments are used to investigate some aspect of verbal communication. The frequency of subjects discussed, the agreement on the variety of topics communicated about, patterns and styles of communication, and aspects dealing with lack of verbal communication as in "taboo" subjects or barriers to communication, all basically deal with communication behavior. As the preceeding discussion on perceptual interplay suggested, it is the position of this investigator that relational perceptions play a key role in communication transactions. The instrument under construction in the present study will identify perceptual awareness and attributions partners in a marital relationship exhibit. It will also indicate how well those attributions and relational perceptions are communicated between partners. This added dimension of analysis could provide in-depth information to married partners regarding the effectiveness of their communication 
behavior. None of the referenced instruments have the capability of examining perceptual awareness and understanding with the exception of an early effort by Laing, Phillipson and Lee (1966). Their method will now be reviewed and critiqued and selected features will be retained to form the basis of the present endeavor.

\section{Interpersonal Perception Method}

Laing, Phillipson and Lee (1966) suggest that the very simplest schema for understanding the behavior of one person has to include at least two persons and a common situation. This schema must include not only the interaction of the two, but also their interexperience. These authors illustrate this theoretical position in a diagram similar to the following ( $p .12)$ :

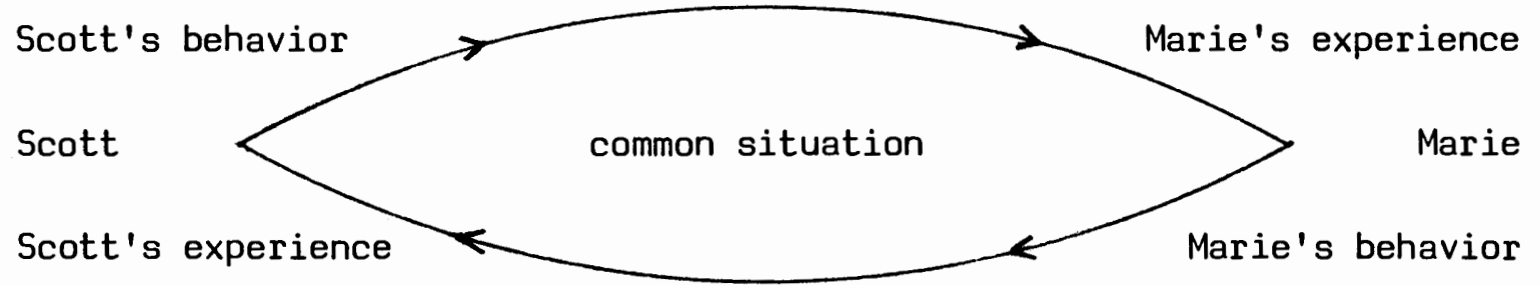

In terms of this schema, Scott's behavior toward Marie is in part a function of Scott's experience of Marie. Scott's experience of Marie is in part a function of Marie's behavior toward Scott. Marie's behavior and experience function in the same manner. Thus, the behavior of Scott toward Marie, and of Marie toward Scott, and the perceptual accretions of each during this behavioral interchange, cannot be categorized apart from the common situation. The behavior of each toward the other is mediated by the experience each has of the other, just as the experience is mediated by the behavior of each (Laing et al., 1966). 
Our experience of another entails a particular interpretation of his/her behavior. To feel loved is to perceive and interpret, that is, to experience, the actions of the other as loving. To feel misunderstood is to experience the actions of the other as misunderstanding. Instances of discrepancies between one's own experience and perception of his/her behavior and another's are familiar to everyone and often cause strain on communication efficiency. Examples of this type of discrepancy in the interexperience and behavioral interpretation of two members of a dyad follow:

Marie acts in a way that is funloving to her, but frivolous to Scott. Scott acts in a way that is pensive to him, but aloof to Marie. Marie sees herself as friendly, Scott sees her as flirtatious. Scott sees himself as cautious, Marie sees him as fearful. Marie sees herself as hardworking, Scott sees her as seeking approval. Scott sees himself as thrifty, Marie sees him as selfish.

Experience in all these cases entails the perception of the act and the interpretation of it. Unless made explicit, the interpretations which mediate between your communication behavior and my experience of you are inaccessible to you. Lacking this explicitness, the interexperience of Scott and Marie on any issues related to the above will be congested with misperceptions and misunderstandings on many levels.

As perceptual differences are brought to bear in everyday situations, communication can become complicated and burdensome. Laing et al. (1966) provide an example for a particular interaction wherein misunderstanding of perceptions, and therefore of intentions, occur. It is adapted as the following interplay between Marie and Scott: 
Marie

1. I am upset.

2. Scott is acting aloof and dispassionate.

3. If Scott really cared about me, he would get involved and show some emotion about this problem.

4. Scott knows it upsets me when he is aloof, especially when I am feeling strongly about something.

5. If Scott knows this behavior hurts me, he must be intending to hurt me.

6. He is really unkind. I think he gets pleasure out of making me feel worse. $\underline{\text { Scott }}$

1. Marie is upset.

2. I'll try to help Marie by remaining calm.

3. Marie is getting even more upset. I must remain even more calm.

4. I had better think this through more clearly. Now she is accusing me of hurting her.

5. I'm really trying to help and understand. Why is she angry with me?

6. She's projecting her emotions on me.

And so it goes as each party gets further and further away from the problem at hand and more involved in the process of perceptual interpretation. Very quickly, through projection, intrepretation, and a failure to express one's own perceptions or check the other's, both parties become involved in a spiral of mismatched perceptions in their interexperience, thereby creating second, third and higher order problems. The original problem is rapidly replaced by a new relational problem with each behavior/experience cycle.

Dyadic difficulties arise from such situations as people get more involved in the relational aspect of communication, as in, how the message is to be received and interpreted, how the relationship is being defined, or who is setting the rules, rather than the content of communication or the information being reported regardless of whether it is true or false or valid or invalid (Watzlawick et al., 1973). 
When two people do not agree on the meaning assigned to their experience or behavior, a very complicated process ensues. If communication is optimum, they understand that they differ in their perception and interpretation of the issue and also realize that understanding has taken place. Unfortunately, in dyadic relationships there is often a lack of knowledge of how one another perceives an issue, there is a misunderstanding that this knowledge of the other's perception does not exist, and there is a failure to realize that misunderstanding has occurred. Thus a vicious cycle of mismatched perceptions, interpretations, expectations, experiences, attributions and counter-attributions is fostered (Laing et al., 1966).

Based on Dymond's (1949) early work, the Interpersonal Perception Method (IPM) was developed by Laing, Phillipson and Lee in 1966, as a measurement of the interplay of perceptions between members of a dyad. The method and instrument entail comparing pairs of perceptions with regard to specific items in a relationship to identify perceptual correspondence.

The IPM and associated questionnaire require 720 responses ( 12 reponses to 60 issues) from each dyadic partner. The 60 issues are presented in phrases that express interaction and interexperience such as "respects," "doubts," or "analyzes." The IPM makes provision for comparisons on three levels. In a husband-wife dyad the levels become: (1) the husband's view of the issue, or the direct perspective, (2) the husband's view of the wife's view of the issue, or the metaperspective, and (3) the husband's view of the wife's view of his view of the issue, or the meta-metaperspective. Three similar levels apply to the wife for each issue. 
An example adapted from Grove and Hays (1978) of the IPM questionnaire format is illustrated in Figure 1. The three levels of perception, the direct, the understanding and the realization, are compared for partner correspondence. At the direct level, each respondent affirms or denies the aspects of an issue. At the understanding level, each partner predicts how the other will respond to the same issue. At the realization level, each indicates the predictions he/she thinks the other will make regarding his/her own direct response.

In the case presented in Figure 1 , subjects disagree at the direct level. At the understanding level, Marie correctly predicted (or understood) Scott's response of "no," but Scott misunderstood Marie's direct response, making this a mismatch in metalevel understanding on his part. On the third level of comparison, the realization response is matched with the understanding response. As is shown, Marie felt that Scott understood her direct response, but actually Scott misunderstood, and Marie failed to realize that Scott misunderstood. On the other hand, Scott felt that Marie misunderstood him and Marie indicated that she did, so Scott realized that Marie misunderstood. As a result, in this dyad, there is perceptual mismatching at two of the three levels examined. An inaccuracy of perceptions of partners in a relationship on any of the three levels indicated results in communication inefficiency. Dyadic interexperience is most fully promoted if the perceptions of individuals are clearly understood and realized in terms of their accuracy or inaccuracy. Potentialities of this method of dyadic perceptual assessment will be discussed in the succeeding analysis of the IPM. 


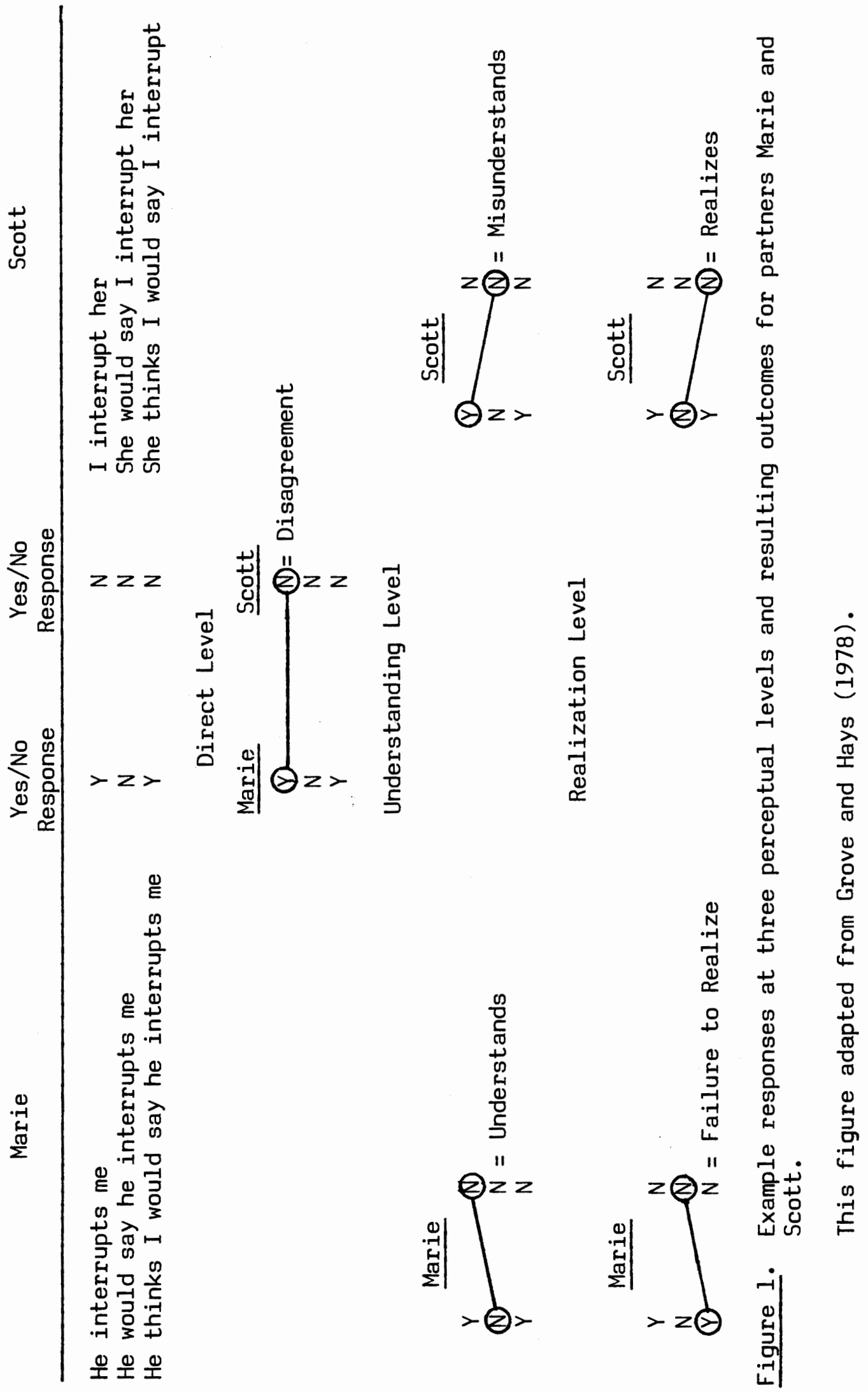




\section{Critique of the Interpersonal Perception Method}

While the IPM represents an important early attempt to assess correspondence of relational perceptions in interpersonal relationships, research and refinement of the instrument have been limited. In an attempt to find validity and reliability data on the IPM, Grove (1977) examined materials generated by a computer search of approximately 40 information-retrieval libraries. The search uncovered no validity or reliability studies, however, a single effort toward developing a computerized data processing of the IPM results was found. After review of this project, Grove and Hays (1978) wrote, "although laudable, this rudimentary version does not retain the comprehensiveness and detail of the original IPM required for complete analysis of matched perceptions" (p. 747).

The complexity of the measure, along with a number of other problems are among the reasons noted by writers that little research has been applied to the instrument in more than a decade (Grove and Hays, 1978; Swensen, 1973). Specifically, problems include: (1) issue selection, (2) utilization of an intrapersonal aspect in statement formats, (3) statements worded for male respondents only, (4) difficulties in scoring the scale, (5) the limited number of subjects used in the original administration of the instrument, and (6) inadequate documentation of validity and reliability. These problems will now be expanded upon.

1. Issue Selection. The IPM contains 60 issues requiring response from each partner. Laing et al., (1966) note that issues were selected from a larger group of some 2,000 words and phrases that were derived from a small standard dictionary. Several stages of issue reduction 
were briefly cited by the authors, but specifications and criteria for selecting issues were not indicated. The authors state that " . . after experience with 300 and then 160 remaining issues, 84 were chosen, excluding those that were most difficult for subjects to understand" ( $p$. 64). Exactly how discriminations were made on issues is not described and would be useful.

Over 275 dyads have filled out the IPM through Advanced Interpersonal Communication courses taught by Dr. Theodore Grove at Portland State University. Criticism by a number of students in these courses indicate problems in issues that were selected for the instrument. It was thought that many issues were ambiguous and archaic and that the content of many issues was redundant, implying the same quality or problem. Additionally, a graduate study group at Portland State analyzed the IPM and determined that included in the 60 issues were 33 issues with negative connotations, 14 with positive and the other 13 were questionable as to whether they were positive or negative. Students objected to the abundance of negative issues and thought there should be more of a balance maintained between positive and negative issues.

The final problematic area in the selection of issues for the IPM has to do with the item operating characteristic. The IPM is a summative scale scored by adding the response scores on its component items. This type of scale implies that each item is a linear, or monotonic, function of the same attribute such that item scores are positively correlated with scale scores (Scott, 1968). This instrument requires forced choice between pairs; subjects are presented with statements to which they must respond positively if they agree or negatively if they disagree. Presumably, issues represent a particular attribute that is of focal interest, 
or an assumed "opposite" to the focal one. Investigation of issues comprising the IPM reveals that some issues are nonmonotonic (nonsummative), that is, item scores do not correlate with each other or with the common attribute. Examples of nonmonotonic issues are, "worries about," "depends on," "analyzes," "is wrapped up in," and "puts on a pedestal." These issues confound the results because a positive or negative response to the item does not preclude acceptance of the opposite attribute.

2. Utilization of an intrapersonal aspect in statement formats. Statements in the IPM require 12 "yes" or "no" responses for each issue. A serious problem in the statement format has to do with inclusion of both interpersonal and intrapersonal aspects of an issue. An examination of the format utilized reveals that often the intrapersonal aspect of an issue is nonsensical. Examples of problematic issues in the IPM in which this aspect is somewhat absurd are listed below as they appear in the instrument:

A. How true do you think the following are?

(1) She spoils me

(2) I spoil her

$\rightarrow$ (3) She spoils herself

$\rightarrow$ (4) I spoil myself

B. How true do you think the following are?

(1) She would like to get away from me

(2) I would like to get away from her

$\rightarrow$ (3) She would like to get away from herself

$\rightarrow(4)$ I would like to get away from myself

C. How true do you think the following are?

(1) She gets on my nerves

(2) I get on her nerves

(3) She gets on her own nerves

(4) I get on my own nerves

While these issues might provide some information about how one feels about oneself, much of the intrapersonal content is confusing and 
contributes noise to the instrument data.

3. Statements worded for male respondents only. Another major difficulty with the IPM relates to the pronoun usage in the statements. Alperson (1975) suggests "it is nearly impossible to avoid getting tangled up in the semantics" (p. 632). Due to the nature of the instrument, it is exacting for anyone to respond to. However, it is particularly laborious for female respondents as statements are all written using pronouns exemplifying a man's perspective and a woman has to transform the statements and pronouns prior to responding.

4. Difficulties in scoring the scale. The methodology of the IPM is significant, yet implementation and analysis of results is difficult due to the scoring procedures. In his article, "Boolean Analysis of the IPM," Alperson (1975) presents the logical integrity of the instrument and discusses the success of this dimension, but also notes that the main obstacle to utilization of the IPM is that the "scoring procedures are tedious and difficult" ( $p .627)$. Kotkas (1969) as well notes that hand coding, scoring and compiling results for a single dyad entails a difficult and time consuming process ( $p .12$ ).

5. Limited number of subjects used in the original administration of the instrument. Swensen (1973) believes that the IPM is a unique contribution to the field of communication but feels that a shortcoming of the initial research done on the measure was the result of the limited size of the data base. The authors (Laing et al., 1966) used the "known groups" method of validation of the IPM; the instrument was administered to two groups of subjects, one consisting of 12 couples seeking "help" and identified as "disturbed marriages" and 10 couples selected in collaboration with their general practitioners who were "supposedly" satisfied 
with their marriage and labelled as "nondisturbed marriages." In reference to the methodology used in subject selection, Scott (1968) writes:

- . it is misleading, however, to infer the extent of validity from the significance level of the resulting $t$ ratio or from the magnitude of the point-biserial correlation coefficients (when utilizing 'known groups'). These indicies are substantially affected by the sizes of groups and by the way in which samples are selected. Very large mean differences can be obtained for instruments that have little predictive value, simply by an opportunistic selection of the 'known groups' and by equating their sizes ( $p .253$ ).

Scott (1968) advocates use of a representative sample of the population to which the instrument will be applied that relates proportionately to the actual size of the population. In that Laing et al. (1966) only used 22 couples in the reported administration of the measurement, the sample many not reflect accurately the instrument's diagnostic validity in the intended population.

6. Inadequate documentation of validity and reliability. Overall findings resulting from implementation of the IPM are summarized by Laing et al. (1966) in several tables reflecting mean scores from each of the two groups. Comparisons between groups are subsequently made on the basis of mean scores calculated from the overall number of agreements, disagreements, understandings, misunderstandings, realizations, failure to realize and so on. As was previously stated by Scott (1968) exclusive utilization of this method of comparison between mean scores for the assessment of validity is inadequate and can be misleading.

Reliability was assessed on the IPM through test-retest score examination and internal consistency analysis of data. Percentages of agreement between the test and retest responses were again displayed in terms of the overall matching scores on the "direct, meta, and meta-meta" perspectives for the two groups. Neither individualized item-total 
correlation coefficients nor test-retest item reliabilities were indicated and make it difficult to determine how individual items reacted in the analysis. Documentation on the degree of internal consistency within the measure was identified only on selected pairs of items which were determined by the authors to be synonymous and antonymous.

In general, the reporting of validity and reliability on the IPM is inadequate and leaves many questions unanswered.

\section{Conclusion}

Efforts in marital communication assessment have been focused primarily on aspects of verbal communication behavior. Though this is an essential part of an interpersonal relationship, transactional communication implies mutual and reciprocal participation in the process of communication and perceptual interplay. Analysis of the perceptions of individuals related to specific issues in a relationship provides an in-depth view of the workings of a dyad. Among the marital assessment techniques reviewed, none, with the exception of the IPM, investigates perceptual awareness and the resulting implications for dyadic communication assessment.

The instrument in the present study is based on Dymond's (1949) model for investigating the empathy of individuals in relationships and the Laing et al. (1966) instrument previously described. A critique of the IPM has shown several weaknesses in methodology and instrumentation; design of the technique under development will take the foregoing criticims into account. 


\section{CHAPTER IV}

\section{METHODS, INSTRUMENT DEVELOPMENT AND PILOT STUDY}

\section{Methods}

The goal of this research was to produce a measure capable of deriving information on the levels of awareness spouses exhibit regarding perceptions of themselves, their partners and the status of their interpersonal relationship. Data on relational perceptions pertinent to a marital dyad were obtained from spouses and the correspondence in perceptions was calculated to determine the degree of perceptual matching.

The methods and procedures utilized in this study will be elaborated on in the following chapters. In summary, procedures included: instrument development, a pilot study, data analysis and instrument refinement and administration and subsequent analysis of the final measure.

Several stages of instrument development produced an initial scale of 40 items which was implemented in a pilot study and included a testretest method of establishing reliability. Individual scale items and total scores were analyzed and those 25 items exhibiting high reliability were retained for the final instrument. The final study provided data for an assessment of discriminant validity which was attained through comparision of the instrument with two other marital assessment measures.

A total of 75 married couples participated in this investigation in the pilot and final studies. Subjects ranged in age, length of time in present marriage and occupation, and indicated varying degrees of 
satisfaction with their present marriage.

Scoring of the instrument was done using the Fortran IV program IPALION, an subprograms "Reliability" and "Pearson Corr" from the Statistical Package for the Social Sciences (SPSS) were used in reliability and validity analyses. A Honeywell 6640 computing system at Portland State University was used in processing all data.

\section{Instrument Development}

Development of the Perceptual Diagnostic Inventory (PDI) for use in marital assessment occurred in several stages including: ( 1 ) three phases of issue reduction, (2) construction of statement formats, (3) addition of issue definitions, (4) assembling of the pilot instrument, and (5) formation of male and female questionnaires. Each of these stages will now be reviewed.

1. Three Phases of Issue Reduction

A compilation of possible issues from the following five sources produced a pool of 307 potential issues: (1) 20 from literature on marital relationships or items utilized in other marital assessment instruments, (2) 53 from a survey of over 30 communication textbooks or chapters in texts discussing marital or interpersonal communication, (3) 60 from the original IPM, (4) 66 from the Webster's New World Thesaurus (1974), and (5) 108 from suggestions for issue candidates by 24 professors that met at the Breckenridge Conference in Interpersonal Communication held in Colorado in August, 1981. Refer to Appendix $B$ for a register of issues and reduction phases. 
a) Phase 1

Duplications of issues and vague or difficult predicates as in "psychological processes," "conceptual tempo" or "respect of non-shared image" were eliminated. Other issues felt to be overly negative as in "hates," "is hostile with" or "is mean with," and those technical terms like "filtering processes," "proxemic behavior" or "ritualized responses" were also disqualified leaving 163 for further analysis.

b) Phase 2

More specific criteria for identifying the issues least suitable for retention in the instrument were rejected if they:

(1) did not refer to relational attitudes or a behavioral disposition toward other

(2) failed to elicit a common valent interpretation from respondents

(3) were nonmonotonic in nature: acceptance of the item did not preclude acceptance of its opposite

Issues not meeting the above criteria were disgarded resulting in 97 remaining issues. Examples of self-reflexive or "trait" issues were: "body clock," "hygiene," "orderliness" and "reticence"; these failed to meet the first criterion and were omitted. Some instances of nonmonotonic issues which were eliminated were: "influences," "is dependent on" and "competes with."

c) Phase 3

All 97 issues were defined in writing using the Random House Dictionary (1980). The list was then reduced by differentiating a set of issues which, by definition, most satisfactorily represented a variety of aspects in a marital relationship without 
tapping identical or similar content. Instances of disgarded issues on the basis of similar meaning for the selected issue "is arrogant toward" were: "antagonizes," "belittles," "insults," "torments," "is condescending toward" and "intimidates." For the selected issue "encourages" eliminated issues were: "motivates," "inspires" and "gives freedom to grow." Forty issues survived the phase three criterion and compiled the pilot test.

2. Construction of Statement Formats

An earlier discussion (Chapter III) presented non sequiturs in the intrapersonal aspect of a number of the IPM issues. Therefore, radical structural change was created in the format of the present instrument in which the intrapersonal aspect, comprising 50 percent of the original IPM, was eliminated and a salience aspect was substituted for all issues. By way of illustration, "she humiliates herself" was supplanted with "she is disturbed by my humiliating her." "She highly values my consulting her" replaced "she consults with herself." A woman respondent would find the following language on the positive items on her questionnaire:

I feel that...

A. he listens to me

B. I listen to him

$\rightarrow C$. he highly values my listening behavior

$\rightarrow$ D. I highly value his listening behavior

She would find the following language on a negative issue:

I feel that...

A. he is irritable with me

B. I am irritable with him

C. he is disturbed by my irritability

$\rightarrow$ D. I am disturbed by his irritability

It was felt that this statement format would give an added dimension 
to the inventory and allow subjects to register feelings of importance or unimportance for every issue. In addition, in this perception matching model, item scores and total scores for a given dyad would reflect not only the level of accuracy which partners achieved in responding to the primary issue, but would also reflect how accurately one judged the salience of that issue for the partner. Hence, $X$ may be irritable with $Y$, and $Y$ may recognize that and yet not be disturbed by $X$ 's irritability, and $X$ may realize this.

3. Addition of Issue Definitions

Denotative definitions of issues derived from the Random House Dictionary (1980) were incorporated into the instrument to provide partners with a similar perspective from which to approach the issue.

4. Assembling of the Pilot Instrument

The inventory was assembled using the 40 issues selected for the pilot instrument which were organized using a random number table (Freund, 1973). The method used in this instrument for gathering data was the forced choice between pairs: participants accepted or rejected each statement individually by responding "yes" or "no." Each of the 40 issues used in the pilot test was comprised of 12 statements. The following example of the issue "communicates openly" appears in the inventory for a male respondent: Communicate openly: frank and direct expression of thoughts and
feelings

I feel that...
A. she communicates openly with me
B. I communicate openly with her
C. she highly values my open communication
D. I highly value her open communication 
She feels that...

E. she communicates openly with me

F. I communicate openly with her

G. she highly values my open communication

H. I highly value her open communication

She thinks that I feel that...

I. she communicates openly with me

J. I communicate openly with her

$K$. she highly values my open communication

L. I highly value her open communication

As is illustrated, participants respond to three levels or perspectives which include: the direct, the understanding, and the realization levels. At the direct level, each partner affirms or denies each of the four aspects of an issue: she communicates openly with me, and so on. At the understanding level, each predicts how the other will respond to the same set of questions. At the realization level, each registers the predictions he/she thinks their partner will make regarding his/her own predictions. The completed pilot instrument appears in Appendix $C$.

5. Formation of Male and Female Questionnaires

To account for the difficulty in pronoun usage that appeared in the IPM, Grove and Hays (1978) developed male and female versions of the measure. Questionnaire forms were thus developed for male and female participants using that pattern of pronoun usage.

\section{Pilot Study}

The purpose of this investigation was to develop an assessment tool to measure the correspondence between the perceptions of partners in a marital dyad. A pilot test was administered to generate data for item analysis and a reliability study. 
Subjects

A total of 15 couples were chosen by the author to participate in a reliability study. The two criteria for selection of subjects were that they had to be heterosexual dyads and they had to be married at least one year. Participation in the pilot study was strictly voluntary. Confidentiality was maintained by providing a code number for each inventory; subjects desiring feedback identified themselves by name and address to the author and this information was destroyed once feedback was sent. Inventories were distributed by the investigator to subjects in the Portland and Eugene metropolitan areas that had previously been contacted and had indicated a willingness to participate in the study.

Married couples ranged in the number of years they were married from 1-20 with the majority (68 percent) being married 4-7 years. The largest proportion of individuals ( 53 percent) were somewhere between the ages of 20 to 29 years and 43 percent were between the ages of 30 to 39 years. The sample consisted of subjects from a variety of occupations which included: three attorneys, four accountants, two bicycle mechanics, two college instructors, four graduate students and two homemakers. All participants had some college; the majority held a bachelor's degree, and several also held master's or professional degrees.

Procedures

Subjects were initially contacted in person or by phone requesting their participation in the pilot study. Once willingness on the part of both spouses to take a test and retest was indicated, scheduled appointments were set up with the author. At the appointment, each couple was given verbal instructions on how to complete the inventory and was provided: 
1. A letter instructing participants how to fill out the inventory, requesting subjects not to collaborate and giving instructions on the two week interval for the test-retest (Appendix D)

2. Personal data inventories (Roach and Boyd, 1975) for descriptive information about the sample (Appendix E - see p. 48 for discussion of this inventory)

3. Male and female versions of the PDI

4. Four sets of computer response sheets for test-retest

5. A pre-addressed and stamped return envelope

The study was set up such that participants completed the initial test which the investigator picked up, and exactly two weeks later completed the retest which was mailed to the investigator. A feedback letter and set of instructions was prepared at this time to provide participants a means to analyze their perceptual matching data (Appendix F). Feedback on the initial test was sent to couples upon request within a few weeks.

Data Analysis and Issue Selection

The scoring procedure for the original IPM seemed to be the main obstacle to utilizing the instrument until 1978 when Grove and Hays developed the fortran IV program, IPALION, for scoring the correspondence between partner's reported perceptions. The program, now in existence, not only provides the information contained in the original IPM analysis, but also furnishes investigators with summary scores, a record of the outcome of every set of compared perceptions and a variety of nonconditional and conditional indicies (Grove and Hays, 1978). This program was used in scoring the instrument and providing dyads with feedback on their perceptual matching.

Total perception matching scores of this pilot sample were computed. 
When participant's responses were compared, each accurate prediction a subject made about their partner contributed one point to the overall score. On a given item, possible scores range from 0 to 20 ; with 40 items a perfect scale score is 800 .

Both test and retest were computer analyzed by subprograms "Reliability" and "Pearson Corr" in SPSS and processed on the Honeywell 6640 computing system. The mean score for the test was 682.73 and the standard deviation was 77.03; the mean score for the retest was slightly lower at 668.13 and the standard deviation was 88.88 . The resulting score distribution was negatively skewed with the majority of scores being over 650 . The test and retest produced Cronbach's alpha of +.8686 and +.9004 respectively. Test-retest reliability analysis produced a Pearson product-moment correlation coefficient of +.7415 .

Item analysis proceeded through inspection of (1) corrected itemtotal correlation coefficients from the first test and the retest, (2) test-retest item reliabilities, and (3) inter-item correlation matrix from the first test. The coefficients produced are indicated in Table II.

of the item-total correlations from the test and retest, six items displayed negative values. Negative test-retest reliability coefficients were obtained from three of these six items and two other items produced negative reliabilities as well. These eight items were eliminated. An additional analysis was deemed necessary in order to achieve maximal repeatability in the remaining scale items and simultaneously reduce markedly the large number of negative inter-item correlations in the correlation matrix. Subsequent inspection of item reliabilities found that a criterion of +.40 item reliability achieved both of these goals, 
TABLE II

ITEM ANALYSIS OF THE PERCEPTUAL DIAGNOSTIC INVENTORY PILOT STUDY

Item No.
Corrected item-total

$$
\text { Test }
$$

Correlations:

Retest
Test-Retest

Reliability

\begin{tabular}{|c|c|c|c|}
\hline 1 & .2683 & .2245 & .7080 \\
\hline 2 & .6319 & .2820 & .8163 \\
\hline 3 & .1370 & -.1671 & -.1494 \\
\hline 4 & .2843 & .1688 & .5951 \\
\hline 5 & .3311 & .3527 & .4661 \\
\hline 6 & -.0954 & .2980 & .4950 \\
\hline 7 & .4539 & .7439 & .6201 \\
\hline 8 & -.0599 & .1273 & -.1504 \\
\hline 9 & .6752 & .6542 & .5709 \\
\hline 10 & .5236 & .0025 & .1485 \\
\hline 11 & .3200 & .8083 & .3036 \\
\hline 12 & .3198 & . 3990 & -.0766 \\
\hline 13 & .7388 & .8444 & .9722 \\
\hline 14 & .7939 & .6827 & .5212 \\
\hline 15 & -.3140 & -.0182 & .2253 \\
\hline 16 & .5398 & .0686 & .3445 \\
\hline 17 & .3645 & .4415 & .9922 \\
\hline 18 & .2889 & .1046 & .4231 \\
\hline 19 & .0359 & .4604 & .5564 \\
\hline 20 & .7440 & .6287 & .9014 \\
\hline 21 & .1063 & .4692 & .6087 \\
\hline 22 & .0280 & .4514 & .4597 \\
\hline 23 & .5943 & .7693 & .9672 \\
\hline 24 & .2583 & .5193 & .8287 \\
\hline 25 & .5949 & .7498 & .8093 \\
\hline 26 & .3902 & .5830 & .9960 \\
\hline 27 & .3687 & .5305 & .3679 \\
\hline
\end{tabular}


TABLE II-Continued

Item No.

28

29

30

31

32

33

34

35

36

37

38

39

40
8

9

30

1

2

3

4

35

38

39
Corrected item-total Correlations: Test
Test-Retest

Reliability
.5381

.3403

.5135

.1580

.7257

.1675

.2694

.4608

.3900

.4112

.6072

.4078

$-.0738$
.2685

.5126

.6183

.3803

.6664

.3504

.2263

.4459

$-.0917$

.7139

.3632

.5530

.0438
.7264

.9794

.5016

$-.0643$

.3404

.0312

.7103

.3751

$-.1359$

.6712

.5934

.8534

.0541 
eliminating seven additional items. The 15 items rejected in this analysis accounted for 250 of the original 285 ( 87.7 percent) negative interitem correlations on the 40 item correlation matrix. The surviving 25 items registered reliability coefficients ranging from +.4231 to +.9960 with an average reliability of +.7139 . These 25 items comprise the final PDI.

Discussion and Instrument Refinement

When item-total correlations were compared with the actual items the coefficients were found interesting. Many of the issues showing high or almost perfect degrees of perception matching within dyads showed very low or negative correlations. This phenomenon is explained by the fact that such high perception matching within and between dyads invalidated issues because they did not contribute a degree of variance to the inventory and thus constituted noise. By way of example, nearly all dyads were found to have perfect matching on the issue "is equal to" and this issue received an item-total correlation of +.0541 . This issue was disgarded as it lacked significance when compared to the other issues in the inventory that displayed a higher degree of variation in participant response.

Conjecture on the occurrence of the negative or low coefficients related to these items may be the result of the relatively limited time the majority of participants had been married. Marriages extending over a greater number of years may have produced more problems or difficulties and more perceptual mis-matches, or disjunctions, would have appeared. The final study will therefore include a greater range in the number of years subjects have been married. 
Several participants noted that the issues were difficult to answer in that the issue may be a problem at given times in the relationship, but that this was not usually the case. It was thus decided that issue statements would include the words "generally" for positive issues and "frequently" for negative issues as in "he generally encourages me" or "she is frequently arrogant with me" to alleviate this problem.

Some subjects also noted that the words "highly values" were somewhat ambiguous and rather lofty. While these participants felt that they appreciated certain qualities or characteristics in their marital relationship or in their spouse, they found "highly values" too strong a statement. Consequently, "highly values" was replaced by "is satisfied with" in positive items. A positive item thus reads, "I am satisfied with his encouragement." Negative item statements were left as they appeared in the pilot test.

Since both of these modifications were minor in comparison to the effectiveness of the inventory in diagnosing correspondence between partner's perceptions, the pilot study results were deemed satisfactory by the author's chief advisor and were accepted as adequate reliability data. After reduction of the items to 25 , and modification of the statement formats, the refined instrument still retains a high degree of scale characteristics and this briefer version offers greater practicability as an assessment tool. The final inventory appears in Appendix G. 
CHAPTER $V$

FINAL STUDY

\section{Discussion of Validity}

The purpose of this study is to develop an instrument for assessing the degree of correspondence in relational perceptions between partners in a marital dyad. The construct of perceptual interplay, here tested, is defined as the interchange in behavior and experience of partners in a dyad and the resulting perceptual accretions. Through this investigation, the interperceptions of partners are examined across different cognitive and affective realms in order to isolate areas of accuracy or inaccuracy in their perceptual relationship.

An essential component in developing any instrument is an assessment of validity (Anastasi, 1968). Validity is represented in the agreement between two attempts to measure the same construct through maximally different methods and is concerned with how well the test measures what it purports to (Anastasi, 1968; Campbell and Fiske, 1959). Three generally accepted forms of validity are: content validity, criterion-related validity and construct validity (Holsti, 1968). Content validity, sometimes called "face validity" is concerned with the adequacy of the measure in sampling the entire content of a construct. It involves essentially the systematic examination of the test content to determine whether it covers a representative sample from the universe of situations occurring within the construct (Anastasi, 1968). While such a validation 
procedure is commonly used in evaluating achievement tests, it was not considered appropriate for analysis in the present study. Criterionrelated validity indicates the effectiveness of a test in predicting an individual's behavior, attitudes, or characteristics in specified situations (predictive validity) or diagnosing or assessing an existing status (concurrent validity) (Holsti, 1968; Spanier, 1976). Again, establishing this type of validity was determined as irrelevant given the confines and methodology of this investigation.

Construct validity pertains to not only validating a measure but the theory underlying the measure (Holsti, 1968), and was determined as the most suitable type of validity for investigation in this project. Construct validity may be established by several methods; the most frequently used is interrelating the measure within a "nomological network" of external variables from many different sources (Anastasi, 1968). In other words, through implementation of other measures one can see whether the test behaves as it is expected to behave if it measures the construct. The two aspects of construct validity originally defined by Campbell and Fiske (1959) are convergent and discriminant validity. According to these scholars (1959), convergent validity, the confirmation by independent measurement procedures, is arrived at through comparisions of scores obtained from two seperate measures of the same construct. In order for convergent validity to be verified, a test must be shown to correlate highly with other variables with which it should theoretically correlate. In the case of this study, no independent measure, in so far as the writer has been able to determine (Chapter III), provides an external measure of the present construct making a direct assessment of convergent validity problematic. The IPM could potentially serve as such 
an independent measure but given the shortcomings of this instrument previously discussed the correlational results might be confounded, further, with the structural changes in the PDI, the instraments no longer measure precisely the same construct.

Lacking an external measure of the construct of perceptual interplay, the investigator turned to instruments purporting to measure constructs different in form, but theoretically related to the PDI. Discriminant validity will consequently be assessed as it concerns the degree to which any single test measures the intended attribute in a different way. Scott (1968) suggests that an instrument may be validated against multiple criteria provided the investigator has sufficient confidence in the other measures and in the theory which defines their relevance.

The related constructs marital satisfaction and marital problems are characteristics of a relationship which suggest a moderate association with perceptual interplay. In that each of these constructs is fundamentally interrelated with the more broad-based construct of communication behavior, the latter can be seen as encompassing these variables and providing a relationship among them. Essentially, if communication between spouses is optimum, perceptual correspondence should be high, marital satisfaction should be high and marital problems should be minimal. Marital satisfaction and marital problems were selected as attributes theoretically related to perceptual interplay; these constructs provide potential diagnostic value in deliniating the quality of communication in a relationship as well as indicating the overall "workingness" of a marriage in a global sense. 


\section{Hypotheses}

The following two hypotheses will be tested in the final study:

Hypothesis 1: The Perceptual Diagnostic Inventory and the Marital Satisfaction Inventory will produce moderately strong positive, but not extremely high positive correlation coefficients.

Hypothesis 2: The Perceptual Diagnostic Inventory and the Marriage Problem Checklist will produce moderately strong negative, but not extremely high negative correlation coefficients.

Given the different but related constructs in each of the measures, high correlations among the variables should not be found as the instruments are intended to differ and high correlations would indicate redundancy in measurement content. To the extent that the PDI is found to be moderately correlated with these variables, there is an indication of construct validity for the measure. If one or both of these related constructs are found to be extremely highly correlated with the PDI, there would be reason to suspect the validity of the instrument.

\section{Description of Instruments}

The instruments utilized in this study, other than the Perceptual Diagnostic Inventory, will be described in the following and include: the Personal Data Inventory (Roach and Boyd, 1977; Appendix E), the Marital Satisfaction Inventory (Roach, 1977; Appendix F), and the Marriage Problem Checklist (Roach, 1977; Appendix G).

Personal Data Inventory. The Personal Data Inventory (Roach and Boyd, 1977) is an instrument designed to gather descriptive data about the sample. Biographical data was collected by means of a slight 
variation in the inventory form as it was tailored to the needs of this study. Information collected on the inventory included such variables as age, income, occupation, and length of marriage. The purpose of this inventory was to provide a description of the study sample.

Marital Satisfaction Inventory. The MSI (Roach, 1977; Appendix F) is an attitude scale consisting of 73 items constructed with a Likerttype format and designed to measure marital satisfaction. Several studies have been done using the MSI (Bowden, 1977; Frazier, 1976; Roach, 1981; Thompson, 1978). In his article discussing the instrument, Roach (1981) notes that the initial administration of the inventory was in a pilot study using 88 subjects. He reports Cronbach's alpha as +.982 as a measure of internal consistency. A factor analysis on the inventory indicated that the items constituted a single-factor scale. "Results of this initial study indicated that, in general, items correlated well with the total scale, that there was a high level of internal consistency and that the scale involved a single factor" (Roach, 1981; p. 541). Frazier's (1976) study of the MSI involving 309 individuals also yielded a high measure of internal consistency. Cronbach's alpha was reported as +.97 and test-retest reliability was +.76 . The validity coefficient based on the correlation of scores on the MSI with scores on the Locke-Wallace Marital Adjustment Test was +. 79 .

Bowden's (1977) study was designed to measure concurrent validity using criterion groups of 15 satisfied and 15 dissatisfied couples who were identified by peer ratings and by professional marriage counselors. A t-test was employed on mean scores for both groups; the difference between the means was significant $(t=112.204, d f=58, p<.0001)$. A correlation of MSI scores and scores on the Marriage Problem Checklist 
was calculated as a measure of discriminant validity. The correlation coefficient of both tests was -.73 indicating that more satisfied couples reported fewer problems and dissatisfied couples reported more problems.

The Thompson (1978) study was implemented to diagnose change in marital satisfaction as a result of intervention such as marital therapy or a marriage communication workshop. MSI scores showed a significant change between the pretests and posttests which were administered three weeks apart to nine couples before and after a weekend sex therapy workshop. When a post-posttest was conducted eight weeks later, there was no significant difference between MSI scores on the two posttests. The results indicated that the MSI can reflect the types of attitudinal change likely to occur in a relatively brief marital intervention while not reflecting a significant change during a period of nonintervention.

Marriage Problem Checklist. This instrument was developed by Roach (1977; Appendix G), as the result of his experience in marital therapy and marital enhancement workshops (1981). The instrument is designed to identify various relationship difficulties experienced by couples in their marriage. At present, this instrument possesses content validity but reliability has not yet been determined (Bowden, 1977).

\section{Subjects}

A total of 50 couples participated in the final study from the Portland and Eugene metropolitan areas of Oregon, and from Walnut Creek, California. Criteria for subject selection were that couples had to be married at least one year and they had to be heterosexual dyads. Participation in the study was strictly voluntary.

As a result of the information given by subjects on the Personal 
Data Inventory, descriptive characteristics of the sample are reported in Table III. Results are summarized in terms of the frequency of response for males and females and calculated totals from both groups are indicated. The majority of subjects ( 76 percent) ranged in age from 20-39 years; the other 24 percent were over 40 years. An extremely large number of the sample population (9l percent) held either a bachelor's, master's, doctoral or professional degree.

Occupational divisions suggested by Warner, Meeker and Eells (1970) were used to categorize individuals by occupation. Divisions receiving the highest frequency of response (69 percent) were divisions 1-4. A suggestion of the type of occupation each of these divisions encompass is given below:

Division 1 - architects, CPA's, doctors, dentists, lawyers, ministers (with adv. degrees), regional and divisional managers, professors, owners of companies

Division 2 - accountants, instructors, librarians with training, nurses, high-school teachers, assistant managers and office managers of large businesses, salespersons of real estate and insurance

Division 3 - administrative assistants, bank clerks, clerical specialists, secretaries to executives, social workers, researchers, grade school teachers, minor officials of businesses

Division 4 - secretaries, bookkeepers, carpenters, office clerks, plumbers, mail carriers, electricians

Most participants were involved in their first marriage and two persons indicated this was their third marriage. The mean number of years in the present marriage was 9.9 years and the mean number of children was 1.6. Both men and women tended to think others would rate their marriage highly and rated their own marital satisfaction quite high. An interesting item is that 12 women indicated their spouse was more in charge and no men similarly checked this statement. Seventy-four percent of the sample felt they were equally in charge. 
TABLE III

DESCRIPTIVE CHARACTERISTICS OF SUBJECTS

Variable

Male

Female

Total

$\mathrm{N}=50$

$N=50$

$\mathrm{N}=100$

1. Age

20-29

16

19

35

30-39

20

21

41

40-49

8

50 and over

6

6

14

10

2. Highest Educational Level

Did not finish high school

High school graduate

1

1

1

3

Some college

11

26

Bachelor's degree

21

15

Master's degree

12

Doctoral or professional degree

4

21

42

23

5

3. Family Income

under $\$ 5,000 / \mathrm{yr}$

$\$ 5,000-\$ 15,000 /$ yr

over $\$ 15,000$ up to $\$ 25,000 / y r$

1

1

$\begin{array}{lll}6 & 7 & 13\end{array}$

$\$ 25,000-\$ 35,000 /$ yr

15

17

32

over $\$ 35,000 / y r$

17

16

33

11

10

21

4. Employed

yes

45

38

83

no

5

12

17

5. Occupation (Warner et al., 1970)

Division 1
Division 2
Division 3
Division 4

$\begin{array}{rrr}8 & 2 & 10 \\ 22 & 11 & 33 \\ 2 & 14 & 16 \\ 2 & 8 & 10\end{array}$


TABLE III - Continued

\begin{tabular}{|c|c|c|c|c|}
\hline & Variable & $\begin{array}{l}\text { Male } \\
\mathrm{N}=50\end{array}$ & $\begin{array}{l}\text { Female } \\
N=50\end{array}$ & $\begin{array}{l}\text { Total } \\
N=100\end{array}$ \\
\hline & Division 5 & 3 & 0 & 3 \\
\hline & Division 6 & 2 & 2 & 4 \\
\hline & Division 7 & 4 & 0 & 4 \\
\hline & Homemaker & 0 & 4 & 4 \\
\hline & Student & 1 & 4 & 5 \\
\hline & Unemployed/No Response & 6 & 5 & 11 \\
\hline 6. & Present Marital Status & & & \\
\hline & First marriage & 41 & 39 & 80 \\
\hline & Second marriage & 8 & 10 & 18 \\
\hline & Third marriage & 1 & 1 & 2 \\
\hline 7. & $\begin{array}{l}\text { Mean Age at Time of Present } \\
\text { Marriage }\end{array}$ & 26.5 & 24.7 & 25.6 \\
\hline 8. & $\begin{array}{l}\text { Mean Number of Years in } \\
\text { Present Marriage }\end{array}$ & 9.9 & 9.9 & 9.9 \\
\hline 9. & Mean Number of Children & 1.6 & 1.6 & 1.6 \\
\hline 10. & Parents Separated/Divorced & & & \\
\hline & Yes & 13 & 9 & 22 \\
\hline & No & 37 & 41 & 78 \\
\hline 11. & Friends Would Rate Marriage & & & \\
\hline & Poor & 1 & 1 & 2 \\
\hline & Fair & 0 & 1 & 1 \\
\hline & Average & 2 & 2 & 4 \\
\hline & Good & 13 & 11 & 24 \\
\hline & Very Good & 21 & 21 & 42 \\
\hline & Excellent & 13 & 14 & 27 \\
\hline
\end{tabular}


TABLE III-Continued

\section{Variable}

Male

$\mathrm{N}=50$
Female

$N=50$

Total

$\mathrm{N}=100$

12. Relationship with Spouse

I am more in charge

9

5

14

My spouse is more in charge

0

12

12

We are about equally in charge

41

33

74

13. Satisfaction with Present Marriage

Extremely satisfied

Very satisfied

Satisfied

Somewhat dissatisfied

Very dissatisfied
17

15

15

2

1
18

20

8

3

1
35

35

23

5

2 


\section{Procedures}

After revision of the PDI and preparation of the MSI and MPC, a general letter was developed informing participants of their role in this research project and instructing subjects on filling out the instruments (Appendix J). Packets were made up of a designated set of male and female inventories, each included: (1) a Personal Data Inventory, (2) a Marital Satisfaction Inventory, (3) a Marriage Problem Checklist, (4) a Perceptual Diagnostic Inventory, (5) two opt scan computer sheets for recording responses to the PDI, and (6) an index card for request of feedback. Packets were placed in a pre-addressed and stamped return envelope so couples could mail the tests back to the investigator.

Four persons known to the author were requested to aid in the distribution of packets. In a session with the author, each individual was advised as to the purpose of the study and how the inventories were to be completed. The author and these assistants contacted couples they knew by phone or in person and asked about their willingness to participate in the investigation. Upon verification of both partners' willingness to fill out the inventories, the author or an assistant met with the couple and explained the project and noted that spouses were to respond to the questionnaires without consulting one another and that it would take approximately one hour to complete.

Couples were told that confidentiality would be maintained by providing code numbers for the inventories in each packet, making names unnecessary; all responses remained anonymous unless subjects requested feedback and identified themselves by name and address to the author. If feedback was requested, individual responses to items were still anonymous until total scores were converted from code number to subject name. 
CHAPTER VI

RESULTS AND DISCUSSION

\section{Results}

The succeeding discussion of the results of the final study involve reporting of: (1) the reliability of the revised PDI, (2) mean scores on the inventories, and ( 3 ) the correlation coefficients generated between the inventories. Data derived from the PDI, MSI and MPC were computer analyzed by subprograms "Reliability" and "Pearson Corr" in SPSS and processed on the Honeywell 6640 computing system at Portland State University.

1. Reliability of the PDI. The reliability of the PDI improved as a result of the pilot study efforts in instrument refinement. The inventory produced Cronbach's alpha of +.9222 as a measure of internal consistency. Analysis of the corrected item-total correlation coefficients showed only two of the 25 items exhibiting a value of less than +.40 ; coefficients ranged from +.3547 to +.7042 with an average reliability of +.5435 . The corrected item-total correlations produced by the PDI in the final study are listed in Table IV.

Inspection of the inter-item correlation matrix showed that only three negative correlations ( 1 percent) were computed out of a possible 300. Again, this figure is substantially reduced from the original 285 out of 780 ( 36.54 percent) negative inter-item correlations that appeared in the pilot study matrix. 
TABLE IV

ITEM ANALYSIS OF THE PERCEPTUAL DIAGNOSTIC INVENTORY

FINAL STUDY

Item No.
Corrected item-total

Correlations
1

2

3

4

5

6

7

8

9

10

11

12

13

14

15

16

17

18

19

20

21

22

23

24

25
.5142

.5542

.5629

.3547

.5344

.5811

.4059

.5832

.4857

.4617

.6785

.4840

.6119

.6949

.4134

.3747

.6441

.5692

.5292

.4840

.7042

.5715

.5702

.5426

.6775 
2. Mean scores on the inventories. Mean scores and standard deviations are indicated for the inventories in Table $V$ beneath. In that a total conjunction score, or total score for the number of correct perceptual matches, was computed for each dyad on the PDI, mean scores for this measure are identical for men and women. The MSI and MPC means and standard deviations were calculated seperately for males and females and then totals were computed.

\section{TABLE $V$}

MEANS AND STANDARD DEVIATIONS ON THE PERCEPTUAL DIAGNOSTIC INVENTORY, THE MARITAL SATISFACTION INVENTORY AND THE MARRIAGE PROBLEM CHECKLIST

\begin{tabular}{|c|c|c|c|c|}
\hline Variable & Males & Females & Total & $\begin{array}{c}\text { Total } \\
\text { Possible }\end{array}$ \\
\hline \multicolumn{5}{|l|}{ PDI } \\
\hline Mean & 415.48 & 415.48 & 415.48 & 500 \\
\hline S.D. & 62.47 & 62.47 & 62.47 & \\
\hline \multicolumn{5}{|l|}{ MSI } \\
\hline Mean & 293.58 & 301.72 & 297.65 & 365 \\
\hline S.D. & 35.63 & 36.18 & 35.90 & \\
\hline \multicolumn{5}{|l|}{ MPC } \\
\hline Mean & 8.14 & 7.22 & 7.68 & 80 \\
\hline S.D. & 7.73 & 6.32 & 7.02 & \\
\hline \multicolumn{5}{|c|}{$\begin{array}{l}\text { A brief examination of the table suggests that means and standarc } \\
\text { tions remained quite stable across the two gender groups, and fur- } \\
\text { that women reported slightly higher satisfaction than men while } \\
\text { eported sliahtly more marital problems. }\end{array}$} \\
\hline
\end{tabular}


As was stated in the pilot study discussion, for each of the 25 issues in the PDI there was a possible 20 points making a total possible of 500 points. Dyadic scores on this measure across the 50 couples ranged from 282-498; the score distribution was negatively skewed with the majority (60 percent) of the scores being over 400 .

Scores on the MSI were determined on a five-point basis. Scoring of each item ranged from 1-5, with 5 indicating the most favorable attitude toward one's marriage and 1 the least favorable attitude. For the 73 items, the maximum possible score was 365. Satisfaction scores computed on total dyad scores ranged from 193 to 345 with the greatest proportion (52 percent) over 300. These figures suggest relatively high marital satisfaction among participants.

A subject could potentially register a total of 80 problems on the MPC. Though there are only 40 items included in the measure, 40 points could be received if a participant placed two checkmarks on each of the 20 relationship problems, indicating he/she considered them very serious. Similarly, an additional 40 points could be tallied if a subject checked both husband and wife columns for each of the individual behavior problems. When husband and wife scores were averaged into a dyad score, 80 percent of the sample indicated less than 10 marital problems, 12 percent indicated from 10-19 problems, and 8 percent indicated over 20 problems in their marriage.

3. Correlation coefficients generated between inventories. Reliability analysis of the three inventories produced the three Pearson product-moment correlation coefficients presented in Table VI. The observed correlations between the PDI and the other two instruments suggest moderate relationships in the directions hypothesized. 
TABLE VI

PEARSON PRODUCT-MOMENT CORRELATION COEFFICIENTS FOR THE PERCEPTUAL DIAGNOSTIC INVENTORY, MARITAL SATISFACTION INVENTORY AND MARRIAGE PROBLEM CHECKLIST

\section{Inventories}

PDI and MSI

PDI and MPC

MSI and MPC

\section{Coefficients Produced}

$+.7222$

$-.7681$

$-.7673$

In addition to the information provided by the Pearson productmoment correlation coefficients, a further breakdown of exactly how dyadic scores interacted within specific categories is presented in Table VII. The categories were determined by discriminating the point at which 60 percent of the subjects fell for each inventory. On the PDI, all dyads having a score of over 400 were in the top 60 percent of the sample. All dyads receiving a score of over 294 on the MSI were in the top 60 percent, and all dyads averaging a score of less than 7 on the MPC were in the lower 60 percent for that inventory.

Some conclusions that can be drawn from this categorization are that a significant number of dyads (44 percent) achieved relatively high perceptual matching scores and reported high marital satisfaction as well as a low number of marital problems. Furthermore, another significant number of couples (28 percent) received relatively low perceptual matching scores, indicated low marital satisfaction and reported a relatively high number of marital problems when compared with the rest of the sample. The 14 remaining couples made up various combinations of scores on the three inventories and generalizations about their marital status are more difficult to determine. 
TABLE VII

CATEGORIZATION OF COUPLES BY SCORES ON ALL INVENTORIES

\begin{tabular}{|c|c|c|c|c|}
\hline Category & \multicolumn{3}{|c|}{$\begin{array}{l}\text { Total Dyadic Scores } \\
\text { on Inventories }\end{array}$} & $\begin{array}{c}\text { Total } \begin{array}{c}\text { No. Couples } \\
N=50\end{array}\end{array}$ \\
\hline 1 & $\begin{array}{l}\text { Above } \\
\text { Above } \\
\text { Below }\end{array}$ & $\begin{array}{r}400 \\
294 \\
7\end{array}$ & $\begin{array}{l}\text { PDI } \\
\text { MSI } \\
\text { MPC }\end{array}$ & 22 \\
\hline 2 & $\begin{array}{l}\text { Below } \\
\text { Below } \\
\text { Above }\end{array}$ & $\begin{array}{r}400 \\
294 \\
7\end{array}$ & $\begin{array}{l}\text { PDI } \\
\text { MSI } \\
\text { MPC }\end{array}$ & 14 \\
\hline 3 & $\begin{array}{l}\text { Above } \\
\text { Below } \\
\text { Below }\end{array}$ & $\begin{array}{r}400 \\
294 \\
7\end{array}$ & $\begin{array}{l}\text { PDI } \\
\text { MSI } \\
\text { MPC }\end{array}$ & 4 \\
\hline 4 & $\begin{array}{l}\text { Below } \\
\text { Above } \\
\text { Above }\end{array}$ & $\begin{array}{r}400 \\
294 \\
7\end{array}$ & $\begin{array}{l}\text { PDI } \\
\text { MSI } \\
\text { MPC }\end{array}$ & 3 \\
\hline 5 & $\begin{array}{l}\text { Above } \\
\text { Above } \\
\text { Above }\end{array}$ & $\begin{array}{r}400 \\
294 \\
7\end{array}$ & $\begin{array}{l}\text { PDI } \\
\text { MSI } \\
\text { MPC }\end{array}$ & 3 \\
\hline 6 & $\begin{array}{l}\text { Below } \\
\text { Below } \\
\text { Below }\end{array}$ & $\begin{array}{r}400 \\
294 \\
7\end{array}$ & $\begin{array}{l}\text { PDI } \\
\text { MSI } \\
\text { MPC }\end{array}$ & 3 \\
\hline 7 & $\begin{array}{l}\text { Below } \\
\text { Above } \\
\text { Below }\end{array}$ & $\begin{array}{r}400 \\
294 \\
7\end{array}$ & $\begin{array}{l}\text { PDI } \\
\text { MSI } \\
\text { MPC }\end{array}$ & 1 \\
\hline & Dis & ussi & & \\
\hline
\end{tabular}

The results of this study suggest several important features of the developed inventory. Reliability as indicated by Cronbach's alpha was quite high at +.9222 providing an initial indication of high internal consistency of the measure. Item discrimination was studied on the basis of corrected item-total correlations; all items were significant beyond 
the .01 level of confidence and 17 items had a coefficient above +.50 .

Mean scores suggested stability across the two gender groups with slight variations in reported satisfaction and marital problems. The majority of couples achieved relatively high scores on perceptual correspondence and marital satisfaction, making results negatively skewed, and relatively low scores on reported marital problems where results were positively skewed.

Campbell and Fiske (1959) report that assessing discriminant validity is an important step in the evaluation of construct validity for any empirical scale. Discriminant validity was thus assessed for the PDI through correlations with instruments measuring the related but different constructs of marital satisfaction and marital problems. Both directional hypotheses confirmed the suggested relationship of the PDI with the selected measures. The moderately strong positive, but not extremely high positive correlation coefficient of +.7222 was computed for the PDI and MSI; the moderately strong negative, but not extremely high negative correlation coefficient of -.7681 was computed on the PDI and MPC. The correlation coefficient -.7673 produced for the MSI and MPC closely resembled Bowden's (1977) figure of -.73 for the same correlation. Observed correlations between the PDI and these other instruments suggests discriminant validity for the scale.

Analysis of the categorizations of couples based on scores for each of the inventories indicated that in general the majority of dyads (72 percent) maintained consistency across all three inventories. More satisfied couples reported fewer problems and received higher scores on their perceptual correspondence, and couples reporting less satisfaction indicated more problems and had lower scores on their perceptual matching. 
Results of the study indicate that the scale has merit and deserves further investigation as an assessment technique for measuring the correspondence in relational perceptions of marital partners. 
CHAPTER VII

SUMMARY AND IMPLICATIONS

Summary

Overall efforts in this research project were toward the development of a measure that would assess the correspondence in relational perceptions between partners in a marital dyad and thereby give an indication of the relative effectiveness of communication within that dyad. Through review of scholarly works related to the field of communication, a framework for viewing individuals as existing within complex systems was established and evidence suggesting a transactional perspective of dyadic communication was presented. The meaning of behavior and experience to interacting persons is seen as mediated through perceptual interplay; this construct provided a basis for analysis of the relational dimensions of a dyad. Systems researchers utilizing traditional research techniques to examine systems hypotheses and propositions have failed due to the inherent inability of such measures to reveal specific systems proporties (Monge, 1982). The Perceptual Diagnostic Inventory is designed to assess relational attitudes or behavioral dispositions rather than individual traits or qualities and thereby focuses on systems characteristics.

The technical goal of this thesis was to develop a measure capable to producing a scorable unit of dyadic, rather than monadic, interaction. The scale provides such an indication by matching the perceptions of 
partners and indicating accuracies or inaccuracies in perceptual accretions; diagnostic value of the instrument lies in exposing the perceived interexperiences of each partner. Once explicitely stated, congested perceptions across different cognitive and affective levels can potentially be explored and/or eliminated. The premise underlying this assessment technique is that dyadic relationships:are more fully actualized and promoted if perceptions are understood and realized by partners.

The investigation included a pilot study conducted to determine the reliability of an initial version of the instrument and subsequent refinement of the scale after internal consistency analyses. The final test included a 25 item scale and produced high internal consistency figures after implementation in the final study. Discriminant validity was established through correlations with two other marital assessment techniques and directional hypotheses on instrument performance were supported. Correlation coefficients revealed an inverse relationship between measures as the PDI and MSI produced a moderately high positive correlation and the PDI and MPC produced a moderately high negative correlation. In general, evidence suggests a correspondence between the degree of perceptual matching, and reported marital satisfaction and marital problems.

Potentialities of the instrument include refinement in deliniating the association between perceptual correspondence and specific communication behaviors which may be successful or unsuccessful. The instrument contributes to the development of a science of interpersonal relationships by providing information on cognitive operations of individuals in a dyad which are difficult to examine, and may reflect new insight into dyadic perceptual analysis. 


\section{Limitations and Recommendations}

Hindsight allows one the interesting opportunity of viewing a completed project with greater insight and understanding as to its nature and particular requirements. Research is based on systematic inquires into subjects and recognition and reporting of not only the results, but also the difficulties encountered and potential shortcomings of the undertaking. The ensuing discussion is designed to provide details on some of the major obstacles yielded by this study as well as offer solutions or suggestions for their rectification. The specific areas covered will be the design of the scale, the research methodology and the sampling technique.

1. Design of the scale. Though the author originally attempted to select issues from several sources, including suggestions from experts in the field of interpersonal communication, the issues pertaining to marital relationships and dyadic communication behavior which comprised the final inventory are not thought to represent the best possible items. After analyzing responses to the other two inventories used in this project, the Marital Problem Checklist, in particular, provided clear indications of additional areas that might be included in marital assessment. By way of example, many couples checked the statements: "problems with in-laws," "sexual difficulties," "financial disagreements," "indecision," and "career dissatisfaction" as major problem areas in their relationship. None of these items appear in the PDI due to the criteria enforced in issue selection. In retrospect, specific behavioral issues may be more suitable items for evoking an accurate registration of one's relational perceptions than the vague issues like "affectionate toward," "blames," 
"disappointed in," or "listens to" that were included in the PDI. While behavioral statements may not evoke phenomenological perspectives, they would allow respondents to more easily report their perceptual status in practical terms.

Statement formats still present some difficulties in the final version of the instrument. As the result of criticism by subjects in the pilot study, the words "generally" and "frequently" were added to issue statements to reduce ambiguity. The final study brought additional complaints about the relative nature of these terms, but judging from the smaller number of registered complaints one would assume that the terms did help clarify the statements. Statement formats still could be improved upon.

This investigator would ultimately like to see a Likert-type attitudinal scale used in the inventory giving subjects a greater range of response possibilities. Unfortunately, in that simple yes and no response categories require over 25 seperate computer transactions for each item, the author's advisor assures her that the programming task of producing a scorable unit from a five-point scale, across three different perceptual levels, would be awesome to say the least. Adjustment of the levels tapped or revision of scale structure might allow a Likertscale to be used.

A final matter concerning the scale has to do with its applicability. A perceptual diagnostic inventory could be developed for use in several situations including businesses, schools and universities, churches and families. Greater practicability for an instrument aimed at intimate relationships would be maintained if the inventory were adjusted for married or cohabitating couples. 
2. Research methodology. Probably the greatest limitation in this investigation is the exclusive use of self-report methodology. Although criterion groups were initially going to be used in the project, time constraints eliminated this possibility and the resulting study consisted of three self-report inventories. By relying on self-report inventories, the author is depending on the subject's ability to reporthis/her perceptions accurately and honestly.

Several research methodologies which could be applied to future investigations of perceptual correspondence include: third party reports, self-monitoring, interviewing, intervention methods and observational coding schemes. Any combination of these techniques with a self-report method contributes substantially to the validity of the instrument. Possible recommendations for future studies might involve: (1) interviewing subjects before or after taking the PDI and having partners discuss the accuracies or inaccuracies of their perceptual matching, (2) collecting third party reports on how well couples communicate and specific problems areas particularly resulting from perceptual differences that might cause strain, and ( 3 ) an observational coding scheme that would allow examination of transactions between couples and could give added information on a couple's communication behavior.

3. Sampling technique. The final problematic area in this study has to do with the lack of random sampling. A random sample would more accurately reflect the universal population of married couples and may provide a greater range in participant responses. In this case, subject age and number of years in marriage were not diversified enough in pilot or final studies. Control groups of functional and dysfunctional couples would also provide additional information and would increase 
validity and reliability.

4. Conclusion. These limitations and recommendations are the result of hours of labor on this study. While some may seem significant, it is important to bear in mind the difficult task of developing an instrument and the numerous revisions most measures go through before they are practically and empirically sound. The author is pleased to make this contribution to the area of marital assessment and to communication research. 


\section{REFERENCES}

Albrecht, T.L. and Cooley, R.E. Androgyny and communication strategies for relational dominance: An empirical analysis. in D. Nimmo (Ed.), Communication yearbook 4. New Brunswick, N.J.: Transaction Books, 1980.

Alperson, B.L. A Boolean analysis of interpersonal perception. Human Relations, 1975, 28, 627-652.

Anastasi, A. Psychological testing. London: MacMillan, 1968.

Argyle, M. Eye-contact. The psychology of interpersonal behavior. Middlesex, England: Harmondsworth, 1967.

Argyle, M. Social interaction. London: Methuen, 1969.

Bales, R.F. Interaction process analysis. Cambridge, Mass.: AddisonWesley, 1951.

Barnlund, D.C. Toward a meaning-centered philosophy of communication. Journal of Communication, 1962, 12, 197-211.

Barnlund, D.C. Communication: The context of change. In C.D. Mortensen (Ed.), Basic readings in communication theory. San Francisco: Harper and Row, 1973.

Bateson, G., Weakland, J.H., and Haley, J. Comments on Haley's "history." In C. Sluzki and D.C. Ransom (Eds.), Double bind: The foundation of the communication approach to the family. San Francisco: Grune and Stratton, 1976.

Beier, E.G. and Sternberg, D.P. Marital communication. Journal of Communication, 1977, 27, 92-103.

Berger, C.R. The covering law perspective as a theoretical basis for the study of human communication. Communication quarterly, 1977, 25, 7-18.

Berman, E.M. and Lief, H. Marital therapy from a psychiatric perspective: An overview. American Journal of Psychiatry, 1975, 132, 583-592.

Bienvenu, M.J. Marital Communication Inventory. Family Life Publications, Salunda, N.C.: 1970.

Bonjean, C.N., Hill, R.J., and McLemore, S.D. Sociological measurements: An inventory of scales and indices. San Francisco: Chandler Publishing, 1967. 
Bowden, S.R. An assessment of the validity of the Marital Satisfaction Inventory. Doctoral Dissertation, Texas A \& M University, 1977.

Brooks, W.D. Speech communication. Dubuque, Iowa: Brown, 1981.

Buber, M. I, thou. Translated by R.G. Smith. New York: Scribner, 1958.

Buckley, W. Sociology and modern systems theory. Englewood Cliffs, N.J.: Prentice-Hall, 1967.

Campbell, B.K. and Barnlund, D.C. Communication patterns and problems of pregnancy. American Journal of Orthopsychiatry, 1977, 1, 134-150.

Campbell, D.T. and Fiske, D.W. Convergent and discriminant validation by the multitrait-multimethod matrix. Psychological Billetin, 1959, $56,81-105$.

Cottrell, L.S., Jr. The case study method in prediction. Sociometry, $1941 \mathrm{a}, 4,358-370$.

Cottrell, L.S., Jr. and Gallegher, R. Developments in social psychology from 1930-1940. Sociometry Monographs, 1941b, 1, 32-54.

Cottrell, L.S., Jr. The analysis of situational fields in social psychology. American Sociological Review, 1942, 7, 370-382.

Cromwell, R.E., Olson, D.H., and Fournier, D.G. Tools and techniques for diagnosis and evaluation in marital and family therapy. Family Process, 1976, 15, 1-32.

Cushman, D.P. The rules perspective as a theoretical basis for the study of human communication. Communication quarterly, 1977, 25, 30-45.

DeVito, J.A. Communicology. San Francisco: Harper and Row, 1982.

Dymond, R.F. A preliminary investigation of the relation of insight and empathy. Journal of Consulting Psychology, 1948, 12, 228-233.

Dymond, R.F. A scale for the measurement of empathic ability. Journal of Consulting Psychology, 1949, 13, 127-133.

Ericson, P. and Rogers, L. New procedures for analyzing relational communication. Family Process, 1973, 12, 245-267.

Filley, A.C. Interpersonal conflict resolution. Glenview, Ill.: Scott, Foresman, 1975.

Fitzpatrick, M.A. and Best, P. Dyadic adjustment in traditional, independent, and seperate relationships: A validation study. Communication Monographs, 1979, 46, 167-178. 
Fitzpatrick, M.A. and Winke, J. You always hurt the one you love: Strategies and tactics in interpersonal conflict. Communication quarterly, 1979, 27, 3-11.

Fitzpatrick, M.A. and Indvik, J. The instrumental and expressive domains of marital communication. Human Communication Research, 1982, 8, 195-213.

Foa, E. and Foa, U. Resource theory of social exchange. In J. Thibaut, J. Spence, and R. Carson (Eds.), Contemporary topics in social psychology. Morristown, N.J.: General Learning Press, 1976, 99-131.

Frazier, L.P. An evaluation of the Marital Satisfaction Inventory. Doctoral Dissertation, Texas A \& M University, 1976.

Freund, J.E. Modern elementary statistics. 4th ed. Englewood Cliffs, N.J.: Prentice-Hall, 1973.

Goffman, E. The presentation of self in everyday life. New York: Doubleday, 1959.

Goffman, E. Interaction ritual. New York: Doubleday, 1967.

Goodman, N. and Ofshe, R. Empathy, communication efficiency and marital status. Journal of Marriage and the Family, 1968, 30, 597-603.

Gottman, J., Markman, H. and Notarius, C. The typography of marital conflict: A sequential analysis of verbal and nonverbal behavior. Journal of Marriage and the Family, 1977, 39, 461-477.

Grove, T.G. Program for matched response instruments. Research and publications grant application, Portland State University, 1977.

Grove, T.G. and Hays, J. IPALION: A Fortran IV program for comparing interpersonal perceptions in dyads. Behavior Research Methods and Instrumentation, 1978, 10, 747-749.

Gurman, A.5. Marital therapy: Emerging trends in research and practice. Family Process, 1973, 12, 45-54.

Haley, J. The family of the schizophrenic: A model system. Journal of Nervous and Mental Disease, 1959, 129, 357-374.

Haley, J. Strategies of psychotherapy. New York: Grune and Stratton, 1963.

Haley, J. Development of a theory: A history of a research project. In C. Sluzki and D.C. Ransom (Eds.), Double bind: The foundation of the communication approach to the family. San Francisco: Grune and Stratton, 1976.

Haley, J. Dimensions of family therapy. Journal of Nervous and Mental Disease, 1977, 165, 88-98. 
Hamachek, D.E. Encounters with self. Holt, Rinehart and Winston, 1971.

Hare, A.P., Borgatta, E. and Bales, R.F. Small groups: Studies in social interaction. New York: Knopf, 1965.

Hastorf, A., Schneider, D. and Polefka, J. Person perception. Reading, Mass.: Addison-Wesley, 1970.

Hawkins, J.L., Weisberg, C., and Ray, D.W. Marital communication style and social class. Journal of Marriage and the Family, 1977, 39, 479-490.

Hawkins, J.L., Weisberg, C., and Ray, D.W. Spouse differences in communication style: Preference, perception, behavior. Journal of Marriage and the Family, 1980, 42, 585-594.

Hill, R.L., Stycos, J.M., and Back, R.W. The family and population control: A Puerto Rican experiment in social change. Chapel Hill, N.C.: University of North Carolina Press, 1959.

Hill, R.L., Stycos, J.M., and Back, R.W. Marital Communication and Agreement Test. In R.L. Hill, Family development in three generations. Cambridge, Mass.: Schenkman, 1970.

Hobart, C.W. and Klausner, W.J. Some social interaction correlates of marital role disagreement and marital adjustment. Marriage and Family Living, 1959, 21, 256-263.

Hodes, A. Martin Buber: An intimate portrait. New York, Viking, 1971.

Holsti, O.R. Content analysis. In G. Lindzey and E. Aronson (Eds.), The handbook of social psychology. Menlo Park, Calif.: Addison-Wesley, 1968.

Homans, G.C. The human group. New York: Harcourt, Brace and World, 1950.

Homans, G.C. Social behavior: Its elementary form. New York: Harcourt, Brace, 1961.

Jackson, D.D. Family interaction, family homeostasis and some implications for conjoint family psychotherapy. In J.H. Masserman (Ed.), Individual and familial dynamics. New York: Grune and Stratton, 1959.

Jackson, D.D., Riskin, J., and Satir, V. A method of analysis and family interview. Archives of General Psychiatry, 1961, 5, 321-386.

Jandt, F.E. Conflict resolution through communication. New York: Harper and Row, 1973.

Jourard, S.M. The transparent self. New York: Van Nostrand Reinhold, 1971. 
Jourard, S.M. and Lasakow, P. A research approach to self-disclosure. Journal of Abnormal Social Psychology, 1958, 56, 91-98.

Kahn, M. Nonverbal communication as a factor in marital satisfaction. Doctoral dissertation, Southern Illinois University, 1969.

Karlsson, G. Adaptability and communication in marriage: A Suedish predictive study of marital satisfaction. Uppsula: Almquist and Wiksells, 1951.

Kleinke, C.L. Self-perception: The psychology of personal awareness. San Francisco: W.H. Freeman, 1978.

Kotkas, L.J. Informal use of the Interpersonal Perception Method in marital therapy. Canadian Psychiatric Association Journal, 1969, $14,11-14$.

Laing, R.D., Phillipson, H., and Lee, A.R. Interpersonal perception: A theory and method of research. New York: Springer, 1966.

Laing, R.D. The politics of experience. New York: Pantheon Books, 1967.

Lake, D.G., Miles, M.B., and Earle, R.B. Measuring human behavior. New York: Teachers College Press, 1973.

Lasswell, H.D. The structure and function of communication in society. In L. Bryson (Ed.), The communication of ideas. New York: Institute for Religion and Social Studies, 1948.

Laszlo, E. The systems view of the world. New York: Braziller, 1972.

Levy, R.B. Self revelation through relationships. Englewood Cliffs, N.J.: Prentice-Hall, 1972.

Littlejohn, 5.W. An overview of contributions to human communication theory from other disciplines. In F.E. Dance (Ed.), Human communication theory. San Francisco: Harper and Row, 1982.

Lively, E.L. Toward concept clarification: The case of marital interaction. Journal of Marriage and the Family, 1969, 31, 108-114.

Locke, N.J., Sabagh, G., and Thomes, M.M. Correlates of primary communication and empathy. Research Studies of State College of Washington, 1956, 24, 116-124.

McCall, M. Boundary rules in relationships and encounters. In G. McCall, M. McCall, N. Denzin, G. Suttles, and S. Kurth (Eds.), Social relationships. Chicago: AVC, 1970.

Mead, G.H. Mind, self and society: From the standpoint of a social behavorist. Chicago: University of Chicago Press, 1934. 
Mehrabian, A. Nonverbal communication. In C.D. Mortensen and K.K. Sereno (Eds.), Advances in communication research. New York: Harper and Row, 1973.

Michel, A. Wife's satisfaction with husband's understanding in Parisian urban families. Journal of Marriage and the Family, 1970, 32, 351-359.

Miller, G.R. and Simons, H.W. (Eds.) Perspectives on communication in social conflict. Englewood Cliffs, N.J.: Prentice-Hall, 1974.

Miller, G. and Steinberg, M. Between people: A new analysis of interpersonal communication. Palo Alto, Calif.: Science Research, 1975.

Minuchin, 5. Families and family therapy. Cambridge: Harvard University Press, 1974.

Monge, P.R. The systems perspective as a theoretical basis for the study of human communication. Communication Quarterly, 1977, 25, 19-29.

Monge, P.R. Systems theory and research in the study of organizational communication: The correspondence problem. Human Communication Research, 1982, 8, 245-259.

National Center for Health Statistics: Births, marriages, divorces, and deaths, United States 1981. Monthly Vital Statistics Report, 1982, $30,2-3$.

Navran, L. Communication and adjustments in marriage. Family Process, $1967,6,173-180$.

Newcomb, T.M. The acquaintance process. New York: Holt, Rinehart, and Winston, 1961 .

Patton, B.R. and Patton, B.R. Living together: Female/male communication. Columbus, Ohio: Merrill, 1976.

Phillips, C. Some useful tests for marriage counseling. The Family Coordinator, 1973, 22, 43-53.

Phillips, G.M. and Metzger, N.J. Intimate communication. Boston: Allyn and Bacon, 1976.

Powell, J. Why am I afraid to tell you who I am? Niles, Ill.: Argus Communications, 1969.

Roach, A.J. The Marriage Problem Checklist. In S.R. Bowden, An assessment of the validity of the Marital Satisfaction Inventory. Doctoral Dissertation, Texas A \& M University, 1977, 62-63.

Roach, A.J. and Boyd, L.F. The Personal Data Inventory. In S.R. Bowden, An assessment of the validity of the Marital Satisfaction Inventory. Doctoral Dissertation, Texas A \& M University, 1977, 54. 
Roach, A.J. The Marital Satisfaction Inventory. In S.R. Bowden, An assessment of the validity of the Marital Satisfaction Inventory. Doctoral Dissertation, Texas A \& M University, 1977, 56-61.

Roach, A.J. The Marital Satisfaction Scale: Development of a measure for intervention research. Journal of Marriage and the Family, 1981, $43,537-546$.

Rogers, L.E. and Farace, R.V. Analysis of relational communication in dyads: New measurement procedures. Human Communication Research, $1975,1,222-223$.

Rogers-Millar, L.E. and Millar, F.E. Domineeringness and dominance: A transactional view. Human Communication Research, 1979, 5, 238-246.

Roloff, M.E. Communication strategies, relationships, and relational changes. In G.R. Miller (Ed.), Explorations in interpersonal communication. Beverly Hills: Sage, 1976.

Roloff, M.E. Interpersonal communication: The social exchange approach. Beverly Hills: Sage, 1981.

Ruben, B.D. General system theory and human communication. Rochelle Park, N.J.: Hayden, 1975.

Safilics-Rothschild, C. Attitudes of Greek spouses toward marital infidelity. In G. Neubeck (Ed.), Extramarital relations. Englewood Cliffs, N.J.: Prentice-Hall, 1969.

Schramm, W. The process and effects of mass communication. Urbana: University of Illinois Press, 1954.

Schrumm, W.R. and Jackson, R.W. Marital communication or marital adjustment? A brief report on the Marital Communication Inventory. Psychological Reports, 1980, 46, 441-443.

Schutz, W.C. The interpersonal underworld. Palo Alto, Calif.: Science and Behavior Books, 1966.

Scott, W.A. Attitude measurement. In G. Lindzey and E. Aronson (Eds.), The handbook of social psychology. Menlo Park, Calif.: AddisonWesley, 1968.

Shannon, C.E. and Weaver, W. The mathematical theory of communication. Urbana: University of Illinois Press, 1949.

Snyder, D.K., Keiser, T.W., and Wills, R.M. Empirical validation of the Marital Satisfaction Inventory: An actuarial approach. Journal of Consulting and Clinical Psychology, 1981, 49, 262-268. 
Spanier, G.B. Measuring dyadic adjustment: New scales for assessing the quality of marriage and similar dyads. Journal of Marriage and the Family, 1976, 38, 15-38.

Stewart, J. Bridges not walls. Menlo Park, Calif.: Addison-Wesley, 1977.

Straus, M.A. and Brown, B.W. Family measurement techniques. Minneapolis: University of Minnesota Press, 1969.

Straus, M.A. and Brown, B.W. Family measurement techniques: Abstracts of published instruments, 1935-1974. (Rev. ed.) Minneapolis: University of Minnesota Press, 1978.

Swensen, C. Interpersonal relations. Illinois: Scott, Foresman, 1973.

Taguiri, R. and Petrullo, L. Person perception and interpersonal behavior. Palo Alto, Calif.: Stanford University Press, 1958.

Thibaut, J.W. and Kelley, H.H. The social psychology of groups. New York: Wiley, 1959.

Thompson, R.R. Effects of a sex therapy treatment program on couple relationships. Unpublished Master's thesis. Texas A and I University, 1978.

Thompson, T.L. The impact of a physical handicap on communicative characteristics of the marital dyad. Western Journal of Speech Communication, 1981, 3, 227-240.

Toch, H. and MacLean, M.S. Perception and communication: A transactional view. Audio Visual Communication Review, 1967, 10, 55-77.

Wampler, K.S. and Sprenkle, D.H. The Minnesota Couple Communication Program: A follow-up study. Journal of Marriage and the Family, 1980, $42,577-584$.

Warner, W.L., Meeker, M., and Eels, L. Social class in America. In D.C. Miller (Ed.), Handbook of research design in social measurement. New York: David McKay, 1970.

Watzlawick, P. and Helmick, J. Pragmatics of human communication. New York: Norton, 1967.

Watzlawick, P., Beavin, J., and Jackson, D. Some tentative axioms of communication. In C.D. Mortensen (Ed.), Basic readings in communication theory. San Francisco: Harper and Row, 1973.

Wilmot, M. Dyadic communication. Menlo Park, Calif.: Addison-Wesley, 1979. 


\section{APPENDICES}

Toward a Measure of Correspondence in Relational

Perceptions in Marital Dyads 
APPENDIX A

\begin{abstract}
COMMUNICATION TEXTBOOKS REVIEWED FOR
MODELS OF COMMUNICATION AND ISSUE CANDIDATES
\end{abstract}

Adler, R. and Towne, N. Looking out/looking in: Interpersonal communication. San Francisco: Holt, Rinehart and Winston, 1978.

Barker, L.L. Communication. New Jersey: Prentice-Hall, 1981.

Cooper, P.J. Speech communication for the classroom teacher. Dubuque, Iowa: Gorsuch Scarisbrick, 1981.

Costigan Lederman, L. New dimensions: An introduction to human communication. Dubuque, Iowa: Wm. C. Brown, 1977.

Egan, G. Face to face. Monterey, Calif.: Brooks/Cole, 1973.

Emmert, P. and Donaghy, W.C. Human communication: Elements and contexts. Menlo Park, Calif.: Addison-Wesley, 1981.

Forrest, M. and 0lson, M.A. Exploring speech communication: An introduction. San Francisco: West, 1981.

Giffin, K. and Patton, B.R. Fundamentals of interpersonal communication. San Francisco: Harper and Row, 1971.

Grove, T.G. Experiences in interpersonal communication. New Jersey: Prentice-Hall, 1976.

King, R.G. Fundamentals of human communication. New York: MacMillan, 1979.

Knapp, M.L. Nonverbal communication in human interaction. San Francisco: Holt, Rinehart and Winston, 1978.

Laing, R.D. Self and others. Baltimore, Maryland: Penguin Books, 1969.

Larson, C.U. Communication: Everyday encounters. Prospect Heights, Illinois: Waveland Press, 1981.

McAuley, J.G. People to people: Essentials of personal and public communication. Belmont, Calif.: Wadsworth, 1979.

Miller, S., Nunnally, E.W. and Wackman, D.B. Alive and aware: Improving communication in relationships. Minneapolis, Interpersonal Communication Programs, 1975. 
Patton, B.R. and Giffin, K. Problem-solving group interaction. San Francisco: Harper and Row, 1973.

Peterson, B.D., Goldhaber, G.M. and Pace, R.W. Communication probes. Palo Alto: Science Research Associates, 1982.

Rein, I.J. The great American communication catalogue. New Jersey: Prentice-Hall, 1976.

Ruesch, J. and Bateson, G. Communication the social matrix of psychiatry. New York: W.W. Norton, 1968.

Toch, H. and Smith, H.C. Social perception. Princeton, N.J.: D. Van Nostrand, 1968.

Verderber, R.F. Communicate! Belmont, Calif.: Wadsworth, 1981.

Watzlawick, P. How real is real? New York: Vintage Books, 1976. 


\section{APPENDIX B}

\section{THREE PHASES OF ISSUE REDUCTION FOR PILOT INSTRUMENT}

A compilation of 307 issue candidates was reduced to 40 for the pilot instrument. Phases of issue reduction are indicated in the following manner:

1 = Phase 1307 to 163 issues

3 = Phase 397 to 40 issues

2 = Phase 2163 to 97 issues

* = Issues used in pilot instrument

1 ability to shift categories

1 accepts

1 accuses falsely

1 activities together

3 acknowledges achievements

* adapts to

1 adjusts to

* admits faults

* affectionate toward

3 afraid of

1 agree on right/proper conduct

3 alienates

1 analogical messages

2 analyzes

1 anomia

3 antagonizes

* appreciates

1 approachability

* argues with

* arrogant toward

3 ashamed of

1 assumed roles

1 at one with

1 attending behavior

1 attitude toward communication

3 attracted to

3 awkward with

1 believes in

3 belittles

1 bewilders

1 bickering

3 bitter toward

* blames
2 body clock

2 body image

2 body orientation

3 bothers

1 can face up to conflicts

1 can handle marriage

1 can't come to terms with

1 can't stand

3 cares about

1 clothing

1 cohesiveness

3 comforts

3 committed to

1 commonality of attitudes

* communicates openly with

2 competes with

1 completing processes

2 compromises

1 conceptual tempo

3 condescending toward

* confidence in

1 confirms

1 conflict management

2 conforms to wishes of

3 confuses

1 congruent goals

3 considerate of

1 consensus

* consults

1 couldn't care less about

1 creates difficulties for

2 creativity

2 deals with anger 
2 deals with durabilities

2 deals with feelings

2 deals with pressure

3 deceives

* defensive toward

1 demands

2 dependability

2 dependence

2 depends on

1 detached from

* disappointed in

2 discipline

1 disconfirmation

1 discouraged with

* disgusted with

1 distance between

* dominates

1 doubts

1 economics

1 educational level

2 ego

1 emotive language

1 emotionally distant

1 empathizes with

* encourages

* enjoys

1 environment

* equal to

1 equivocal language

1 excited by

1 expects too much of

1 expectations not met

2 expressive

2 eye contact

2 face and eye behavior

3 faithful to

1 fantasies

1 feedback

1 fights with

1 filtering processes

2 financial problems

1 finds fault with

1 flusters

3 forgives

2 forthright

1 future promising

1 gender roles

1 gestures

1 gets along well with

1 gets me into a false position

1 gets on my nerves

3 gives freedom to grow

3 gives positive feedback
3 good to

3 goals similar

2 happy with relationship

3 has fun with

2 has lost hope for future

1 has warped view of

1 hates

1 hidden antagonizers

3 honest with

1 hostile toward

* humiliates

2 humor

* hurts

2 hygiene

* ignores

2 importance of work

1 impression management

1 inclusion

2 independence

* indifferent toward

2 influences

3 inhibits

1 inspires

2 instructs

3 insults

3 interested in

1 interesting

* interrupts

1 intimacy

3 intimate with

3 intimidates

1 intrapersonal communication

* irritable with

3 jealous of

1 joint experience

1 kind to

1 language sophistication

1 learning styles

3 lectures to

3 let's be self

1 let's down

3 likes

* listening behavior

1 listening - one-way

1 listening - two-way

1 listens to me

* loves

3 maddens

1 makes a clown of

1 makes center of world

1 makes contradictory demands on

1 makes into a puppet

* makes me angry 
* makes reasonable requests of

1 makes up mind for

* manipulates

1 mannerisms

2 marriage bad on health

2 marriage successul

1 marriage too confining

2 materialism

2 maturity

1 mean with

3 mocks

1 money matters

3 motivates

* nags

2 neatness

2 need for time alone

1 need fulfillment

* negatively criticizes

3 neglects

2 neglects responsibilities

1 openness to change

3 oppresses

2 orderliness

1 owes everything to

1 paralanguage

* patient with

1 perceptual styles

3 physical compatabilities

1 pities

1 plays with

3 pleasant toward

1 political persuasion

1 power

1 praises

2 preoccupation with self

2 privacy

1 problem-solving techniques

* proud of

1 proxemic behavior

1 psychological behavior

1 psychological processes

1 psychological set

2 puts on pedestal

2 readily forgives

3 reasonable with

2 reasoning processes

2 recreation activities

2 regrets marriage

2 relationships with animals

2 relationships with children

2 relationships with friends

2 relationships with other gender

2 relationships with parents
2 reliability

2 relies upon judgment

* resolves conflicts

1 respect for non-shared image

* respects

1 responding to conflict

3 responsible with

* responsive to

* responsible language usage

2 reticence

1 ritualized responses

1 roles

1 role taking

* sarcastic toward

1 selection of messages

1 self-actualization

2 self-concept

2 self-disclosure

2 self-esteem

2 self-fulfilling prophecy

3 selfish with

2 selfishness

1 sexual activity

1 sexual attraction

1 sexual behavior

1 sexy

3 shared beliefs

1 shared decision making

1 shared goals

* shared interests

3 shared role definitions

1 shared role expectations

3 shared successes

3 shared values

1 sharing

1 silence usage

2 similar philosophy of life

2 size

3 slanders

1 snares

1 social life

1 solid

1 sorry for

3 spends time with

1 spiritual matters

1 spoils

2 spontaneous

1 status

1 steady

1 supportiveness

3 supportive of

1 symbolization

3 sympathizes with 
1 tactile communication

1 takes good care of

1 takes offense with

2 takes responsibility for

3 takes seriously

* talks "at"

2 territoriality

1 thinks a lot of

1 time together

1 tolerates hobbies

1 tolerates values

3 torments

1 treats like a machine

1 tries to outdo

3 trusts

1 trustworthiness

1 truthfulness

* understands

3 understands nonverbal commun.

1 unfair demands

1 unilateral decision making

1 use of metaphors

1 uses abusive language

3 values

2 vocational compatibilities

1 won't let be

2 worries about

1 would like to get away from

2 wrapped up in 


\section{APPENDIX C \\ PERCEPTUAL DIAGNOSTIC INVENTORY \\ PILOT STUDY - MALE FORMAT*}

1. communicate openly: frank and direct expression of thoughts and feelings

I feel that...
A. she communicates openly with me
B. I communicate openly with her
C. she highly values my open communication
D. I highly value her open communication

She feels that...

E. she communicates openly with me

F. I communicate openly with her

G. she highly values my open communication

H. I highly value her open communication

She thinks that I feel that...

I. she communicates openly with me

J. I communicate openly with her

$\mathrm{K}$. she highly values my open communication

L. I highly value her open communication

2. dominate: to rule or control

I feel that...

A. she dominates me

B. I dominate her

C. she is disturbed by my dominating her

D. I am disturbed by her dominating me

She feels that...

E. she dominates me

F. I dominate her

G. she is disturbed by my dominating her

$H$. I am disturbed by her dominating me

She thinks that I feel that...

I. she dominates me

J. I dominate her

*The female format is exactly the same with the exception of pronoun usage. 
K. she is disturbed by my dominating her

L. I am disturbed by her dominating me

3. consult: to seek advice from

I feel that...

A. she consults with me

B. I consult with her

C. she highly values my consulting with her

D. I highly value her consulting with me

She feels that...

$E$. she consults with me

F. I consult with her

G. she highly values my consulting with her

H. I highly value her consulting with me

She thinks that I feel that...

I. she consults with me

J. I consult with her

$\mathrm{K}$. she highly values my consulting with her

L. I highly value her consulting with me

4. share interests: share one's feelings of concern or curiosity

I feel that...

A. she shares my interests

B. I share her interests

C. she highly values my sharing her interests

D. I highly value her sharing my interests

She feels that...

E. she shares my interests

F. I share her interests

G. she highly values my sharing her interests

H. I highly value her sharing my interests

She thinks that I feel that...

I. she shares my interests

J. I share her interests

K. she highly values my sharing her interests

L. I highly value her sharing my interests

5. talk "at": lecture to; one-way communication

I feel that...

A. she talks "at" me

B. I talk "at" her

C. she is disturbed by my talking "at" her

D. I am disturbed by her talking "at" me 
She feels that...

E. she talks "at" me

F. I talk "at" her

G. she is disturbed by my talking "at" her

H. I am disturbed by her talking "at" me

She thinks that I feel that...

I. she talks "at" me

J. I talk "at" her

K. she is disturbed by my talking "at" her

L. I am disturbed by her talking "at" me

6. encourage: to inspire with courage or confidence

I feel that...
A. she encourages me
B. I encourage her
C. she highly values my encouragement
D. I highly value her encouragement

She feels that...

E. she encourages me

$F$. I encourage her

G. she highly values my encouragement

H. I highly value her encouragement

She thinks that I feel that...

I. she encourages me

J. I encourage her

$K$. she highly values my encouragement

L. I highly value her encouragement

7. argument: verbal opposition or contention

I feel that...

A. she starts arguments with me

B. I start arguments with her

C. she is disturbed with my starting arguments

D. I am disturbed with her starting arguments

She feels that...

$E$. she starts arguments with me

F. I start arguments with her

G. she is disturbed with my starting arguments

H. I am disturbed with her starting arguments

She thinks that I feel that...

I. she starts arguments with me

J. I start arguments with her

$K$. she is disturbed with my starting arguments

L. I am disturbed with her starting arguments 
8. respect: high admiration or esteem for a person or quality

I feel that...
A. she respects me
B. I respect her
C. she highly values my respect for her
D. I highly value her respect for me

She feels that...

E. she respects me

F. I respect her

G. she highly values my respect for her

$H$. I highly value her respect for me

She thinks that I feel that...

I. she respects me

J. I respect her

K. she highly values my respect for her

L. I highly value her respect for me

9. arrogant: haughty or overbearing

I feel that...
A. she is arrogant toward me
B. I am arrogant toward her
C. she is disturbed by my arrogance
D. I am disturbed by her arrogance

She feels that...

E. she is arrogant toward me

F. I am arrogant toward her

G. she is disturbed by my arrogance

H. I am disturbed by her arrogance

She thinks that I feel that...

I. she is arrogant toward me

J. I am arrogant toward her

$K$. she is disturbed by my arrogance

L. I am disturbed by her arrogance

10. patient: calmly tolerating provocation or delay

I feel that...
A. she is patient with me
B. I am patient with her
C. she highly values my patience with her
D. I highly value her patience with me

She feels that...

E. she is patient with me

F. I am patient with her

G. she highly values my patience with her

H. I highly value her patience with me 
She thinks that I feel that...

I. she is patient with me

J. I am patient with her

K. she highly values my patience with her

L. I highly value her patience with me

11. unjustly criticize: to make unjust judgments as to the merits

I feel that...

A. she unjustly criticizes me

B. I unjustly criticize her

C. she is disturbed by my unjust criticisms

D. I am disturbed by her unjust criticisms

She feels that...

E. she unjustly criticizes me

F. I unjustly criticize her

G. she is disturbed by my unjust criticisms

H. I am disturbed by her unjust criticisms

She thinks that I feel that...

I. she unjustly criticizes me

J. I unjustly criticize her

$K$. she is disturbed by my unjust criticisms

L. I am disturbed by her unjust criticisms

12. adapt: adjust to changes

I feel that...

A. she adapts to me

B. I adapt to her

C. she highly values my adapting to her

D. I highly value her adapting to me

She feels that...

E. she adapts to me

$F$. I adapt to her

G. she highly values my adapting to her

H. I highly value her adapting to me

She thinks that I feel that...

I. she adapts to me

J. I adapt to her

K. she highly values my adapting to her

L. I highly value her adapting to me

13. indifferent: without interest or concern

I feel that...

A. she is indifferent toward me

B. I am indifferent toward her

C. she is disturbed by my indifference

D. I am disturbed by her indifference 
She feels that...

$E$. she is indifferent toward me

F. I am indifferent toward her

G. she is disturbed by my indifference

H. I am disturbed by her indifference

She thinks that I feel that...

I. she is indifferent toward me

3. I am indifferent toward her

$K$. she is disturbed by my indifference

L. I am disturbed by her indifference

14. angry: feeling anger or resentment

I feel that...

A. she makes me angry

B. I make her angry

C. she is disturbed by my making her angry

D. I am disturbed by her making me angry

She feels that...

$E$. she makes me angry

F. I make her angry

G. she is disturbed by my making her angry

H. I am disturbed by her making me angry

She thinks that I feel that...

I. she makes me angry

J. I make her angry

K. she is disturbed by my making her angry

L. I am disturbed by her making me angry

15. reasonable request: asking for something to be given or done in accord with reason

I feel that...

A. she makes reasonable requests of me

B. I make reasonable requests of her

C. she highly values my making reasonable requests

D. I highly value her making reasonable requests

She feels that...

E. she makes reasonable requests of me

F. I make reasonable requests of her

G. she highly values my making reasonable requests

H. I highly value her making reasonable requests

She thinks that I feel that...

I. she makes reasonable requests of me

3. I make reasonable requests of her

$K$. she highly values my making reasonable requests

L. I highly value her making reasonable requests 
16. manipulate: to suit one's purpose or advantage

I feel that...
A. she manipulates me
B. I manipulate her
C. she is disturbed by my manipulating her
D. I am disturbed by her manipulating me

She feels that...
E. she manipulates me
F. I manipulate her
G. she is disturbed by my manipulating her
H. I am disturbed by her manipulating me

She thinks that I feel that...

I. she manipulates me

J. I manipulate her

$\mathrm{K}$. she is disturbed by my manipulating her

L. I am disturbed by her manipulating me

17. Love: a profoundly tender, passionate affection / feeling of warm personal attachment

I feel that...
A. she loves me
B. I love her
C. she highly values my love
D. I highly value her love

She feels that...
E. she loves me
F. I love her
G. she highly values my love
H. I highly value her love

She thinks that I feel that...

I. she loves me

J. I love her

K. she highly values my love

L. I highly value her love

18. responsible language: accountable and answerable for what one says

I feel that...

A. she uses responsible language with me

B. I use responsible language with her

C. she highly values my use of responsible language

D. I highly value her use of responsible language

She feels that...

E. she uses responsible language with me

F. I use responsible language with her

G. she highly values my use of responsible language 
H. I highly value her use of responsible language

She thinks that I feel that...

I. she uses responsible language with me

J. I use responsible language with her

$K$. she highly values my use of responsible language

L. I highly value her use of responsible language

19. appreciate: to be grateful for, highly value

I feel that...
A. she appreciates me
B. I appreciate her
C. she highly values my appreciation
D. I highly value her appreciation

She feels that...
E. she appreciates me
F. I appreciate her
G. she highly values my appreciation
H. I highly value her appreciation

She thinks that I feel that...
I. she appreciates me
J. I appreciate her
K. she highly values my appreciation
L. I highly value her appreciation

20. humiliate: lower or injure the self-respect of, especially in public

I feel that...
A. she humiliates me
B. I humiliate her
C. she is disturbed by my humiliating her
D. I am disturbed by her humiliating me

She feels that...
E. she humiliates me
$F$. I humiliate her
G. she is disturbed by my humiliating her
H. I am disturbed by her humiliating me

She thinks that I feel that...

I. she humiliates me

J. I humiliate her

$K$. she is disturbed by my humiliating her

L. I am disturbed by her humiliating me

21. affectionate: displaying fond devotion

I feel that...

A. she is affectionate toward me

B. I am affectionate toward her 

C. she highly values my affection
D. I highly value her affection

She feels that...

E. she is affectionate toward me

F. I am affectionate toward her

G. she highly values my affection

$H$. I highly value her affection

She thinks that I feel that...

I. she is affectionate toward me

J. I am affectionate toward her

$K$. she highly values my affection

L. I highly value her affection

22. listen to: give attention for the purpose of hearing or understanding

I feel that...
A. she listens to me
B. I listen to her
C. she highly values my listening behavior
D. I highly value her listening behavior

She feels that...

E. she listens to me

F. I listen to her

G. she highly values my listening behavior

H. I highly value her listening behavior

She thinks that I feel that...

I. she listens to me

J. I listen to her

$K$. she highly values my listening behavior

L. I highly value her listening behavior

23. sarcasm: a sharply sneering or cutting remark

I feel that...

A. she is sarcastic toward me

B. I am sarcastic toward her

C. she is disturbed by my sarcasm

D. I am disturbed by her sarcasm

She feels that...

E. she is sarcastic toward me

F. I am sarcastic toward her

G. she is disturbed by my sarcasm

H. I am disturbed by her sarcasm

She thinks that I feel that...

I. she is sarcastic toward me

J. I am sarcastic toward her 
$K$. she is disturbed by my sarcasm

L. I am disturbed by her sarcasm

24. responsive: reacting readily to influences, appeals, etc.

I feel that...

A. she is responsive to me

B. I am responsive to her

C. she highly values my being responsive

D. I highly value her being responsive

She feels that...

E. she is responsive to me

F. I am responsive to her

G. she highly values my being responsive

H. I highly value her being responsive

She thinks that I feel that...

I. she is responsive to me

J. I am responsive to her

K. she highly values my being responsive

L. I highly value her being responsive

25. irritable: easily irritated or exasperated

I feel that...

A. she is irritable with me

B. I am irritable with her

C. she is disturbed by my irritability

D. I am disturbed by her irritability

She feels that...

E. she is irritable with me

F. I am irritable with her

G. she is disturbed by my irritability

H. I am disturbed by her irritability

She thinks that I feel that...

I. she is irritable with me

J. I am irritable with her

$\mathrm{K}$. she is disturbed by my irritability

L. I am disturbed by her irritability

26. disappoint: to fail to fulfill the expectations or wishes of

I feel that...

A. she is disappointed in me

B. I am disappointed in her

C. she is disturbed by my disappointment in her

D. I am disturbed by her disappointment in me

She feels that...

E. she is disappointed in me 
F. I am disappointed in her

G. she is disturbed by my disappointment in her

H. I am disturbed by her disappointment in me

She thinks that I feel that...

I. she is disappointed in me

J. I am disappointed in her

K. she is disturbed by my disappointment in her

L. I am disturbed by her disappointment in me

27. understand: has a thorough knowledge of; perceives the meaning of

I feel that...
A. she understands me
B. I understand her
C. she highly values my understanding
D. I highly value her understanding

She feels that...

E. she understands me

F. I understand her

G. she highly values my understanding

$H$. I highly value her understanding

She thinks that I feel that...

I. she understands me

J. I understand her

K. she highly values my understanding

L. I highly value her understanding

28. admit faults or weaknesses: to acknowledge or confess imperfections or shortcomings

I feel that...
A. she won't admit her faults or weaknesses
B. I won't admit my faults or weaknesses
C. she is disturbed by my not admitting my faults or weaknesses
D. I am disturbed by her not admitting her faults or weaknesses

She feels that...

E. she won't admit her faults or weaknesses

F. I won't admit my faults or weaknesses

G. she is disturbed by my not admitting my faults or weaknesses

H. I am disturbed by her not admitting her faults or weaknesses

She thinks that I feel that...

I. she won't admit her faults or weaknesses

J. I won't admit my faults or weaknesses

$\mathrm{K}$. she is disturbed by my not admitting my faults or weaknesses

L. I am disturbed by her not admitting her faults or weaknesses 
29. blame: place responsibility for fault or error

I feel that...
A. she blames me
B. I blame her
C. she is disturbed by my blaming behavior
D. I am disturbed by her blaming behavior

She feels that...
E. she blames me
F. I blame her
G. she is disturbed by my blaming behavior
H. I am disturbed by her blaming behavior

She thinks that I feel that...
I. she blames me
J. I blame her
$\mathrm{K}$. she is disturbed by my blaming behavior
L. I am disturbed by her blaming behavior

30. disgust: strong distaste

I feel that...
A. she is disgusted with me
B. I am disgusted with her
C. she is disturbed about my being disgusted with her
D. I am disturbed about her being disgusted with me

She feels that...

E. she is disgusted with me

F. I am disgusted with her

G. she is disturbed about my being disgusted with her

H. I am disturbed about her being disgusted with me

She thinks that I feel that...

I. she is disgusted with me

J. I am disgusted with her

$K$. she is disturbed about my being disgusted with her

L. I am disturbed about her being disgusted with me

31. resolve conflicts: to solve or settle disagreements as of ideas or interests

I feel that...
A. she resolves conflicts with me
B. I resolve conflicts with her
C. she highly values my resolving conflicts with her
D. I highly value her resolving conflicts with me

She feels that...

E. she resolves conflicts with me

F. I resolve conflicts with her 
G. she highly values my resolving conflicts with her

H. I highly value her resolving conflicts with me

She thinks that I feel that...

I. she resolves conflicts with me

J. I resolve conflicts with her

$\mathrm{K}$. she highly values my resolving conflicts with her

L. I highly value her resolving conflicts with me

32. ignore: to refuse deliberately to consider or take notice of

I feel that...
A. she ignores me
B. I ignore her
C. she is disturbed by my ignoring her
D. I am disturbed by her ignoring me

She feels that...

E. she ignores me

$F$. I ignore her

G. she is disturbed by my ignoring her

$H$. I am disturbed by her ignoring me

She thinks that I feel that...

I. she ignores me

J. I ignore her

$\mathrm{K}$. she is disturbed by my ignoring her

L. I am disturbed by her ignoring me

33. proud of: thinking well of one's accomplishments

I feel that...
A. she is proud of me
B. I am proud of her
C. she highly values my pride in her
D. I highly value her pride in me

She feels that...

E. she is proud of me

F. I am proud of her

G. she highly values my pride in her

H. I highly value her pride in me

She thinks that I feel that...

I. she is proud of me

J. I am proud of her

$\mathrm{K}$. she highly values my pride in her

L. I highly value her pride in me 
34. confidence: full trust

I feel that...

A. she has confidence in me

B. I have confidence in her

C. she highly values my having confidence in her

D. I highly value her having confidence in me

She feels that...

E. she has confidence in me

F. I have confidence in her

G. she highly values my having confidence in her

$H$. I highly value her having confidence in me

She thinks that I feel that...

I. she has confidence in me

J. I have confidence in her

$K$. she highly values my having confidence in her

L. I highly value her having confidence in me

35. nag: annoy with persistent demands

I feel that...
A. she nags me
B. I nag her
C. she is disturbed by my nagging
D. I am disturbed by her nagging

She feels that...

$E$. she nags me

F. I nag her

G. she is disturbed by my nagging

H. I am disturbed by her nagging

She thinks that I feel that...

I. she nags me

J. I nag her

$K$. she is disturbed by my nagging

L. I am disturbed by her nagging

36. enjoy: to experience with joy and satisfaction

I feel that...
A. she enjoys me
B. I enjoy her
C. she highly values my enjoying her
D. I highly value her enjoying me

She feels that...

E. she enjoys me

F. I enjoy her

G. she highly values my enjoying her

H. I highly value her enjoying me 
She thinks that I feel that...

I. she enjoys me

J. I enjoy her

$K$. she highly values my enjoying her

L. I highly value her enjoying me

37. hurt: cause bodily or mental pain

I feel that...
A. she hurts me
B. I hurt her
C. she is disturbed by my hurting her
D. I am disturbed by her hurting me

She feels that...

E. she hurts me

F. I hurt her

G. she is disturbed by my hurting her

H. I am disturbed by her hurting me

She thinks that I feel that...

I. she hurts me

J. I hurt her

K. she is disturbed by my hurting her

L. I am disturbed by her hurting me

38. interrupt: to break off or cause to cease in the middle of something

I feel that...
A. she interrupts me
B. I interrupt her
C. she is disturbed by my interrupting her
D. I am disturbed by her interrupting me

She feels that...

E. she interrupts me

F. I interrupt her

G. she is disturbed by my interrupting her

H. I am disturbed by her interrupting me

She thinks that I feel that...

I. she interrupts me

J. I interrupt her

K. she is disturbed by my interrupting her

L. I am disturbed by her interrupting me

39. defensive: fearful, doubtful and resistant to possible attack

I feel that...
A. she is defensive toward me
B. I am defensive toward her
C. she is disturbed by my defensive behavior
D. I am disturbed by her defensive behavior 
She feels that...

E. she is defensive toward me

F. I am defensive toward her

G. she is disturbed by my defensive behavior

H. I am disturbed by her defensive behavior

She thinks that I feel that...

I. she is defensive toward me

J. I am defensive toward her

$\mathrm{K}$. she is disturbed by my defensive behavior

L. I am disturbed by her defensive behavior

40. equal: having the same rights or privileges

I feel that...
A. she treats me as equal
B. I treat her as equal
C. she highly values my treating her as equal
D. I highly value her treating me as equal

She feels that...

E. she treats me as equal

F. I treat her as equal

G. she highly values my treating her as equal

$H$. I highly value her treating me as equal

She thinks that I feel that...

I. she treats me as equal

J. I treat her as equal

$\mathrm{K}$. she highly values my treating her as equal

L. I highly value her treating me as equal 


\section{APPENDIX D \\ PILOT STUDY INSTRUCTION LETTER}

Dear Participant:

This Perceptual Diagnostic Inventory is designed to measure the accuracy or inaccuracy of you and your spouse's perceptions on a key range of issues related to your marital relationship. This part of my research is a reliability study on the inventory and includes a test and retest.

PERSONAL DATA INVENTORY: I would appreciate your completing the information on this form. All responses to this and the Perceptual Diagnostic Inventory will remain anonymous unless you request feedback and then they will be seen only by myself. Code numbers have been provided for ease in keeping marital information together.

DIRECTIONS FOR SCORING THE INVENTORY: Please do not write on the computer forms except when shading in the answers: use a 非 pencil to complete the inventory. Do not consult with your partner prior to completing the inventory or until you have finished the retest in two weeks.

Note that attached are two sets ( 4 sheets) of computer forms and the inventory itself. You will use the computer form marked "TEST" for the initial test, and the other, marked "RETEST" for the retest.

The computer forms provided have elongated boxes numbered 1-24 horizontally. In that there are 40 issues to complete, mark the first 24 on page 1 and mark issues $25-40$ on page 2. Each issue will have 12 
statements to which you will respond. Shade in " $y$ " for yes, and " $n$ " for no, going vertically from letter A-L.

Do not leave any items blank as that will make interpretation for all the following items impossible.

Definitions are given for each item so that you can approach these statements from a similar perspective to that of your partner. Answer the statements in terms of the general nature of your relationship. An additional set of computer forms is provided for use in the retest. The test should be taken EXACTLY TWO WEEKS from the time you completed the initial test. An envelope is provided so you can mail the answer sheets back to me when you are finished. If you would like feedback on your perceptual matching, please include your name and address. Thank you for your participation in this study. You have helped me out a great deal.

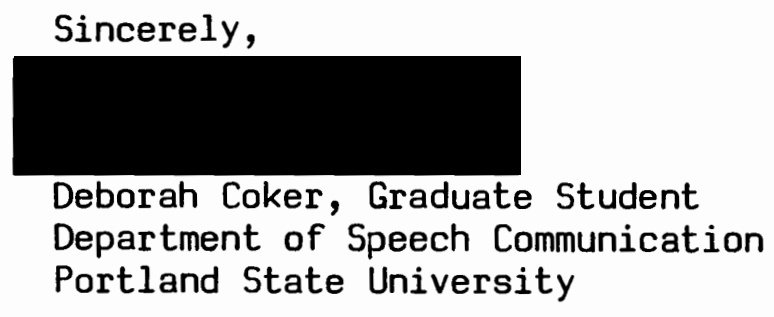

Please provide your signature below indicating that you understand what participation in this study involves and agree to serve as a subject in this research project. 


\section{APPENDIX E}

PERSONAL DATA INVENTORY

Deborah Coker, Portland State University

AGE

$20-29$ yrs
$30-39$ yrs
$40-49$ yrs
50 yrs or over

Did not finish high school

High school graduate

Some college

Bachelor's degree

Master's degree

Doctoral or other

professional degree

FAMILY INCOME

under $\$ 5,000 / \mathrm{yr}$

$\$ 5,000-\$ 15,000 / \mathrm{yr}$

over $\$ 15,000$ up to

$\$ 25,000 / \mathrm{yr}$

$\$ 25,000$ to $\$ 35,000 / \mathrm{yr}$

over $\$ 35,000 / \mathrm{yr}$

ARE YOU NOW EMPLOYED

yes

no
OCCUPATION

PRESENT MARITAL STATUS

First marriage Second marriage Divorced/Separated

AGE AT TIME OF PRESENT MARRIAGE

NUMBER OF YEARS IN PRESENT MARRIAGE

WERE YOUR PARENTS SEPARATED/DIVORCED yes

no

MY FRIENDS WOULD RATE MY MARRIAGE AS

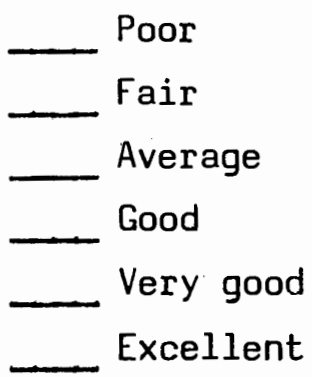


YOUR RELATIONSHIP WITH YOUR SPOUSE

I am more in charge

My spouse is more in charge

We are about equally in charge

ALL THINGS CONSIDERED MY SATISFACTION

WITH MY MARRIAGE RIGHT NOW IS

Extremely satisfied

Very satisfied

Satisfied

Somewhat dissatisfied

Very dissatisfied

Adapted from: A. J. Roach and L. F. Boyd, 1975. 


\section{APPENDIX $F$}

\section{PILOT STUDY LETTER ACCOMPANYING INVENTORY FEEDBACK}

Dear Participant:

Thank you very much for your participation in my research study on developing an instrument for matching the perceptions of marital partners. Your participation was greatly appreciated and I have altered the inventory somewhat as a result of the pilot study.

Enclosed please find a computer printout with your perceptual matching scores. Although it may seem rather complicated, directions are provided on the attached sheets. These scores are based on the preliminary test you took approximately three weeks ago.

For a quick estimation of how well your perceptions matched, you may just wish to look at the far right column under the "Profiles" section which indicates the summary of correct matches between you and your partner. A perfect score is 20 . Overall percentages for your response matching can be seen in the "Indices" section, again at the far right.

I really appreciate your help on this project, particularly your willingness to take both the test and the retest.

Sincerely,

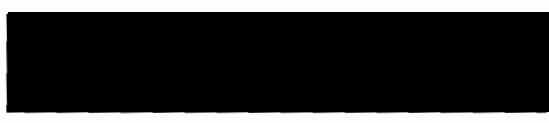

Deborah Coker, Graduate Student Department of Speech Communication Portland State University 


\section{PERCEPTUAL DIAGNOSTIC INVENTORY}

EXPLANATION OF RESULTS

Interpretation of the results of your perceptual matching will be simplified by reading the explanations and examples below. "Profiles" section

Column 1 displays the item number enabling you to identify the issue corresponding to each row by consulting the original inventory. The last column displays the total number of matches for the item with that row number; 20 is a perfect score per item.

The middle four columns consist of five-letter clusters which enable you to see exactly how your responses matched or did not match those of your spouse. Each of the five positions in the cluster will be one of two letters, as follows:

lst Position 2nd Position 3rd Position 4th Position 5th Position

$\begin{array}{lllll}R & U & A & U & R \\ F & M & D & M & F\end{array}$

Males are identified as $P$ and females are identified as 0.

Cluster letters have the following meaning:

Middle Position

$A=P$ and $O$ Agree
$D=P$ and $O$ Disagree

2nd Position

$U=P$ understands that agreement (or disagreement) has occurred

$M=P$ misunderstands that agreement (or disagreement) has occurred

4th Position

$U=0$ understands that agreement (or disagreement) has occurred

$M=0$ misunderstands that agreement (or disagreement) has occurred

lst Position

$R=P$ realized that 0 understands (or misunderstands)

$F=P$ fails to realize that 0 understands (or misunderstands) 
5th Position

$R=0$ realizes that $P$ understands (or misunderstands)

$F=0$ fails to realize that $P$ understands (or misunderstands)

Note that the letters to the left of middle give P's perceptual matches and mismatches and those to the right of middle give $D^{\prime} s$ matches or mismatches. The four columns refer to four different aspects of the perceived relationship.

Using the example of "encourages" the following format is used:

$P 0=$ whether $P$ encourages $D$

$O P=$ whether $O$ encourages $P$

$P P=$ whether $P$ highly values $D$ 's encouragement

$00=$ whether 0 highly values $P^{\prime}$ 's encouragement

Thus if a couple's score was: PO - FUAMR

$A=P$ and $D$ agree that $P$ encourages (or does not encourage) $D$

$U=P$ understands that 0 agrees

$M=0$ misunderstands that $P$ agreed

$F=P$ failed to realize that 0 misunderstood

$R=0$ realized that $P$ understood

"Indicies" section

This part of the results presents totals across all issues.

Columns 1 and 2 display total matches and percents for $P$ (male) in each category.

Columns 3 and 4 display total matches and percents for 0 (female) in each category.

Columns 5 and 6 display total matches and percents for both participants. Index $\# 7$ displays total overall matches. 
APPENDIX G

\section{PERCEPTUAL DIAGNOSTIC INVENTORY \\ FEMALE FORMAT* \\ Deborah Coker \\ Portland State University}

Communication researchers have found that the perceptions people have of themselves and others affect their communication to a great degree. This inventory is designed to measure you and your spouse's perceptions on a key range of issues related to your relationship.

How you perceive yourself, how you perceive your spouse, and how you perceive your spouse perceiving you are all issues that are investigated here. The inventory measures the accuracy or inaccuracy of the perceptual matching in your relationship. Again, there are no "right" or "wrong" answers to the questionnaire as each relationship is different.

Please do not consult with your spouse prior to completing the inventory and answer as thoughtfully and honestly as you can.

DIRECTIONS FOR SCORING THE INVENTORY: You have been provided with two computer sheets on which to score your answers to the inventory (please note pages 1 and 2 in the top right corners of the scoring sheets).

The computer forms have elongated boxes numbered 1-24 horizontally. Each of the 25 issues has 12 parts to which you will respond "y" for yes and " $n$ " for no going vertically from letters A-L. In that there are 25 issues to complete, mark issues $1-24$ on page 1 and issue 25 on page 2 in the first column. 
Please do not write on the computer forms other than when you shade in the answers. Use a 非 pencil and mark inside the boxes heavily (this will save me hours of remarking and erasing the scoring sheets).

Do not leave any items blank as that will make interpretation of all the following items impossible.

Again, thank you for your participation in the development of this inventory. Your responses will help me know how empirically valid it is.

*The male format is exactly the same with the exception of pronoun usage. 
1. communicate openly: frank and direct expression of thoughts and beelings

I feel that...

A. he generally communicates openly with me

B. I generally communicate openly with him

C. he is satisfied with my open communication

D. I am satisfied with his open communication

He feels that...

E. he generally communicates openly with me

F. I generally communicate openly with him

G. he is satisfied with my open communication

H. I am satisfied with his open communication

He thinks that I feel that...

I. he generally communicates openly with me

J. I generally communicate openly with him

$K$. he is satisfied with my open communication

L. I am satisfied with his open communication

2. dominate: to rule or control

I feel that...

A. he frequently dominates me

B. I frequently dominate him

C. he is disturbed by my frequent dominance

D. I am disturbed by his frequent dominance

He feels that...

$E$. he frequently dominates me

F. I frequently dominate him

G. he is disturbed by my frequent dominance

H. I am disturbed by his frequent dominance

He thinks that I feel that...

I. he frequently dominates me

J. I frequently dominate him

$\mathrm{K}$. he is disturbed by my frequent dominance

L. I am disturbed by his frequent dominance

3. share interests: share one's feelings of concern or curiosity

I feel that...

A. he generally shares my interests

B. I generally share his interests

C. he is satisfied with my sharing his interests

D. I am satisfied with his sharing my interests

He feels that...

$E$. he generally shares my interests

F. I generally share his interests 
G. he is satisfied with my sharing his interests

$H$. I am satisfied with his sharing my interests

He thinks that I feel that...

I. he generally shares my interests

J. I generally share his interests

$\mathrm{K}$. he is satisfied with my sharing his interests

L. I am satisfied with his sharing my interests

4. talk "at": lecture to; one-way communication

I feel that...

A. he frequently talks "at" me

B. I frequently talk "at" him

C. he is disturbed by my frequently talking "at" him

D. I am disturbed by his frequently talking "at" me

He feels that...

$E$. he frequently talks "at" me

F. I frequently talk "at" him

G. he is disturbed by my frequently talking "at" him

$\mathrm{H}$. I am disturbed by his frequently talking "at" me

He thinks that I feel that...

I. he frequently talks "at" me

J. I frequently talk "at" him

$\mathrm{K}$. he is disturbed by my frequently talking "at" him

L. I am disturbed by his frequently talking "at" me

5. argument: verbal opposition or contention

I feel that...

A. he frequently starts arguments with me

B. I frequently start arguments with him

C. he is disturbed by my frequently starting arguments

D. I am disturbed by his frequently starting arguments

He feels that...

$E$. he frequently starts arguments with me

F. I frequently start arguments with him

G. he is disturbed by my frequently starting arguments

H. I am disturbed by his frequently starting arguments

He thinks that I feel that...

I. he frequently starts arguments with me

J. I frequently start arguments with him

$K$. he is disturbed by my frequently starting arguments

L. I am disturbed by his frequently starting arguments

6. arrogant: haughty or overbearing

I feel that...

A. he is frequently arrogant with me 
B. I am frequently arrogant with him

C. he is disturbed by my frequent arrogance

D. I am disturbed by his frequent arrogance

He feels that...

E. he is frequently arrogant with me

F. I am frequently arrogant with him

G. he is disturbed by my frequent arrogance

H. I am disturbed by his frequent arrogance

He thinks that I feel that...

I. he is frequently arrogant with me

J. I am frequently arrogant with him

$K$. he is disturbed by my frequent arrogance

L. I am disturbed by his frequent arrogance

7. love: a profoundly tender affection/feeling of warm personal attachment

I feel that...

A. he generally loves me

B. I generally love him

C. he is satisfied with my love for him

D. I am satisfied with his love for me

He feels that...

E. he generally loves me

F. I generally love him

G. he is satisfied with my love for him

$H$. I am satisfied with his love for me

He thinks that I feel that...

I. he generally loves me

J. I generally love him

$\mathrm{K}$. he is satisfied with my love for him

L. I am satisfied with his love for me

8. indifferent: without interest or concern

I feel that...

A. he is frequently indifferent toward me

B. I am frequently indifferent toward him

C. he is disturbed by my frequent indifference

D. I am disturbed by his frequent indifference

He feels that...

$E$. he is frequently indifferent toward me

F. I am frequently indifferent toward him

G. he is disturbed by my frequent indifference

H. I am disturbed by his frequent indifference

He thinks that I feel that...

I. he is frequently indifferent toward me 
J. I am frequently indifferent toward him

$K$. he is disturbed by my frequent indifference

L. I am disturbed by his frequent indifference

9. responsible language: accountable and answerable for what one says

I feel that...

A. he generally uses responsible language with me

B. I generally use responsible language with him

C. he is satisfied with my use of responsible language

D. I am satisfied with his use of responsible language

He feels that...

$E$. he generally uses responsible language with me

F. I generally use responsible language with him

G. he is satisfied with my use of responsible language

$\mathrm{H}$. I am satisfied with his use of responsible language

He thinks that I feel that...

I. he generally uses responsible language with me

J. I generally use responsible language with him

$\mathrm{K}$. he is satisfied with my use of responsible language

L. I am satisfied with his use of responsible language

10. angry: feeling anger or resentment

I feel that...

A. he frequently makes me angry

B. I frequently make him angry

C. he is disturbed by my frequently making him angry

D. I am disturbed by his frequently making me angry

He feels that...

E. he frequently makes me angry

F. I frequently make him angry

G. he is disturbed by my frequently making him angry

H. I am disturbed by his frequently making me angry

He thinks that I feel that...

I. he frequently makes me angry

J. I frequently make him angry

$\mathrm{K}$. he is disturbed by my frequently making him angry

L. I am disturbed by his frequently making me angry

11. humiliate: lower or injure the self-respect of, especially in public

I feel that...

A. he frequently humiliates me

B. I frequently humiliate him

C. he is disturbed by my frequently humiliating him

D. I am disturbed by his frequently humiliating me 
He feels that...

E. he frequently humiliates me

F. I frequently humiliate him

G. he is disturbed by my frequently humiliating him

H. I am disturbed by his frequently humiliating me

He thinks that I feel that...

I. he frequently humiliates me

J. I frequently humiliate him

$K$. he is disturbed by my frequently humiliating him

L. I am disturbed by his frequently humiliating me

12. sarcasm: a sharply sneering or cutting remark

I feel that...

A. he is frequently sarcastic toward me

B. I am frequently sarcastic toward him

C. he is disturbed by my frequent sarcasm

D. I am disturbed by his frequent sarcasm

He feels that...

$E$. he is frequently sarcastic toward me

F. I am frequently sarcastic toward him

G. he is disturbed by my frequent sarcasm

H. I am disturbed by his frequent sarcasm

He thinks that I feel that...

I. he is frequently sarcastic toward me

J. I am frequently sarcastic toward him

$\mathrm{K}$. he is disturbed by my frequent sarcasm

L. I am disturbed by his frequent sarcasm

13. appreciate: to be grateful for; highly value

I feel that...
A. he generally appreciates me
B. I generally appreciate him
C. he is satisfied with my appreciation of him
D. I am satisfied with his appreciation of me

He feels that...

$E$. he generally appreciates me

F. I generally appreciate him

G. he is satisfied with my appreciation of him

H. I am satisfied with his appreciation of me

He thinks that I feel that...

I. he generally appreciates me

J. I generally appreciate him

$\mathrm{K}$. he is satisfied with my appreciation of him

L. I am satisfied with his appreciation of me 
14. disgust: strong distaste

I feel that...

A. he is frequently disgusted with me

B. I am frequently disgusted with him

C. he is disturbed by my being frequently disgusted with him

D. I am disturbed by his being frequently disgusted with me

He feels that...

E. he is frequently disgusted with me

F. I am frequently disgusted with him

G. he is disturbed by my being frequently disgusted with him

H. I am disturbed by his being frequently disgusted with me

He thinks that I feel that...

I. he is frequently disgusted with me

J. I am frequently disgusted with him

$K$. he is disturbed by my being frequently disgusted with him

L. I am disturbed by his being frequently disgusted with me

15. affectionate: displaying fond devotion

I feel that...

A. he is generally affectionate toward me

B. I am generally affectionate toward him

C. he is satisfied with my affection

D. I am satisfied with his affection

He feels that...

E. he is generally affectionate toward me

F. I am generally affectionate toward him

$G$. he is satisfied with my affection

H. I am satisfied with his affection

He thinks that I feel that...

I. he is generally affectionate toward me

J. I am generally affectionate toward him

$K$. he is satisfied with my affection

L. I am satisfied with his affection

\section{6. irritable: easily irritated or exasperated}

I feel that...

A. he is frequently irritable with me

B. I am frequently irritable with him

C. he is disturbed by my frequent irritability

D. I am disturbed by his frequent irritability

He feels that...

E. he is frequently irritable with me

F. I am frequently irritable with him

G. he is disturbed by my frequent irritability

H. I am disturbed by his frequent irritability 
He thinks that I feel that...

I. he is frequently irritable with me

J. I am frequently irritable with him

$K$. he is disturbed by my frequent irritability

L. I am disturbed by his frequent irritability

17. disappoint: to fail to fulfill the expectations or wishes of

I feel that...

A. he is frequently disappointed in me

B. I am frequently disappointed in him

C. he is disturbed by my frequent disappointment in him

D. I am disturbed by his frequent disappointment in me

He feels that...

E. he is frequently disappointed in me

F. I am frequently disappointed in him

G. he is disturbed by my frequent disappointment in him

$H$. I am disturbed by his frequent disappointment in me

He thinks that I feel that...

I. he is frequently disappointed in me

J. I am frequently disappointed in him

$\mathrm{K}$. he is disturbed by my frequent disappointment in him

L. I am disturbed by his frequent disappointment in me

18. admit faults or weaknesses: to acknowledge or confess imperfections or shortcomings

I feel that...

A. he frequently won't admit his faults or weaknesses

B. I frequently won't admit my faults or weaknesses

C. he is disturbed by my frequently not admitting my faults or weaknesses

D. I am disturbed by his frequently not admitting his faults or weaknesses

He feels that...

$E$. he frequently won't admit his faults or weaknesses

F. I frequently won't admit my faults or weaknesses

G. he is disturbed by my frequently not admitting my faults or weaknesses

H. I am disturbed by his frequently not admitting his faults or weaknesses.

He thinks that I feel that...

I. he frequently won't admit his faults or weaknesses

J. I frequently won't admit my faults or weaknesses

$K$. he is disturbed by my frequently not admitting my faults or weaknesses

L. I am disturbed by his frequently not admitting his faults or weaknesses. 
19. blame: place responsibility for fault or error

I feel that...
A. he frequently blames me
B. I frequently blame him
C. he is disturbed by my frequently blaming him
D. I am disturbed by his frequently blaming me

He feels that...

E. he frequently blames me

F. I frequently blame him

G. he is disturbed by my frequently blaming him

H. I am disturbed by his frequently blaming me

He thinks that I feel that...

I. he frequently blames me

J. I frequently blame him

$\mathrm{K}$. he is disturbed by my frequently blaming him

L. I am disturbed by his frequently blaming me

20. responsive: reacting readily to influences, appeals, etc.

I feel that...

A. he is generally responsive to me

B. I am generally responsive to him

C. he is satisfied with my responsive behavior

D. I am satisfied with his responsive behavior

He feels that...

E. he is generally responsive to me

F. I am generally responsive to him

G. he is satisfied with my responsive behavior

H. I am satisfied with his responsive behavior

He thinks that I feel that...

I. he is generally responsive to me

J. I am generally responsive to him

$\mathrm{K}$. he is satisfied with my responsive behavior

L. I am satisfied with his responsive behavior

21. hurt: cause bodily or mental pain

I feel that...

A. he frequently hurts me

B. I frequently hurt him

C. he is disturbed by my frequently hurting him

D. I am disturbed by his frequently hurting me

He feels that...

E. he frequently hurts me

F. I frequently hurt him

G. he is disturbed by my frequently hurting him

H. I am disturbed by his frequently hurting me 
He thinks that I feel that...

I. he frequently hurts me

J. I frequently hurt him

$K$. he is disturbed by my frequently hurting him

L. I am disturbed by his frequently hurting me

22. interrupt: to break off or cause to cease in the middle of something

I feel that...
A. he frequently interrupts me
B. I frequently interrupt him
C. he is disturbed by my frequent interruptions
D. I am disturbed by his frequent interruptions

He feels that...
E. he frequently interrupts me
F. I frequently interrupt him
G. he is disturbed by my frequent interruptions
H. I am disturbed by his frequent interruptions

He thinks that I feel that...

I. he frequently interrupts me

J. I frequently interrupt him

$K$. he is disturbed by my frequent interruptions

L. I am disturbed by his frequent interruptions

23. confidence: full trust

I feel that...

A. he generally has confidence in me

B. I generally have confidence in him

C. he is satisfied with my confidence in him

D. I am satisfied with his confidence in me

He feels that...

$E$. he generally has confidence in me

F. I generally have confidence in him

G. he is satisfied with my confidence in him

H. I am satisfied with his confidence in me

He thinks that I feel that...

I. he generally has confidence in me

J. I generally have confidence in him

$k$. he is satisfied with my confidence in him

L. I am satisfied with his confidence in me

24. defensive: fearful, doubtful and resistant to possible attack

I feel that...

A. he is frequently defensive toward me

B. I am frequently defensive toward him

C. he is disturbed by my frequent defensive behavior

D. I am disturbed by his frequent defensive behavior 
He feels that...

E. he is frequently defensive toward me

F. I am frequently defensive toward him

G. he is disturbed by my frequent defensive behavior

H. I am disturbed by his frequent defensive behavior

He thinks that I feel that...

I. he is frequently defensive toward me

J. I am frequently defensive toward him

$K$. he is disturbed by my frequent defensive behavior

L. I am disturbed by his frequent defensive behavior

25. listen to: give attention for the purpose of hearing or understanding

I feel that...
A. he generally listens to me
B. I generally listen to him
C. he is satisfied with my listening behavior
D. I am satisfied with his listening behavior

He feels that...

E. he generally listens to me

F. I generally listen to him

G. he is satisfied with my listening behavior

H. I am satisfied with his listening behavior

He thinks that I feel that...

I. he generally listens to me

J. I generally listen to him

$\mathrm{K}$. he is satisfied with my listening behavior

L. I am satisfied with his listening behavior 


\section{APPENDIX H}

\section{MARITAL SATISFACTION INVENTORY}

Arthur J. Roach, Ph.D.

The following specific statements concern your feelings, beliefs, and attitudes toward your marriage. There are 73 items in this inventory. For each statement, a five-point scale is provided for indicating whether you strongly agree (SA), agree (A), disagree (D), or strongly disagree (SD) with the statement as it refers to you. If you cannot commit yourself to one of these answers, use the neutral $(\mathrm{N})$ response; however, you are asked to use the $\mathrm{N}$ response as little as possible. Thus, for example, you would check the space SD on the scale if you strongly disagreed with the following statement:

SD $\quad D \quad N \quad A \quad S A$

I worry a lot about my marriage.

There are no "right" or "wrong" answers to these statements; work as rapidly as you can without being careless and do not spend too much time on any one statement.

Response symbols and their meanings are:

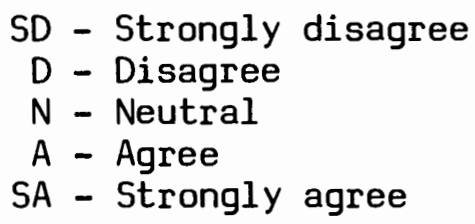


1. I feel that I have an adequate understanding of what my spouse expects of me in our marriage.

2. It is necessary for me to do things I dislike in order to please my spouse.

3. I feel that my spouse could make things easier if he/she cared to do so.

4. I worry a lot about my marriage.

5. I feel if I could start over again, I would marry a different person than my present spouse.

6. I feel that people in general respect my marriage.

7. I dislike my spouse telling me what to do.

8. I feel that I can always trust my spouse.

9. My life would seem empty without my marriage.

10. My marriage is too confining to suit me.

11. I feel that I am "in a rut" in my marriage.

12. I feel that I know where I stand with my spouse.

13. I feel that my marriage has a bad effect on my health.

14. I become upset, angry or irritable because of things that occur in my marriage.

15. I feel competent and fully able to handle my marriage.

16. I feel my marriage suffers because I have too much work to do.

17. I feel that my family and friends respect my marriage. 
Answer every question.

18. I think I really wanted to be married to my spouse at the time of our wedding.

19. I regard my present marriage as a lifetime relationship.

20. I do not think my present marriage is one I would wish to remain in permanently.

21. I expect my marriage to give me more satisfaction the longer it continues.

22. I feel I was adequately prepared for marriage.

23. I feel I have made real and lasting friends among my in-laws.

24. My marriage forces me to get along with certain in-laws whom I dislike.

25. I get discouraged trying to make my marriage work out.

26. I feel that my marriage detracts from my status in the community where I live.

27. I consider my marital situation to be as pleasant as it should be.

28. I get restless during weekends and holidays spent with my spouse and feel that time is dragging endlessly.

29. My marriage gives me more real personal satisfaction that anything else I do.

30. I feel my marriage forces me to live in home surroundings which are uncomfortable or inadequate according to my standards.

31. I wonder whether the people with whom I work approve of my marriage.

32. I think my marriage gets more difficult for me each year.

33. My spouse gets me badly flustered and jittery.

SD $\quad D \quad N \quad A \quad S A$
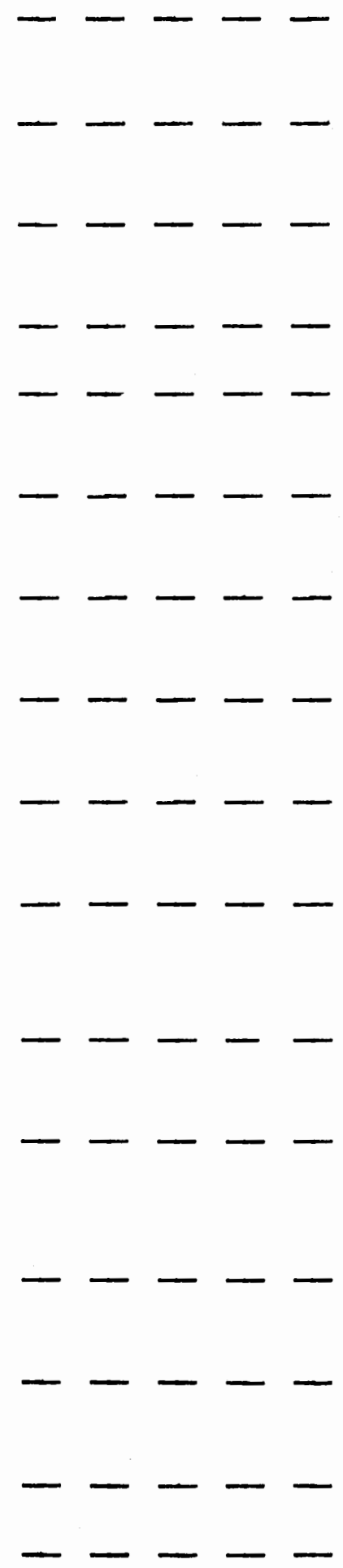
Answer every question.

34. I feel at ease in the presence of my spouse.

35. My spouse and I frequently disagree on matters of religion.

36. My spouse and I hold similar political views.

37. I am satisfied with the degree to which my spouse gives an opportunity for me to express my opinion.

38. I find my marriage so interesting that it is on my mind a lot when I am at work.

39. I feel I have made a success of my marriage so far.

40. My marriage forces me to maintain too fast a pace.

41. I feel that my spouse regards me as an equal.

42. I feel that I must look outside my marriage for things that make life worthwhile and interesting.

43. Our family income is sufficient to meet our financial obligations and support ourselves.

44. I feel that my spouse inspires me to do better work.

45. I think my marriage has "smothered" my personality.

46. The future of my marriage looks promising to me.

47. I feel that I am really interested in my spouse.

48. I get along well with my spouse.

49. I am afraid of losing my spouse through divorce.

SD $\quad D \quad N \quad A \quad S A$
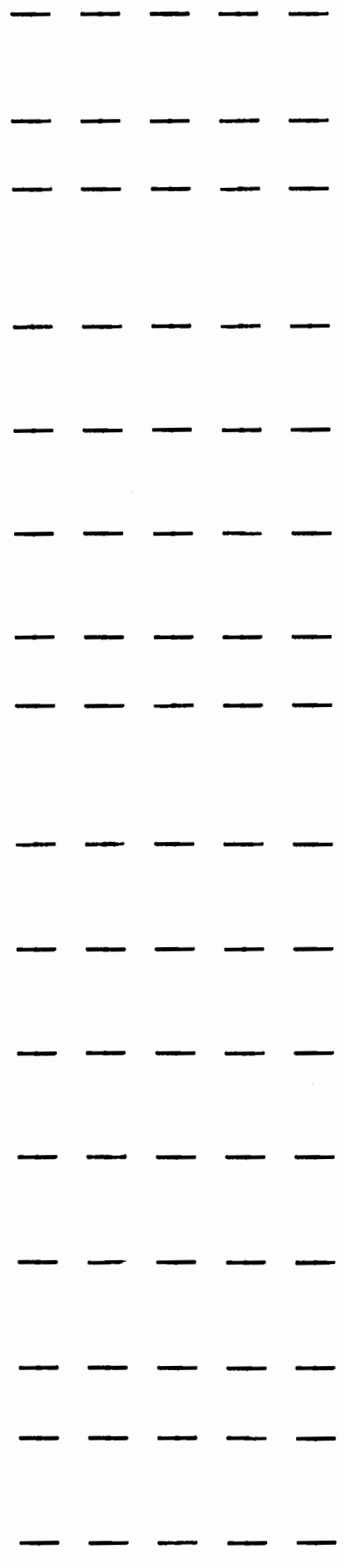
Answer every question.

50. I feel that my spouse makes unfair demands on my free time.

51. My spouse seems unreasonable in his/her dealings with me.

52. I feel my marriage helps me toward the goals I have set for myself.

53. My spouse is desirous of and willing to make improvements in our relationship.

54. I am satisfied with our handling of family finances.

55. I feel that my marriage suffers from disagreement concerning matters of recreation.

56. Demonstrations of affection by me and my spouse are mutually acceptable.

57. My spouse and I disagree on the choice of our friends.

58. An unhappy sexual relationship is a blight on my marriage.

59. My spouse and I agree on what is right and proper conduct.

60. I do not share the same philosophy of life as my spouse.

61. When disagreements with my spouse arise, I usually am the one who must give in.

62. My spouse and I enjoy several mutually satisfying outside interests together.

63. I sometimes wish I had not married.

64. If I had my life to do over, I would still marry the same person.

65. I confide in my mate in most things.

SD $\quad D \quad N \quad A \quad 5 A$
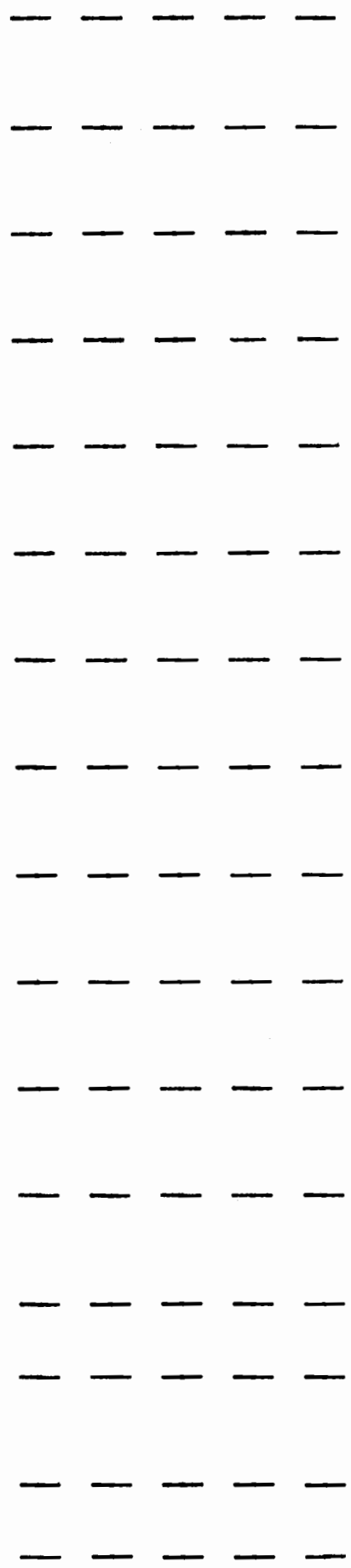
Answer every question.

66. I would rank the degree of happiness in my marriage as definitely unhappy.

67. I look forward to sexual activity with my spouse with pleasant anticipation.

68. I feel my spouse lacks respect for me.

69. I have definite difficulty in confiding in my spouse.

70. Most of the time my spouse understands the way I feel.

71. My spouse does not listen to what I have to say.

72. I frequently enjoy pleasant conversations with my spouse.

73. I am definitely satisfied with my marriage.
SD $\quad D \quad N \quad A \quad S A$
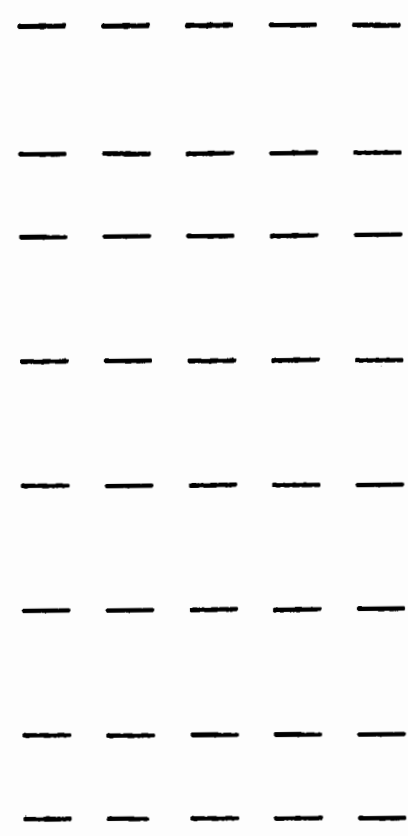


\section{APPENDIX I}

\section{MARRIAGE PROBLEM CHECKLIST \\ Arthur J. Roach, Ph.D.}

Items in this checklist describe problems frequently found in marriage relationships. You are asked to complete this inventory on your own without consulting your spouse.

Relationship Problems

Indicate which of these areas is a source of difficulty in your marriage by placing a checkmark in front of those categories. Place a second checkmark by your most serious problems and disagreements.

Personality differences

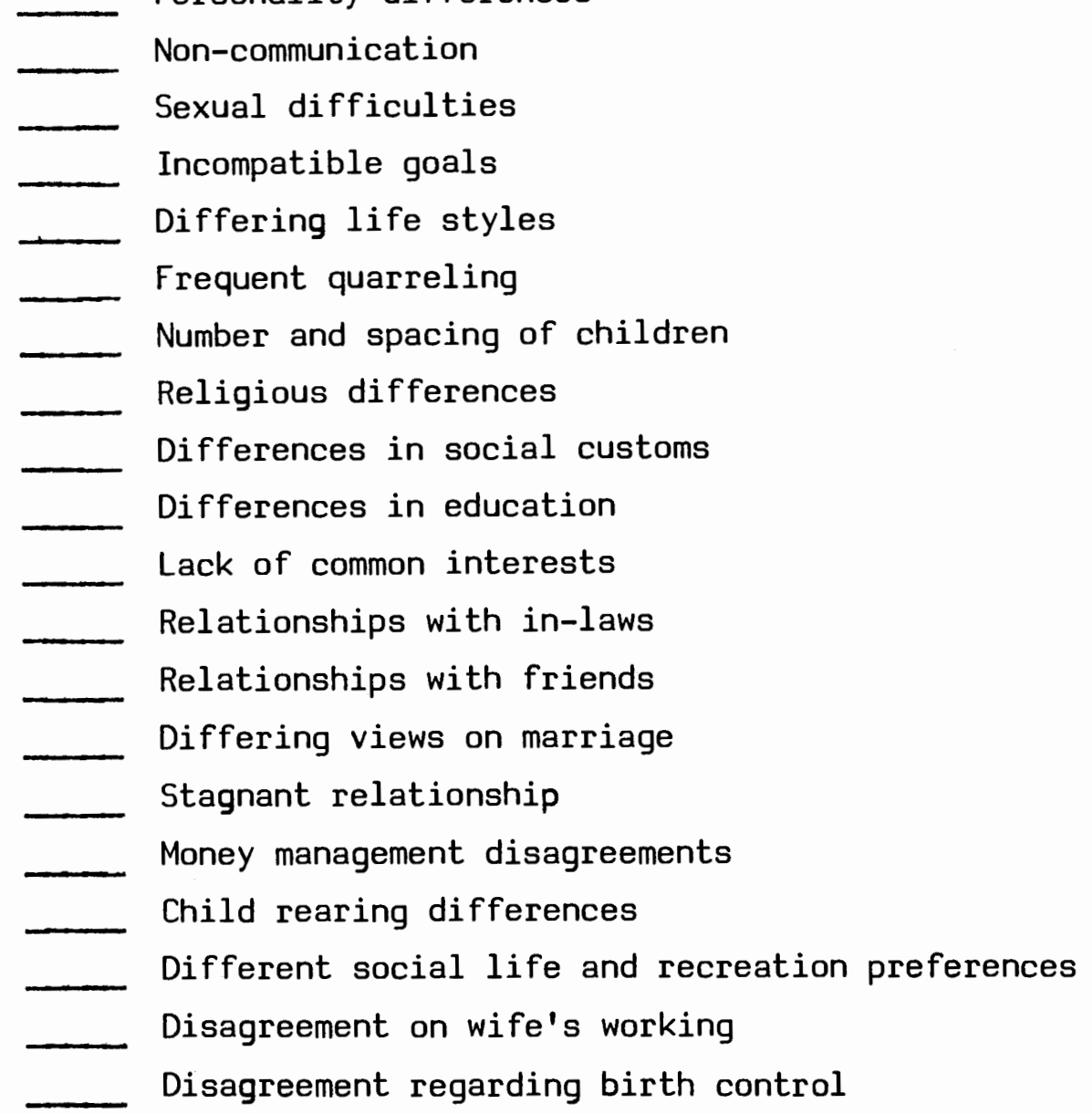


Individual Behaviors

Incicate which of these individual behaviors is a problem in your marriage by placing a check in one or more of the columns following the category. Check the $H$ column if the behavior is that of the husband. Check the $W$ column if the behavior is that of the wife. Check both columns i $\bar{f}$ the behavior pertains to both husband and wife.

H W

Lying or deception

Jealousy

Infidelity

Work habits

Lacking respect for spouse

Physically assaulting spouse

Gambling

Laziness

Smoking

Obesity

Career dissatisfaction

Homosexuality

Alcohol abuse

Drug dependency

Annoying personal habits

Depression

Anger or hostility

Indecision

Boredom

Lack of cleanliness

After you have completed the checklist, state in one sentence the single most serious problem you see in your marriage. 
APPENDIX J

FINAL STUDY INSTRUCTION LETTER

Dear Participant:

I am currently working on my master's thesis in the area of communication and have requested your help in developing a questionnaire for analyzing married partners' perceptions of themselves and each other. This questionnaire (inventory), once developed, will aid marital therapists or counselors in diagnosing problem areas in a relationship and can be applied to other communication-intensive contexts.

Included in this packet are four color-differentiated inventories related to marital relationships. These questionnaires serve two main purposes: (1) as empirical verification for my thesis, and (2) as a means whereby you can analyze various areas of your marriage should you decide to request feedback on the inventories.

Each of the four questionnaires have explanations on how to fill them out with the exception of the Personal Data Inventory which simply gives descriptive information about the subjects involved in this study. After completing the Personal Data Inventory, please work quickly through the second and third questionnaires; you may then want to take a break before completing the final inventory as it gets a bit complex.

You are asked to complete the inventories without consulting your spouse. All responses are anonymous and will remain so unless you request feedback. If you would like feedback on you and your spouse's responses to the Marital Satisfaction Inventory and the Perceptual Diagnostic 
Inventory, please note your name and address on the index card provided. Feedback will be forwarded in two to three weeks.

After you have completed all parts of this test, please mail them back in the envelope provided. I request that you DO NOT include either the male or female Perceptual Diagnostic Inventories as you may need them to refer to if you request feedback and they will make the packet too heavy for the number of stamps provided. The computer sheets are all I need for correlation purposes.

Thank you for your participation in this study. You have helped me out a great deal.

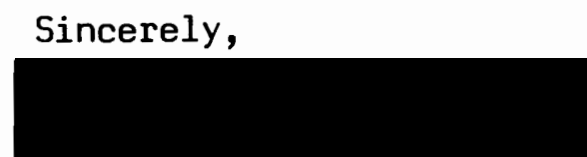

Deborah Coker, Graduate Student Department of Speech Communication Portland State University

Please provide your signature below indicating that you understand what participation in this study involves and agree to serve as a subject in this research project. 
APPENDIX K

FINAL STUDY LETTER ACCOMPANYING INVENTORY FEEDBACK

Dear Participants:

Let me begin by apologizing for the delay in forwarding these results. I did not foresee either the difficulty in getting all the packets back or the time consuming process of compiling the results and wrapping up my thesis. These things, along with moving to Eugene and starting a doctoral program at the University of Oregon, have delayed delivery of this feedback.

After review of some 75 couple's responses to the questionnaires on a pilot and final study, let me say that effective marital relationships do not come naturally or easily for anyone. These days approximately one-half of all relationships fail; one of the main factors in this is ineffective communication. By agreeing to take these inventories and then requesting feedback on your scores, you have distinguished yourselves as a couple concerned about the nature and quality of your relationship.

The following information briefly describes your responses on the three questionnaires: the Marriage Problem Checklist; the Marital Satisfaction Inventory; and the Perceptual Diagnostic Inventory. It is suggested that you reivew the following results together and discuss any problematical areas that may come up.

\section{MARRIAGE PROBLEM CHECKLIST}

The total number of relationship or individual behavior problems indicated was:

Husband:

Wife:

The average number of problems for the 50 couples surveyed was 7.7 out of a possible 40 problems listed.

If you find that there are more than 10 problems shown for either spouse, you might want to discuss specifically which areas in your marriage you each find to be problematic and then suggest specific solutions for these problems.

Communication scholars suggest that you use the following formula when problem solving or discussing conflict areas: 
"I have a problem. When you (specific behavior)

(specific consequences) happens, and I feel (your feelings).

Experts further suggest that you:

1) Define the problem in mutually acceptable terms to make sure you are discussing the same thing.

2) Explicitely state your thoughts and feelings about the problem and explore and share ideas concerning it. Try not to be evaluative when the other person is describing his/her feelings.

3) Suggest possible solutions for the problem. Openly negotiate and compromise. The solution that is ultimately reached must be mutually satisfactory.

4) Decide on a time to review the problem again. Evaluate and possibly renegotiate the problem at a later date.

\section{MARITAL SATISFACTION INVENTORY}

Total satisfaction scores reported were:

Husband:

Wife:

The mean satisfaction for the 50 couples was 298 out of a possible 365 points.

If there is more than a 20-25 point spread between your scores, either you approached the test from very different perspectives or you may have differing levels of satisfaction with your marriage.

Often satisfaction is best facilitated when both members of a relationship feel they are gaining from it. If one party feels he/ she is giving too much and not receiving enough in return, dissatisfaction usually occurs.

If you feel you are not very satisfied with your present relationship it is suggested that you identify your feelings about what the relationship is costing you and what the rewards are which you are deriving from the relationship. If you find little profit in your marriage, it is important that you discuss this with your partner.

You may want to focus on:

1) The specific areas of the relationship you are dissatisfied with

2) Which of your needs are not being met

3) What expectations do you have that are not being met 
4) What specific solutions can you suggest to bring about more satisfaction in this relationship

\section{PERCEPTUAL DIAGNOSTIC INVENTORY}

Total couple score indicating the overall perceptual matching was:

The mean score for the 50 couples was 415 out of a possible 500 points.

The enclosed computer printout provides data on your perceptual matching as a couple. The column of numbers at the far right is the total score you got for each item; 20 is a perfect score. The items used in the inventory are listed below for your convenience.

1. communicates openly
2. dominates
3. shares interests
4. talks "at"
5. starts arguments
6. arrogant with
7. loves
8. indifferent toward
9. uses responsible language
10. makes angry
11. humiliates
12. sarcastic toward
13. appreciates

14. disgusted with

15. affectionate toward

16. irritable with

17. disappointed in

18. won't admit faults/weaknesses

19. blames

20. responsive to

21. hurts

22. interrupts

23. confidence in

24. defensive toward

25. listens to

Any item showing a low score should be examined for discrepancies in perceptual correspondence.

In general, a low number of reported problems and a relatively high level of marital satisfaction and high perceptual matching suggests stability in the relationship.

A high number of problems and low scores on marital satisfaction and perceptual matching suggests problems or difficulties in the marriage.

Development of a questionnaire such as the Perceptual Diagnostic Inventory is an extremely difficult and complicated process. Many variables have to be taken into consideration and tests like this go through several stages of revision before they are ready for practical use.

Thank you very much for your support in this research project, your input is extremely valuable in the development of this questionnaire and $I$ appreciate the time and effort you put into completing these 
three inventories. I hope you have gained some insights from the results and I wish you the best in your relationship.

Cordially,

Deborah A. Coker, Graduate Student Department of Speech Communication Portland State University 